\title{
Brain Renin-Angiotensin System at the Intersect of Physical and Cognitive Frailty
}

\author{
Caglar Cosarderelioglu1,2, Lolita S. Nidadavolu², Claudene J. George ${ }^{3}$, Esther S. Oh², \\ David A. Bennett ${ }^{4}$, Jeremy D. Walston ${ }^{2}$ and Peter M. Abadir ${ }^{2 *}$ \\ ${ }^{1}$ Division of Geriatrics, Department of Internal Medicine, Ankara University School of Medicine, Ankara, Turkey, ${ }^{2}$ Division \\ of Geriatric Medicine and Gerontology, Johns Hopkins University School of Medicine, Baltimore, MD, United States, \\ ${ }^{3}$ Division of Geriatrics, Department of Medicine, Albert Einstein College of Medicine, Montefiore Medical Center, Bronx, NY, \\ United States, ${ }^{4}$ Rush Alzheimer's Disease Center, Rush University Medical Center, Chicago, IL, United States
}

\section{OPEN ACCESS}

Edited by:

Antonio Lucio Teixeira,

The University of Texas Health Science Center at Houston,

United States

Reviewed by: Jannette Rodriguez-Pallares, University of Santiago

de Compostela, Spain

Vanessa Amaral Mendonça, Universidade Federal dos Vales do Jequitinhonha e Mucuri (UFVJM),

Brazil

*Correspondence: Peter M. Abadir pabadir1@jhmi.edu

Specialty section:

This article was submitted to Neuroendocrine Science, a section of the journal Frontiers in Neuroscience

Received: 22 July 2020

Accepted: 25 August 2020 Published: 30 September 2020

Citation: Cosarderelioglu C, Nidadavolu LS, George CJ, Oh ES, Bennett DA, Walston JD and Abadir PM (2020) Brain Renin-Angiotensin System at the Intersect of Physical and Cognitive Frailty.

Front. Neurosci. 14:586314. doi: 10.3389/fnins.2020.586314
The renin-angiotensin system (RAS) was initially considered to be part of the endocrine system regulating water and electrolyte balance, systemic vascular resistance, blood pressure, and cardiovascular homeostasis. It was later discovered that intracrine and local forms of RAS exist in the brain apart from the endocrine RAS. This brainspecific RAS plays essential roles in brain homeostasis by acting mainly through four angiotensin receptor subtypes; $A T_{1} R, A T_{2} R$, MasR, and $A T_{4} R$. These receptors have opposing effects; $A T_{1} R$ promotes vasoconstriction, proliferation, inflammation, and oxidative stress while $A T_{2} R$ and MasR counteract the effects of $A T_{1} R$. $A T_{4} R$ is critical for dopamine and acetylcholine release and mediates learning and memory consolidation. Consequently, aging-associated dysregulation of the angiotensin receptor subtypes may lead to adverse clinical outcomes such as Alzheimer's disease and frailty via excessive oxidative stress, neuroinflammation, endothelial dysfunction, microglial polarization, and alterations in neurotransmitter secretion. In this article, we review the brain RAS from this standpoint. After discussing the functions of individual brain RAS components and their intracellular and intracranial locations, we focus on the relationships among brain RAS, aging, frailty, and specific neurodegenerative diseases, such as Alzheimer's disease, Parkinson's disease, and vascular cognitive impairment, through oxidative stress, neuroinflammation, and vascular dysfunction. Finally, we discuss the effects of RAS-modulating drugs on the brain RAS and their use in novel treatment approaches.

Keywords: renin-angiotensin system, RAS, brain, neurodegenerative diseases, neuroinflammation, oxidative stress, physical and cognitive frailty, aging

One of the biggest challenges of healthcare in the 21st century is the care of older adults suffering from cognitive impairment and frailty because of their high medical, economic, psychological, and social burden. Frailty, among the most common geriatric syndromes, is characterized by failure of homeostatic mechanisms, diminished physical function, and reduced age-related physiologic reserve leading to decreased ability to cope with stressors and increased vulnerability to adverse outcomes (Fried et al., 2001; Ma and Chan, 2020). There is growing evidence linking frailty and cognitive impairment (Boyle et al., 2010; Subra et al., 2012; Robertson et al., 2013; Ma et al., 2019; Wallace et al., 2019). Although studies in 
epidemiology and pathology have shown strong associations between frailty and cognitive impairment, the association's biological basis still remains elusive. One study found shared pathologies associated with both (Buchman et al., 2014). There are likely additional shared mechanisms linking the two, including inflammation, oxidative stress, mitochondrial damage, and cellular regeneration failure. The identification of this biological link can lead to new preventive and therapeutic interventions for both conditions. In this regard, the following section introduces the reninangiotensin system, a critical hormonal system that can provide further insight into the biological links between frailty and cognition.

\section{INTRODUCTION: AN OVERVIEW OF THE CLASSICAL AND LOCAL RENIN-ANGIOTENSIN SYSTEM}

The renin-angiotensin system (RAS) was first identified as part of the endocrine system, which regulates water and electrolyte balance, systemic vascular resistance, aldosterone release, and cardiovascular homeostasis. After the discovery of renin (Tigerstedt and Bergman, 1898), it took 40 years to isolate the other component of the RAS, angiotensin, by two groups simultaneously (BraunMenendez et al., 1940; Page and Helmer, 1940). The classical RAS is activated by the release of renin from juxtaglomerular cells of renal afferent arterioles into the circulation. As the first and rate-limiting step, renin converts the precursor molecule angiotensinogen to angiotensin I (Ang I), which is then transformed to angiotensin II (Ang II) by angiotensin-converting enzyme (ACE), localized mostly in the endothelial cells of the lungs. Within this system, Ang II is a primary bioactive product, leading to antagonistic effects including vasoconstriction and vasodilation by, respectively, binding to angiotensin II type 1 receptor $\left(\mathrm{AT}_{1} \mathrm{R}\right)$ and angiotensin $\mathrm{II}$ type 2 receptor $\left(\mathrm{AT}_{2} \mathrm{R}\right)$ (Griendling et al., 1993; Unger et al., 1996; Vajapey et al., 2014).

Beyond the classical endocrine (circulating) RAS, additional research identified the autocrine (cell to the same cell type) and paracrine (cell to different cell type) effects of RAS. Further, it has been shown that RAS can be locally synthesized and act in many tissues including endothelial cells, adrenal and pituitary glands, testis, ovary, kidney, heart, and eye (Dzau, 1988; Paul et al., 2006; Vajapey et al., 2014). This form of RAS was termed local or tissue RAS. The broad clinical relevance of local RAS is shown in Figure 1. Among the local RASs, brain RAS (b-RAS), discovered by Ganten et al. (1971) has a particular importance, as systemic RAS components cannot access most brain regions because of the blood-brain barrier (BBB) (Wright and Harding, 2013). Besides these tissue-level RAS, subcellular functional units of RAS in organelles such as mitochondria and nuclei were revealed by different research groups (Abadir et al., 2011, 2012; Gwathmey et al., 2012).
Further research on b-RAS has shown that it has complicated effects on the central nervous system beyond its wellknown roles, including sodium retention, vascular, and blood pressure control. There is growing evidence of b-RAS' impact on oxidative stress, endothelial dysfunction, microglial polarization, neuroinflammation, brain homeostasis, alterations in neurotransmitter secretion, cognition, and even aging and frailty (Rodriguez-Pallares et al., 2008; Abadir, 2011; De Silva and Faraci, 2013; Wright and Harding, 2013; Labandeira-Garcia et al., 2017; Forrester et al., 2018). The use of classical RASacting drugs like angiotensin receptor blockers (ARB) or ACE inhibitors (ACEI) for the regulation of b-RAS has long been under investigation.

After reviewing the structure and function of b-RAS, we consider its roles in aging and neurodegenerative diseases with respect to oxidative stress, neuroinflammation, and vascular dysfunction. Finally, we summarize the effects of angiotensin system modulators on b-RAS and their therapeutic potential.

\section{STRUCTURE OF THE BRAIN RENIN-ANGIOTENSIN SYSTEM}

There are two main RASs in the brain: circulating and local (Saavedra, 2005; Grobe et al., 2008). Circulating RAS exerts its effect via the circumventricular organs, which are regions of the brain that lack BBB and project to nuclei in the hypothalamus and medulla (Lenkei et al., 1997; Gao and Zucker, 2011). In contrast, b-RAS, which is the independent local RAS of the brain, can synthesize all components of the circulatory RAS (Harding et al., 1988; Wright and Harding, 2013). Despite a few recent studies with conflicting results (van Thiel et al., 2017), it is generally accepted that there is de novo production of RAS components as well as active RAS genes and their promoter regions in the brain (Fuxe et al., 1980; Hermann et al., 1987; Harding et al., 1988; Keisuke et al., 2017). In a double-transgenic mouse, it was demonstrated that there are specific renin-expressing cells near angiotensinogen-expressing cells, specifically within the rostral ventrolateral medulla (RVLM) (Lavoie et al., 2004a,b).

\section{Angiotensin Ligands and Peptidases Within the Brain}

Angiotensinogen is mainly produced and secreted from astrocytes within the brain to be cleaved into various neuroactive angiotensin peptides (Stornetta et al., 1988; Milsted et al., 1990). Conversion of angiotensinogen to the decapeptide Ang I is catalyzed by renin. Then, the zinc metalloprotease ACE hydrolyzes the carboxy-terminal dipeptide of Ang I to form the octapeptide Ang II (Wright and Harding, 2013). Cathepsin and chymase can also hydrolyze Ang I (Unger and Li, 2004; Mogi et al., 2012). Glutamyl aminopeptidase A (AP-A) cleaves the aspartate residue at the N-terminal of Ang II to form the heptapeptide angiotensin III (Ang III), which is then converted to the hexapeptide angiotensin IV (Ang IV) by alanyl aminopeptidase N (AP-N) cleaving arginine at the N-terminal. Ang IV can be further converted 


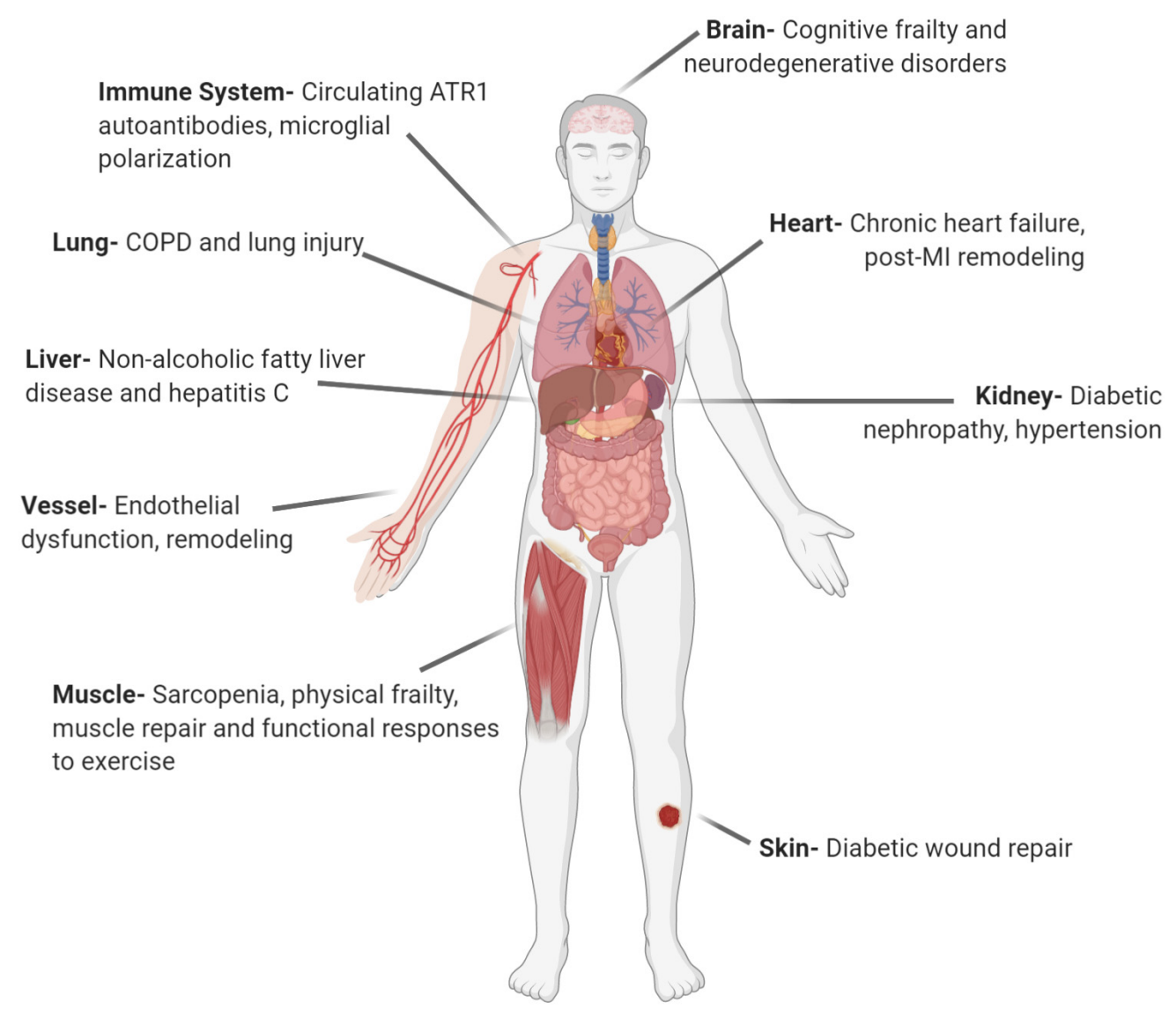

FIGURE 1 | Local angiotensin systems have broad clinical relevance. AT 1 R, angiotensin receptor type 1; COPD, chronic obstructive pulmonary disease; MI, myocardial infarction (Created with BioRender.com).

to Ang (3-7) by carboxypeptidase P and prolyl oligopeptidase. Alternatively, Ang II can be converted to Ang (1-7) by carboxypeptidase $\mathrm{P}$ and ACE2, which is an isoform of ACE (Wright and Harding, 2013). ACE2 can also convert Ang I to Ang (1-9). Ang (1-7) can be converted from Ang (19) by ACE or from Ang I by neutral endopeptidase (Jiang et al., 2013). A recently discovered component of RAS is alamandine, which is formed by the decarboxylation of Ang (1-7) (Lautner et al., 2013). Alternatively, alamandine can be generated by ACE2 cleaving angiotensin A, which is obtained by decarboxylation of Ang II (Lautner et al., 2013). Ang II, Ang (1-7), and Ang IV are the main neuroactive angiotensin peptides that trigger signal transduction as they bind to their cognate receptors. The entire pathway is illustrated in Figure 2.

In classical RAS, renin is formed by the cleavage of prorenin. However, renin activation that generally occurs in secretory granules of renal juxtaglomerular cells is not as common in extrarenal tissues such as the brain (Hirose et al., 1981). Renin concentration is low within neurons and astrocytes (Grobe et al., 2008; Bodiga and Bodiga, 2013). However, prorenin receptor (PRR), which activates prorenin without prosegment removal, is highly expressed in neurons and some microglial cells in several cardiovascular brain regions such as the subfornical organ (SFO), paraventricular nucleus (PVN), the nucleus of the solitary tract (NTS), and RVLM as well as non-cardiovascular brain regions such as brain cortex and basal ganglia (Nguyen et al., 2002; Valenzuela et al., 2010; Li et al., 2012a,b; Garrido-Gil et al., 2013b, 2017; Xu et al., 2016). Overactivation of this system can lead to cognitive impairment by the activation of the Ang II/AT ${ }_{1} \mathrm{R}$ axis (Wright and Harding, 2011; Bodiga and Bodiga, 2013). Besides increasing the catalytic activity of prorenin and renin to hydrolyze angiotensinogen into angiotensin, PRR has Ang II-independent effects (Nguyen and Contrepas, 2008; Shan et al., 2008). In this context, PRR can initiate its own signaling pathway and induce its prooxidative effects (Labandeira-Garcia et al., 2017). Although it was shown that there is a relationship between PRR and neural development (Trepiccione et al., 2016), RASindependent functions of PRR within the brain are not yet clear (Nakagawa et al., 2020).

Furthermore, another brain-specific renin isoform called renin-b was also discovered (Lee-Kirsch et al., 1999; Sinn and Sigmund, 2000). While renin-b was initially believed to be effective in the intracellular generation 


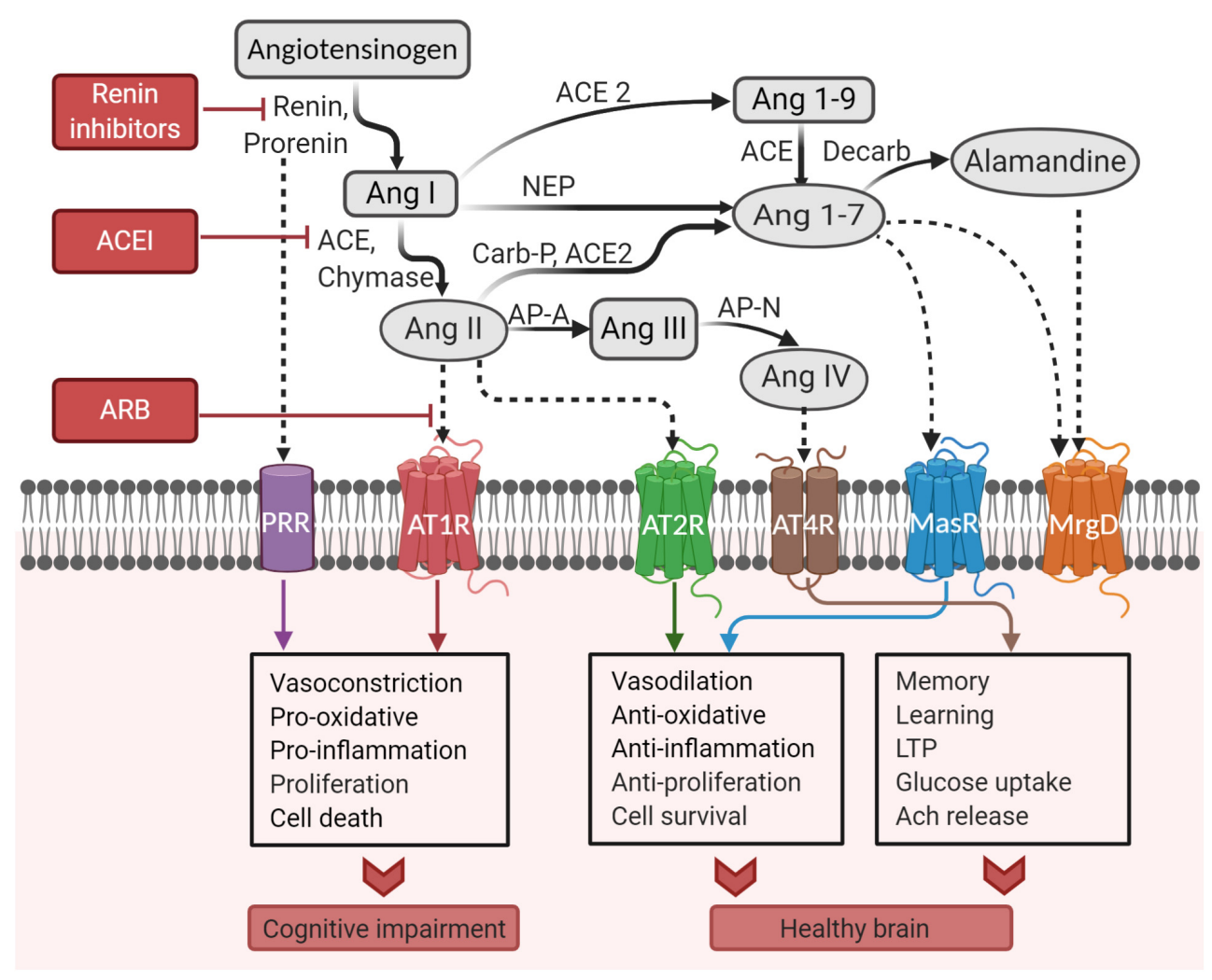

FIGURE 2 | Pathways of the brain renin-angiotensin system. ACE, angiotensin-converting enzyme; ACEl, angiotensin-converting enzyme inhibitor; Ang, angiotensin; AP-A, aminopeptidase A; AP-N, aminopeptidase N; ARB, angiotensin receptor blocker; $A T_{1} R$, angiotensin II type I receptor; $A T_{2} R$, angiotensin II type 2 receptor; $\mathrm{AT}_{4} \mathrm{R}$, angiotensin IV receptor; Carb-P, carboxypeptidase-P; decarb, decarboxylase; LTP, long-term potentiation; MasR, Mas receptor; MrgD, Mas-related-G protein-coupled receptor; NEP, neutral endopeptidase; PRR, prorenin receptor (Created with BioRender.com).

of Ang II, it is now thought to be more involved in intracellular regulation of b-RAS (Grobe et al., 2008; Keisuke et al., 2017).

\section{Angiotensin Receptors and Their Locations Within the Brain}

Ang II acts through two receptor subtypes: $\mathrm{AT}_{1} \mathrm{R}$ and $\mathrm{AT}_{2} \mathrm{R}$, both of which are members of the G-protein-coupled receptor (GPCR) family (Miura et al., 2013). Ang III also binds to these receptors although forms higher-affinity bonds with $\mathrm{AT}_{2} \mathrm{R}$ and lower-affinity bonds with $\mathrm{AT}_{1} \mathrm{R}$ compared to Ang II (Wright and Harding, 2011). Human $\mathrm{AT}_{1} \mathrm{R}$ contains 359 amino acids and has a molecular mass of $41 \mathrm{kDa}$, while $\mathrm{AT}_{2} \mathrm{R}$, which is $34 \%$ identical to $\mathrm{AT}_{1} \mathrm{R}$, consists of 363 amino acids and also has a mass of $41 \mathrm{kDa}$ (de Gasparo et al., 2000; Zhang et al., 2017). Binding of Ang II to $\mathrm{AT}_{1} \mathrm{R}$, accompanied by changes in its transmembrane 3-6 conformation, induces cell signaling (Inoue et al., 1997; Ghanouni et al., 2001; Miura et al., 2013). $\mathrm{AT}_{1} \mathrm{Rs}$ and $\mathrm{AT}_{2}$ Rs were identified mostly in the cortex, hippocampus, and basal ganglia in humans and many animals (Lenkei et al., 1996; RodriguezPallares et al., 2008; Joglar et al., 2009; Valenzuela et al., 2010; Garrido-Gil et al., 2013b, 2017; Jackson et al., 2018). There are two types of $\mathrm{AT}_{1}$ Rs: AT1A and AT1B. The AT1A receptor is mainly expressed in brain regions contributing to homeostatic regulation of blood pressure and electrolyte balance (Jöhren et al., 1995; MacGregor et al., 1995; Lenkei et al., 1997), whereas the AT1B receptor is seen in structures involved in memory and higher brain functions such as the cerebral cortex and hippocampus (Jöhren et al., 1995). $\mathrm{AT}_{2} \mathrm{R}$ is present in brain regions involved in learning and memory, particularly the hippocampus, cingulate cortex, lateral septum, and locus coeruleus, but also the superior colliculus, thalamic and subthalamic nuclei, and inferior olive (Millan et al., 1991; Lenkei et al., 1996). $\mathrm{AT}_{1}$ Rs and $\mathrm{AT}_{2}$ Rs have been identified mostly in neurons, astrocytes, oligodendrocytes, and microglia of those regions (Tsutsumi and Saavedra, 1991; Fogarty and Matute, 2001; Rodriguez-Pallares et al., 2008; Joglar et al., 2009; Garrido-Gil et al., 2013b, 2017). However, a few studies could not identify $\mathrm{AT}_{1}$ Rs in microglia (Lenkei et al., 1997; Benicky et al., 2009) likely because of their methodology and the fact that $\mathrm{AT}_{1}$ Rs are undetectable in microglia's non-activated state and then upregulated only upon activation (Lanz et al., 2010; Rodriguez-Perez et al., 2015; Sun et al., 2015; Labandeira-Garcia et al., 2017). A more recent investigation of cellular locations of $\mathrm{AT}_{1} \mathrm{R}$ and $\mathrm{AT}_{2} \mathrm{R}$ under normal and hypertensive conditions showed that $\mathrm{AT}_{1} \mathrm{Rs}$ and $\mathrm{AT}_{2} \mathrm{Rs}$ are localized to neurons rather than astrocytes and microglia in PVN, NTS, arcuate nucleus, dorsomedial hypothalamus, area postrema, median preoptic 
nucleus, SFO, and organum vasculosum of the lamina terminalis (Sumners et al., 2020).

Another receptor is angiotensin receptor $4\left(\mathrm{AT}_{4} \mathrm{R}\right)$, to which Ang IV binds. However, in high concentrations of Ang IV, it can bind to $\mathrm{AT}_{1} \mathrm{R}$ (Jackson et al., 2018). Unlike other angiotensin receptors, $\mathrm{AT}_{4} \mathrm{R}$ is identical to insulin-regulated aminopeptidase (IRAP), which is a type 2 transmembrane protein of the gluzincin aminopeptidase family, including homologous aminopeptidases AP-A and AP-N (Lee et al., 2003; Farag et al., 2017; Wright and Harding, 2019). $\mathrm{AT}_{4} \mathrm{Rs}$ are more abundant in sensory and cognitive regions of the brain in contrast to $\mathrm{AT}_{1} \mathrm{Rs}$ that are abundant in cardiovascular and osmoregulatory areas (Wyse et al., 1995). The fact that $\mathrm{AT}_{4} \mathrm{R}$ and cholinergic receptors are closely localized suggests that $\mathrm{AT}_{4} \mathrm{Rs}$ have a potential role in learning and memory (Wilson et al., 2009). $\mathrm{AT}_{4} \mathrm{Rs}$ are present in many components of the central nervous system, particularly the caudate, putamen, cerebellum, anterior pituitary globus pallidus, neocortex, CA1-CA3 pyramidal layers of hippocampus, nucleus basalis of Meynert, lateral geniculate body, ventral lateral thalamic nucleus, motor neurons of the brain stem, and ventral horn of the spinal cord (Wright and Harding, 2011). At the cellular level, it is well known that $\mathrm{AT}_{4} \mathrm{R}$ is located on neurons (Chai et al., 2000; Albiston et al., 2001). However, there are conflicting results about their presence on astrocytes (Greenland et al., 1996; Jackson et al., 2018; O'Connor and Clark, 2018). In a recent study, the presence of $\mathrm{IRAP}_{\mathrm{ATT}} \mathrm{R}$ was shown in both pinealocytes and astrocytes in the rat pineal gland (Abrahão et al., 2019).

Ang (1-7) binds to Mas receptors (MasRs) with the highest affinity, but it can also bind to Mas-related-G protein-coupled receptors (MrgDs) and $\mathrm{AT}_{2} \mathrm{Rs}$ with low affinity (Elased et al., 2008; Bernstein et al., 2014; Tetzner et al., 2016). MasRs are GPCRs with high concentrations in the brain structures associated with memory and cognition such as the hippocampus, but also the piriform cortex involved in smell (Freund et al., 2012). Although they were seen in both neuronal and glial cells, the MasR immunoreactivity was higher in neurons than in glia (Costa-Besada et al., 2018). Recently discovered MrgDs are also GPCRs, and their primary ligand is alamandine (Lautner et al., 2013). The discovery of MrgDs has added another level of complexity into RAS, and further studies are needed for a complete understanding of their roles within the brain.

Hetero-dimerizations have been observed between GPCRs of the RAS. While $\mathrm{AT}_{1} \mathrm{R}$ and bradykinin $\mathrm{B} 2$ receptor heterodimerization enhances G-protein activation (Quitterer et al., 2011; Miura et al., 2013), $\mathrm{AT}_{2} \mathrm{R} / \mathrm{AT}_{1} \mathrm{R}$ and $\mathrm{MasR} / \mathrm{AT}_{1} \mathrm{R}$ heterodimers directly antagonize and inactivate $\mathrm{AT}_{1} \mathrm{Rs}$, leading to a decrease in $\mathrm{AT}_{1} \mathrm{R}$ signaling cascade (AbdAlla et al., 2001). Also, $\mathrm{AT}_{2} \mathrm{Rs}$ and MasRs may form heterodimers as they have similar signaling mechanisms, and are functionally dependent on each other (Leonhardt et al., 2017). In this regard, it was shown that MasR protein expression and mRNA levels in the substantia nigra ( $\mathrm{SN}$ ) of $\mathrm{AT}_{2} \mathrm{R}$ knockout $(\mathrm{KO})$ mice decreased, rendering Ang (1-7) ineffective in astrocytes, whereas MasR expression did not change in $\mathrm{AT}_{1} \mathrm{R} \mathrm{KO}$ mice (Villela et al., 2015; Leonhardt et al., 2017). However, notably, $\mathrm{AT}_{2} \mathrm{R}$ expression and ACE2 and
Ang 1-7 levels decreased in the absence of the Ang II/AT $\mathrm{AT}_{1}$ axis (Villar-Cheda et al., 2010).

Angiotensin receptors can also be located intracellularly. Specifically, they have been found in the nucleus, mitochondria, neurosecretory vesicles, and the plasma membrane (Sadoshima et al., 1993; Vila-Porcile and Corvol, 1998; Sherrod et al., 2005; Peters, 2008; Abadir et al., 2011). Intracellular RAS can be regulated independently from the systemic circulation (Abadir et al., 2012). Whether circulating (classical), local, or subcellular (intracrine) RAS, the main system processes are the same (Kumar R. et al., 2012). Ang II and enzymes such as renin and ACE can be localized to cytoplasm and nuclei; ACE also has been found on the endoplasmic reticulum (Shen et al., 2008; Abadir et al., 2012).

\section{FUNCTIONS OF RENIN-ANGIOTENSIN SYSTEM RECEPTORS}

Here, we review the general functions of RAS receptors and discuss their cell type-specific functions within the brain.

\section{Prelude to the Renin-Angiotensin System Signaling and Functions}

$\mathrm{AT}_{1} \mathrm{R}$ and $\mathrm{AT}_{2} \mathrm{R}$ stimulation generally lead to opposing actions. While $\mathrm{AT}_{1} \mathrm{R}$ mediates vasoconstriction, cellular proliferation, cell growth, and production of superoxide, $\mathrm{AT}_{2} \mathrm{R}$ mediates vasodilatation and has both anti-oxidant and anti-inflammatory properties (Abadir, 2011; Abadir et al., 2011).

Although Ang II can bind to both $\mathrm{AT}_{1} \mathrm{R}$ and $\mathrm{AT}_{2} \mathrm{R}, \mathrm{ACE}$ upregulation prompts $\mathrm{AT}_{1} \mathrm{R}$ signaling (Jackson et al., 2018). After G-protein coupling stimulation of $\mathrm{AT}_{1} \mathrm{R}$ with Ang II, second messenger signaling, which consists of inositol trisphosphate, diacylglycerol, and arachidonic acid, initiates activation of downstream effectors, such as phospholipases C, A, and D. Response of these signals can differ across tissues. Protein kinase C, Akt, intracellular protein kinases (such as receptor and nonreceptor tyrosine kinases), and serine/threonine kinases [such as mitogen-activated protein kinase (MAPK) family kinases] are activated by the $\mathrm{AT}_{1} \mathrm{R}$ signaling cascade (Forrester et al., 2018). Overactivation of $\mathrm{AT}_{1} \mathrm{R}$ cascade may result in hypertrophy, vascular remodeling, and hyperplasia (Suzuki et al., 2005).

The Ang II/AT $\mathrm{AT}_{2}$ axis signals through three major transduction pathways that seem to oppose the actions of $\mathrm{AT}_{1} \mathrm{R} \cdot \mathrm{AT}_{2} \mathrm{R}$ activates several protein phosphatases and nitric oxide (NO)/cyclic GMP system and stimulates phospholipase A2, with subsequent release of arachidonic acid (Abadir, 2011). $\mathrm{AT}_{2} \mathrm{R}$ also inhibits cell growth and proliferation by inhibiting autophosphorylation of insulin and epidermal growth factor receptors (Steckelings et al., 2010). Furthermore, $\mathrm{AT}_{1} \mathrm{R}$ blockade increases angiotensinogen and $\mathrm{AT}_{2} \mathrm{R}$ stimulation by inhibition of negative feedback (Carey et al., 2001). The $\mathrm{AT}_{1} \mathrm{R}$ blockade also increases renal $\mathrm{NO}$, which is blunted by concomitant $\mathrm{AT}_{2} \mathrm{R}$ blockade (Siragy et al., 2000), suggesting $\mathrm{AT}_{2} \mathrm{R}$ 's role in increasing $\mathrm{NO}$ production via direct stimulation of $\mathrm{NO}$ synthase (NOS) or indirectly through bradykinin-dependent mechanisms (Abadir et al., 2003). 


\section{Receptor Functions According to Cell Type}

\section{Neurons}

Neurons have all types of angiotensin receptors on their cell membrane; also, they have an intracellular angiotensin system that works separately. It has been shown that neurons have intracrine RAS, including $\mathrm{AT}_{1} \mathrm{Rs}, \mathrm{AT}_{2} \mathrm{Rs}$, and MasRs in their mitochondria and nuclei (Valenzuela et al., 2016; Villar-Cheda et al., 2017; Costa-Besada et al., 2018). Although astrocytes synthesize most of the angiotensinogen within the brain, neurons can also synthesize angiotensinogen. Angiotensinogen immunoreactivity is found in the entire brain, predominantly in areas responsible for water and electrolyte balance such as the SFO, PVN, NTS, and RVLM (Grobe et al., 2008). This wide distribution of angiotensinogen in the brain shows that b-RAS is not limited to cardiovascular regulatory functions (Bodiga and Bodiga, 2013). As neurons contain RAS enzymes (e.g., intracellular renin, prorenin, etc.), angiotensinogen can be converted to active angiotensin peptides intracellularly (LeeKirsch et al., 1999; Abadir et al., 2012; Jackson et al., 2018).

The Ang II/AT $\mathrm{A}_{1} \mathrm{R}$ axis produces reactive oxygen species (ROS) and causes oxidative stress by NADPH oxidase in neurons, as in other tissues. Conversely, the Ang II/AT 2 R axis and Ang (1-7)/MasR axis produces NO and inhibits superoxide increment (Costa-Besada et al., 2018). In neurons, while the Ang II/AT $\mathrm{A}_{1}$ axis and the (Pro)renin/PRR axis have pro-oxidative and proinflammatory properties, the Ang II/ $\mathrm{AT}_{2} \mathrm{R}$ axis and the Ang (1-7)/MasR axis act as the protective arm of the RAS (CostaBesada et al., 2018). Mitochondrial $\mathrm{AT}_{2} \mathrm{Rs}$ are more common than $\mathrm{AT}_{1} \mathrm{Rs}$ in dopaminergic neurons (Valenzuela et al., 2016). Notably, even though MasR is less concentrated in mitochondria than the rest of the cell, both ACE2 and Ang (1-7) are more abundant in mitochondria (Costa-Besada et al., 2018). This study supports a recent finding suggesting that MrgDRs and $\mathrm{AT}_{2} \mathrm{Rs}$ are additional Ang (1-7) receptors (Tetzner et al., 2016).

In neurons, Ang II, Ang III, and $\mathrm{AT}_{2} \mathrm{Rs}$ are colocalized in the mitochondrial inner membrane (Abadir et al., 2011). This colocalization is important since mitochondrial NOS, a possible mitochondrial respiration regulatory enzyme, is also known to exist in the mitochondrial inner membrane (Ghafourifar and Richter, 1997). Also, it was shown that the $\mathrm{AT}_{2} \mathrm{R}$ agonist CGP421140 activates NO production in a dosedependent manner, and that $\mathrm{AT}_{2} \mathrm{R}$ blocker PD-123319 mitigates it (Abadir et al., 2011).

As with mitochondrial RAS, nuclear RAS is essential for the regulation of oxidative stress. It maintains the balance between detrimental and protective pathways of RAS through transcription and trafficking of additional receptor types (Zawada et al., 2015; Villar-Cheda et al., 2017; Costa-Besada et al., 2018). When nuclear $\mathrm{AT}_{1} \mathrm{Rs}$ are activated, both oxidative and anti-oxidative mechanisms are initiated. An increase in mRNA levels of PRR, angiotensinogen, and renin are seen, leading to intracellular synthesis of more Ang II and Ang (1-7). Concomitantly, protective $\mathrm{AT}_{2} \mathrm{R}$ levels increase. $\mathrm{AT}_{2} \mathrm{Rs}$ are then delivered to different organelles such as mitochondria and cell membranes. While Ang (1-7) shows its protective effects, increased Ang (1-7) levels suppresses $\mathrm{AT}_{2} \mathrm{R}$ expression (Villar-Cheda et al., 2017; Costa-Besada et al., 2018). These compensatory mechanisms can be dysfunctional in aging and cognitive disorders (Labandeira-Garcia et al., 2017).

Overactivation of the Ang II/AT ${ }_{1} \mathrm{R}$ axis has many detrimental effects on the brain, such as hypertension, neuroinflammation, increased oxidative stress, BBB disruption, and neurotoxicity. Neuronal $\mathrm{AT}_{1} \mathrm{R}$ activation in situ or brain slices may increase the firing rate of neurons in specific brain regions, such as the SFO, PVN, and RVLM (Knowles and Phillips, 1980; Sumners et al., 2002). This effect can be reversed by losartan, an ARB (Sumners et al., 2002). The Ang II/AT ${ }_{1} \mathrm{R}$ axis enhances sympathetic neurotransmitter release in the central nervous system. In particular, the release of vasopressin, dopamine, and norepinephrine is facilitated (Stadler et al., 1992; Medelsohn et al., 1993; Tsuda, 2012). Also, studies have investigated the effects of the Ang II/AT $\mathrm{A}_{1} \mathrm{R}$ axis b-RAS on inhibitory GABA and excitatory glutamate transmitters. It was shown that Ang $\mathrm{II} / \mathrm{AT}_{1} \mathrm{R}$ axis decreases $\mathrm{GABA}$ and enhances glutamate release (Tedesco and Ally, 2009; Fujita et al., 2012; Tsuda, 2012). Notably, there is evidence that activation of $\mathrm{AT}_{2} \mathrm{R}$ and MasR functions in opposition to $\mathrm{AT}_{1} \mathrm{R}$ 's neurosecretory effect (Tsuda, 2012; de Kloet et al., 2016).

In contrast to the effects of Ang II/AT $\mathrm{AT}_{1} \mathrm{R}$ signaling, Ang II induces neuroprotective mechanisms, NO production, neurite outgrowth, and brain development through $\mathrm{AT}_{2} \mathrm{R}$ activation, thus improving cognitive function (Farag et al., 2017). In this regard, impaired $\mathrm{AT}_{2} \mathrm{R}$ signaling results in $\mathrm{AT}_{1} \mathrm{R}$-mediated oxidative stress and neuroinflammation, which may lead to impaired cognition. For example, within the hippocampus, decreased $\mathrm{AT}_{2} \mathrm{R}$ activation was shown to cause dendritic spine abnormalities and spatial memory deficits (Maul et al., 2008). As another neuroprotective mechanism, $\mathrm{AT}_{2} \mathrm{R}$ activation improved neuronal survival and neurological deficits via increased VEGF production after ischemic injury in rodents (Mateos et al., 2016). $\mathrm{AT}_{2} \mathrm{R}$ activation also enhances the repair of damaged DNA and differentiation in the nervous system through induction of methyl methanesulfonate sensitive 2, a ubiquitin-conjugating enzyme variant (Mogi and Horiuchi, 2013).

Another neuroprotective axis is Ang (1-7)/MasR, which limits the pressor, angiogenic, and proliferative actions of Ang II (Ho and Nation, 2018). This axis has both anti-oxidant and antiinflammatory properties (Jiang et al., 2013). It has essential roles in learning, memory, neuroprotection, and cell survival (Wright et al., 2013; Farag et al., 2017). Besides, the Ang (1-7)/MasR axis is well known for promoting the production of arachidonic acid and activation of endothelial and neuronal NO synthase, which are crucial for object recognition memory and longterm potentiation (LTP) in the hippocampus and amygdala (Hellner et al., 2005; Yang et al., 2010). Indeed, deficient object recognition memory was observed in MasR KO mice (Lazaroni et al., 2012). This axis also plays a neuroprotective role against ischemic stroke by significantly increasing the density of brain capillaries, improving regional cerebral blood flow (CBF), and decreasing infarct volume and neurological deficits (Jiang et al., 2013). This role was further confirmed by a study in which the brain angiogenic effects of Ang (1-7) were attenuated with MasR 
antagonist A-779 (Jiang et al., 2014). A recently discovered effect of Ang (1-7)/MasR axis is an increase of glucose utilization and decrease of insulin resistance (IR) (Williams et al., 2016; Loloi et al., 2018; Wright and Harding, 2019). Consistent with this effect, chronic administration of Ang-(1-7) improved glucose tolerance in fructose-fed rats (Guimaraes et al., 2014).

As discussed above, $\mathrm{AT}_{4} \mathrm{Rs}$ are mostly located on neurons, specifically in the sensory and cognitive regions. One of the first studies presenting behavioral evidence for the cognitive effects of $\mathrm{AT}_{4} \mathrm{Rs}$ showed improvement in the learning and memory functions of rats with scopolamine-induced deficits in the circular water maze task by using an Ang IV analog intracerebroventricularly (Pederson et al., 1998). Previous work suggested that actions of Ang IV are partially mediated by IRAP which codistributes with the insulin-regulated glucose transporter (GLUT 4) (Albiston et al., 2001, 2003). In this context, $\mathrm{AT}_{4} \mathrm{Rs}$ show some of their effects by inhibiting the catalytic activity of IRAP (Lew et al., 2003; Singh and Karnik, 2016; Abrahão et al., 2019). With this inhibition, Ang IV extends the half-life of several pro-cognitive endogenous peptides such as vasopressin, oxytocin, somatostatin, and endothelial NOS, which have been shown to enhance memory consolidation and retrieval. A parallel $\mathrm{AT}_{4} \mathrm{R} / \mathrm{IRAP}$ mediated pathway that enhances memory is through neuronal glucose uptake via regulation of GLUT4 vesicular trafficking (Chai et al., 2004; Fernando et al., 2008; Wright and Harding, 2011; Farag et al., 2017). Moreover, $\mathrm{AT}_{4} \mathrm{R}$ activation induces a non- $N$-methyl-Daspartate (non-NMDA)-dependent form of LTP via increases in intracellular calcium influx (Davis et al., 2006). Regarding the cognitive effects of Ang IV, IRAP inhibitors are shown to improve memory (De Bundel et al., 2009; Albiston et al., 2011; Mountford et al., 2014). Another suggested neuroprotective pathway of Ang IV/AT $\mathrm{A}_{4} \mathrm{R}$ is through hepatic growth factor and type 1 tyrosine kinase receptor (c-Met) signaling. As a mediator of the HGF/c-Met pathway, Ang IV stimulates c-Met (Ma et al., 2003; Wright and Harding, 2011), which then attenuates neurodegenerative changes by facilitating the non-NMDAdependent LTP pathway and increasing dendritic arborization in the hippocampus (Akimoto et al., 2004; Shimamura et al., 2006; Tyndall and Walikonis, 2007). Additionally, the HGF/cMet system shows cerebroprotective effects by facilitating CBF. All of these functions of the HGF/c-Met system overlap with those of the AngIV/AT4 system (Wright and Harding, 2015). Another manifestation of the learning and memory effects of Ang IV is through regulation of neurotransmitter secretion. In this regard, it has been hypothesized that Ang IV modulates serotonin, dopamine, and acetylcholine release (Lee et al., 2001; Fernando et al., 2008; Gard, 2008). This hypothesis has been supported by studies showing close localization of $\mathrm{AT}_{4} \mathrm{Rs}$ and D2 receptors, correlation of IRAP with cholinergic cell bodies and terminals, and limitation of AngIV-induced cognitive facilitation via blockade of the D2 and D4 dopamine receptors (Chai et al., 2000; Braszko, 2006, 2009; Wright and Harding, 2011).

\section{Astrocytes}

Astrocytes, microglial cells, and oligodendrocytes are the principal glial cells of the brain. Astrocytes are the most common type of glial cells. Astrocytes have essential roles, such as supporting brain tissue, regulating the chemical content of extracellular space, restricting the spread of neurotransmitter molecules toward unwanted regions by encircling synaptic junctions, and removing many neurotransmitters from the synaptic cleft (Bear et al., 2016; Almad and Maragakis, 2018). These functions make them essential not only for support but also for LTP, thus memory.

Astrocytes are the main angiotensinogen source of the brain. In particular, they have $\mathrm{AT}_{1} \mathrm{R}, \mathrm{AT}_{2} \mathrm{R}$, and MasR on their cell membranes, mitochondria, and nuclei (Fogarty and Matute, 2001; Garrido-Gil et al., 2013b; Costa-Besada et al., 2018). Although not entirely clear, few studies demonstrate the existence of $\mathrm{AT}_{4} \mathrm{Rs}$ on the astrocytes (Greenland et al., 1996; Holownia and Braszko, 2007). As with neurons, over-activation of $\mathrm{AT}_{1} \mathrm{Rs}$ on astrocytes contribute to oxidative stress, inflammation, cognitive impairment, and cell death while Ang II and Ang (1-7) have protective roles. However, $\mathrm{AT}_{1} \mathrm{Rs}$ on astrocytes differ from those on neurons in that astrocytic $\mathrm{AT}_{1} \mathrm{R}$ activation can affect the permeability of $\mathrm{BBB}$, although it is commonly accepted that overactivation of Ang II/AT 1 R axis increases the permeability of BBB (Biancardi and Stern, 2016; Guo et al., 2019). A study, however, reported counterintuitive results such that astrocytederived Ang II restricts BBB permeability with tight junction stabilization, thus diminishing peripheral immune cell entry to the brain (Wosik et al., 2007; Füchtbauer et al., 2010).

\section{Microglia}

Microglial cells are macrophages that mediate immune and inflammatory responses of the brain (Bear et al., 2016). They can be in two states: resting or activated. In normal conditions, microglia remain in the resting state due to immunosuppressive proteins secreted by neurons. Contrary to their name, resting-state microglia cells actively scan their surrounding environment to detect any abnormalities in brain homeostasis. When they are activated, they can polarize into two distinct substates: proinflammatory/classically activated (M1) and anti-inflammatory/alternatively activated (M2) substates (Labandeira-Garcia et al., 2017). The M1 substate exacerbates neuronal death by secreting proinflammatory mediators and free radicals. In contrast, the M2 substrate, being immunoregulatory microglia, promotes brain repair/regeneration, produces growth factors and antiinflammatory cytokines protecting neurons, and reduces inflammation (Labandeira-Garcia et al., 2017). An inadequate transition from the proinflammatory M1 to immunoregulatory M2 substrate in the presence of any brain lesions may result in the prolonged release of inflammatory cytokines and ROS, which is followed by increased neuroinflammation and neurodegeneration (Kigerl et al., 2009; Heneka et al., 2015; Tang and Le, 2016). It is known that RAS has roles in this immunoregulatory response as it does in the peripheral immune system (Labandeira-Garcia et al., 2017). In particular, RAS affects microglia via $\mathrm{AT}_{1} \mathrm{Rs}, \mathrm{AT}_{2} \mathrm{Rs}$, and MasRs on mitochondria, nuclei, and cell membranes (Garrido-Gil et al., 2013b; Regenhardt et al., 2013; Costa-Besada et al., 2018). Under non-pathologic conditions, the presence of $\mathrm{AT}_{1} \mathrm{R}$ and $\mathrm{AT}_{2} \mathrm{R}$ 
are undetectable, unlike the MasR, which can be observed in healthy microglia (Regenhardt et al., 2013; Labandeira-Garcia et al., 2017; Costa-Besada et al., 2018). However, as M1 microglia exerts its pro-inflammatory response, $\mathrm{AT}_{1} \mathrm{Rs}$ and $\mathrm{AT}_{2} \mathrm{Rs}$ are upregulated. In this way, activation of nuclear $\mathrm{AT}_{1} \mathrm{R}$ upregulates itself and leads to a shift toward an M1 phenotype. $\mathrm{AT}_{1} \mathrm{R}$ mediated activation of the M1 pro-inflammatory response was suggested to be the mechanism that exacerbates cell death and inflammation, ultimately leading to impaired cognition (Bernstein et al., 2014). Similar to what is observed with $\mathrm{AT}_{1} \mathrm{R}$, activation of nuclear $\mathrm{AT}_{2} \mathrm{R}$ upregulates itself and leads to a shift toward an M2 phenotype. This shift further leads to the production of anti-inflammatory cytokines such as IL-10 and IL4 and the upregulation of phagocytic receptors that help synaptic clearance (Rodriguez-Pallares et al., 2008; Regenhardt et al., 2013; Biancardi et al., 2015; Fouda et al., 2017). MasR and $\mathrm{AT}_{2} \mathrm{R}$, both of which have antioxidant and anti-inflammatory properties, also enhance the production of brain-derived neurotrophic factor, known to promote cell survival and synaptic plasticity (Bernstein et al., 2014) and improve cognition (Liu et al., 2016). While $\mathrm{AT}_{2} \mathrm{R}$ expression is usually upregulated alongside $\mathrm{AT}_{1} \mathrm{R}$ as a compensatory mechanism, this relationship was shown to be blunted in aging (Labandeira-Garcia et al., 2017).

\section{Oligodendrocytes}

Oligodendrocytes are axon-myelinating cells. To our knowledge, they have $\mathrm{AT}_{1} \mathrm{Rs}$ and $\mathrm{AT}_{2} \mathrm{Rs}$ on their cell membrane, which is known to have opposing effects. In particular, for oligodendrocytes, $\mathrm{AT}_{1} \mathrm{Rs}$ lead to demyelination, while $\mathrm{AT}_{2} \mathrm{Rs}$ promote re-myelination to enhance synaptic transmission and improve neuronal communication (Valero-Esquitino et al., 2015; Jackson et al., 2018).

\section{THE LINK BETWEEN RAS, OXIDATIVE STRESS, NEUROINFLAMMATION, AND VASCULAR DYSFUNCTION}

As reviewed in the previous section, functions of RAS within the brain are not limited to hypertension. Dysregulation of these functions can have detrimental effects on the brain. In this regard, a role for b-RAS has been identified in many different neuropsychiatric disorders, including anxiety, depressive disorder, and alcoholism within the brain (LabandeiraGarcia et al., 2017). Above all, the b-RAS may also lead to chronic neurodegenerative diseases by playing a pivotal role in oxidative stress and neuroinflammation (Barnham et al., 2004). In the following subsections, we will describe the mechanisms through which RAS contributes to oxidative stress and neuroinflammation.

\section{Oxidative Stress}

Although ROS have essential roles in metabolism, cell signaling, and the proper formation of learning and memory processes under physiological conditions (Chandel et al., 2000; Massaad and Klann, 2011; Chandel, 2014), in excessive amounts, they can lead to oxidative stress ( $\mathrm{Li}$ et al., 2013). ROS are produced as a primary product of NADPH-oxidase (NOX) and secondary products of many other enzymatic processes such as those including xanthine oxidase, cyclooxygenases, uncoupled NOS, and the mitochondrial electron transport chain (De Silva and Faraci, 2013). Among them, membrane NOX complexes and mitochondria are the two main sources of ROS (Babior, 2004). Notably, there is a NOX-derived ROS-mediated cross-talk between them, which can further enhance the production of ROS by mitochondria (Cai, 2005). Furthermore, accumulated amounts of ROS can impair mitochondrial integrity, decrease ATP production, and lead to more mitochondria-derived ROS. It is known that mitochondrial-derived ROS contribute to cellular dysfunction by reaching the cytoplasm, demonstrating additional detrimental consequences.

Reactive oxygen species-associated oxidative stress leads to structural and functional modifications of proteins via oxidation. These modifications can increase the hydrophobicity of some proteins, thus leading to protein aggregation. To restrain cellular toxicity as a consequence of protein aggregation, effective removal of oxidized and damaged proteins is essential. This removal can be performed by either proteasome-mediated protein degradation or the autophagic pathway. However, ROS can also impair the proteasome system, thus leading to reduced protein degradation and accumulation of abnormal proteins such as synuclein, tau, or huntingtin in neurodegenerative diseases (Dröge, 2002; Turrens, 2003). ROS-related inhibition of the proteasome-based protein degradation upregulates autophagy. Although autophagy in response to mild oxidative stress is neuroprotective, its excessive or chronic upregulation promotes cellular death (Dasuri et al., 2013). With these pathways, ROS production and the destructive effects of oxidative stress can be further exacerbated (Gao et al., 2014). Notably, both proteasomemediated degradation and autophagy demonstrate age-associated dysfunction and the effects of ROS on these processes contributes to the development of age-related neurodegenerative diseases (Grune et al., 2004; Dasuri et al., 2013).

There are seven isoforms of NOX. Among them, NOX1, NOX2, and NOX4 have been identified in the brain (Miller et al., 2007). Overstimulation of the Ang II/AT $\mathrm{A}_{1} \mathrm{R}$ axis can activate these brain NOX complexes and generate excessive amounts of ROS (Chan et al., 2005). In this regard, it has been demonstrated that ROS is elevated in the cerebrum with acute and chronic administration of Ang II via activation of NOX2 (Girouard et al., 2006; Chrissobolis et al., 2012). As extracellular Ang II binds to membrane $\mathrm{AT}_{1} \mathrm{R}$, it activates NOX2, increases intracellular $\mathrm{Ca}^{2+}$ levels, and generates intracellular oxidative stress (Wang, 2004). In addition, Ang II is known to be capable of destroying endothelium-dependent vasodilation in the cerebral circulation. However, interestingly, Chrissobolis et al. (2012) showed that these deleterious effects of Ang II did not occur in NOX2 deficient mice treated with Ang II. Oxidative stress also mediates Ang II-induced inward remodeling and hypertrophy in cerebral arterioles that blunt cerebral perfusion in hypertension. Consistent with previous findings, this inward remodeling was also not observed in NOX2 deficient mice (Chan and Baumbach, 2013). Activation of nuclear and mitochondrial $\mathrm{AT}_{1} \mathrm{Rs}$ produce NOX4-derived ROS in neurons by coupling 
to phosphoinositol-3 kinase and protein kinase $\mathrm{C}$ activation (Hongpaisan et al., 2004; Kimura et al., 2005; Abadir et al., 2012; Valenzuela et al., 2016; Villar-Cheda et al., 2017). Importantly, activation of nuclear $\mathrm{AT}_{1} \mathrm{Rs}$ regulates gene expression and triggers several mechanisms that protect cells against oxidative stress (Villar-Cheda et al., 2017). In particular, nuclear RAS increases expression of $\mathrm{AT}_{2} \mathrm{R}$ mRNA and angiotensinogen and activates Ang II/ $\mathrm{AT}_{2} \mathrm{R}$ and Ang (1-7)/MasR axes to counteract $\mathrm{AT}_{1} \mathrm{R}$ effects in neurons (Villar-Cheda et al., 2010, 2017; CostaBesada et al., 2018).

Finally, local Ang II levels impair insulin signaling and contribute to IR by impacting insulin-stimulated increases in insulin receptor substrate1-associated phosphoinositol-3 kinase activity (Folli et al., 1999). In addition to Ang II, hyperglycemia is also known to induce oxidative stress. Therefore, the combined effect of Ang II and hyperglycemia may exacerbate oxidative stress damage in diabetic tissue (Chen et al., 2007; Fukumoto et al., 2008). Separately, abnormalities in brain insulin signaling pathways are associated with cognitive impairment and $\mathrm{AD}$ pathology (Arvanitakis et al., 2020).

Besides increasing ROS generation, the RAS can alter the mitochondrial redox balance by diminishing the activity of scavenging enzymes. Many scavengers, including superoxide dismutase (SOD), catalase, and glutathione, have an essential role in reducing oxidative stress in the brain. There are three forms of SOD: cytosolic copper-zinc SOD (CuZnSOD; SOD1), mitochondrial manganese SOD (MnSOD; SOD2), and extracellular CuZnSOD (SOD3). SOD1 and SOD2 are especially crucial for age-related brain disorders (Gao et al., 2014). In transgenic mouse models of Alzheimer's disease (AD) pathology, the deletion of one allele of SOD2 increased amyloid plaque formation while the deletion of SOD1 increased $\beta$-amyloid oligomerization, cognitive impairment, and neuronal dysfunction (Esposito et al., 2006; Murakami et al., 2011). Furthermore, overexpression of SOD was shown to be related to decreased susceptibility to $\beta$-amyloid-induced neurotoxicity and ischemic brain injury (Celsi et al., 2004; Chen et al., 2011), yet it has been shown that the activity of antioxidant molecules glutathione, SOD, and catalase decrease with activation of the RAS (Bechara et al., 2005; Rodriguez-Iturbe et al., 2007; Xiong et al., 2010). Consistent with this observation, NO bioavailability and SOD activity increased, and endothelial function improved in humans after treatment with the $\mathrm{AT}_{1} \mathrm{R}$ blocker losartan (Hornig et al., 2001).

ROS production in the brain is high due to its high oxygen consumption, and the oxidative metabolism of neurotransmitters, making the brain extremely vulnerable to additional free radical attacks (Sian et al., 1994; Kumar H. et al., 2012). Therefore, regulation of RAS is particularly essential as it may lead to impaired neurotransmitter release. Within the basal ganglia, cell death and dysfunction increased with $\mathrm{AT}_{1} \mathrm{R}$ upregulation in dopaminergic neurons (GarridoGil et al., 2013a; Zawada et al., 2015; Ou et al., 2016). By contrast, in the same type of cells, Ang (1-7)/MasR and Ang $\mathrm{II} / \mathrm{AT}_{2} \mathrm{R}$ axes reduced ROS production and mitochondrial respiration (Costa-Besada et al., 2018). Further, it has been shown that upregulated ACE expression reduced acetylcholine release from cholinergic neurons (Barnes et al., 1992; Tota et al., 2012). This RAS-mediated upregulation of oxidative stress leads to the release of pro-inflammatory response exacerbating cell death (Garrido-Gil et al., 2013a; Ou et al., 2016).

\section{Neuroinflammation}

Within the brain, microglial cells are the most significant contributor to NOX-derived ROS (Gao et al., 2012). Among NOX isoforms, NOX2 is the primary source of extracellular ROS in microglia (Gao et al., 2014). NOX-derived ROS also affect intracellular signaling pathways related to microglial activation, proliferation, and release of pro-inflammatory signals (Shacter, 2000; Qin et al., 2004; Shulaev and Oliver, 2006; Gao et al., 2014). Although activation of microglial cells is necessary for removing dead cells and debris, exacerbation of this inflammatory cascade can harm the surrounding neurons and cause the progression of neurodegeneration (Vowinckel et al., 1997).

As discussed in Section "Receptor Functions According to Cell Type," the Ang II/AT ${ }_{1} \mathrm{R}$ axis plays a role in the transition of microglia between its activated substates proinflammatory $\mathrm{M} 1$ and anti-inflammatory $\mathrm{M} 2$. In particular, $\mathrm{AT}_{1} \mathrm{R}$-induced NOX activation regulates the shift between $M 1$ and $M 2$, with upregulation of the $\mathrm{AT}_{1} \mathrm{R} / \mathrm{NOX}$ axis promoting proinflammatory and suppressing anti-inflammatory substates. With this signal cascade, microglia further exacerbate ROS production (Choi et al., 2012). This mechanism was also supported by a study showing that $\mathrm{AT}_{1} \mathrm{R}$ antagonists reduce $\mathrm{M} 1$ microglia activation and promote M2 microglia polarization (Saavedra, 2017). In microglial cells, $\mathrm{AT}_{1} \mathrm{R}$-induced NOX activation is mediated by protein kinase C (Joglar et al., 2009). The initial NOX-derived superoxides are amplified by activation of nuclear factor- $\mathrm{k} \beta$ $(\mathrm{NF}-\mathrm{k} \beta)$ and the RhoA/Rho kinase pathway, which further increased NOX activation, hence yielding ROS production (Borrajo et al., 2014; Rodriguez-Perez et al., 2015). With a feed-forward mechanism, Rho-kinase activation upregulates $\mathrm{AT}_{1} \mathrm{R}$ expression via $\mathrm{NF}-\mathrm{k} \beta$ in microglial cells. Activation of the microglial RhoA/Rho kinase pathway is a significant modulator of the actin cytoskeleton and mediates microglial polarization and neurodegeneration (Labandeira-Garcia et al., 2015, 2017). Moreover, Ang II/AT $\mathrm{AT}_{1}$ axis can increase toll-like receptor 4 , which is known to mediate microglial activation and neuroinflammation (Biancardi et al., 2015; Rietdijk et al., 2016). It was shown that Ang II and prorenin promotes the production of ROS and pro-inflammatory cytokines [e.g., interleukin-1 beta (IL-1 $\beta$ ) and IL-6] while reducing anti-inflammatory IL-10 levels (Winklewski et al., 2015). As an example, a recent study showed that Ang II administration leads to a pro-inflammatory response in the hippocampus with an increase in hippocampal CD68positive cells (Takane et al., 2017).

In astrocytes, the Ang II/AT ${ }_{1} \mathrm{R}$ axis mediates the production of IL-6 and ROS via NF-k $\beta /$ ROS pathway (Gowrisankar and Clark, 2016). Also, Ang III can induce signal transducer and activator of transcription 3 , which is a crucial signal transduction protein that mediates cell differentiation, proliferation, apoptosis, and inflammation in astrocytes (Costantino and Barlocco, 2008; Kandalam et al., 2015). 
There are also inflammation-regulating mechanisms induced through RAS receptors. Neuronal $\mathrm{AT}_{2} \mathrm{R}$ signaling can lead to a downregulated signal transducer and activator of transcription 1 and 3 phosphorylation that can suppress microglia activation (Jackson et al., 2018). $\mathrm{AT}_{4} \mathrm{R}$ was shown to mediate antiinflammatory effects in a mouse model of AD (Royea et al., 2017). Thus, there is a delicate balance between Ang II/AT ${ }_{1} \mathrm{R} / \mathrm{NOX}$ pro-oxidative and pro-inflammatory axes and Ang II/AT $2 \mathrm{R}$ Ang (1-7)/MasR antioxidant and anti-inflammatory axis, which determine RAS effects within the brain.

The precise reason for sex differences (premenopausal women vs. men) in the prevalence of cerebrovascular diseases is not yet fully understood. However, an association of Ang II-estrogen was suggested as a possible mechanism due to Ang II's sexually dimorphic effects on the cerebral vasculature (De Silva and Faraci, 2013). Consistent with this suggestion, it was shown that activation of microglial estrogen receptor B suppresses Ang IIinduced increase in levels of several significant mediators (e.g., IL-1 $\beta$ and rho kinase) of the microglial inflammatory response (Rodriguez-Perez et al., 2015).

\section{Vascular Dysfunction}

Renin-angiotensin system can affect CBF through several mechanisms. The first such mechanism acts through Ang II-induced hypertension, which is characterized by many forms of alterations in the cerebral vasculature, including pathological remodeling of arteries, vasoconstriction, diminished cerebrovascular autoregulation, cerebrovascular inflammation, and decreased vascular compliance (Faraci and Heistad, 1990). A consequence of this RAS/hypertension-based mechanism is the development of an impaired response to reduced cerebral perfusion, which may render the brain vulnerable to ischemia and cellular injuries (Saavedra, 2017).

Renin-angiotensin system can also cause vascular dysfunction independent of hypertension. Based on its pro-oxidative and pro-inflammatory properties, it can cause vasoconstriction, endothelial damage, $\mathrm{BBB}$ breakdown, and disruption of neurovascular coupling (Ahmed et al., 2019). Impairments of neurovascular coupling, defining the alterations in CBF according to local neural activity, was shown to be associated with Ang II independent of hypertension based on evidence in phenylephrine-induced hypertensive mice showing no impairment in their neurovascular coupling (Kazama et al., 2003; Capone et al., 2011). Similarly, the detrimental effects of the Ang II/AT ${ }_{1} \mathrm{R}$ axis on BBB permeability have not been seen in a deoxycorticosterone acetate-induced hypertension state (Rodrigues and Granger, 2012). Ang II can induce vasoconstriction via smooth muscle- and endotheliumdependent mechanisms. First of all, smooth muscle contraction generally occurs via $\mathrm{AT}_{1} \mathrm{R}$-mediated activation of phospholipase $\mathrm{C}$, resulting in inositol 1,4,5-triphosphate and diacylglycerol production. These products mediate two distinct pathways, which commonly result in smooth muscle contraction via activation of several protein kinases, such as myosin light chain kinase and Rho-kinase (Hilgers and Webb, 2005). Ang II-induced constriction of basilar arteries was destroyed by Rho-kinase inhibitor Y-27632 (Faraci et al., 2006). Another path to vasoconstriction is endothelium-dependent constriction via cyclooxygenase- and/or superoxide-dependent mechanisms mediated by $\mathrm{AT}_{1} \mathrm{R}$ in cerebral endothelium (De Silva et al., 2009). Finally, the Ang II/AT ${ }_{1} \mathrm{R}$ axis causes an alteration in endothelium-dependent vasodilation by decreasing the bioavailability of NO (Intengan and Schiffrin, 2001).

\section{AGE- AND DISEASE-RELATED CHANGES IN THE RAS}

The pathophysiologies reviewed in the last section generally develop in the elderly. In this section, we discuss their connection with aging and how they lead to frailty and neurodegenerative diseases.

\section{RAS, Aging, and Frailty}

Aging and RAS are interrelated. Age-associated unbalanced activation of RAS influences the aging phenotype. RAS component levels changing with age accelerate cellular senescence and age-related tissue/organ dysfunction, thus leading to chronic age-related diseases through various mechanisms including oxidative stress, inflammation, apoptosis, and vascular changes. Several studies investigated the relationship between RAS, longevity, and neurodegenerative diseases. The relationship between RAS and longevity was first shown in mice by demonstrating that disruption of the $\mathrm{AT}_{1} \mathrm{R}$ promotes longevity via attenuation of oxidative stress and pro-survival gene induction (Benigni et al., 2009). Benigni et al. (2013) also showed the association between prolonged life span and reduced $\mathrm{AT}_{1} \mathrm{R}$ protein in humans with $\mathrm{AT}_{1} \mathrm{R}$ gene variation. Furthermore, it has been shown in multiple studies that Ang II mediates premature senescence (Kunieda et al., 2006; Tsai et al., 2016).

Changes in RAS components with age are differently regulated in circulating and local RAS (Abadir, 2011). While circulating RAS components have lower levels in older animals, perhaps, due to age-related increase in blood pressure (Diz, 2008), $\mathrm{AT}_{1} \mathrm{R}$ levels in local RAS are found to be upregulated (Kobori et al., 2007; Abadir, 2011; Abadir et al., 2011; Rodriguez-Perez et al., 2019). Previous work investigating changes in $\mathrm{AT}_{1} \mathrm{R}$ and $\mathrm{AT}_{2} \mathrm{R}$ level with age showed that mitochondrial and nuclear $\mathrm{AT}_{1} \mathrm{R}$ levels increased significantly with age (Gwathmey et al., 2010; Abadir et al., 2011) as opposed to decreased $\mathrm{AT}_{2} \mathrm{R}$ expression (Millan et al., 1991). Furthermore, the maximal expression of $\mathrm{AT}_{2} \mathrm{R}$ was found in developing fetal tissues, followed by an immediate reduction after birth and maintenance of relatively lower levels in adulthood (Carey and Siragy, 2003). This was also confirmed by increased $\mathrm{AT}_{1} \mathrm{R} / \mathrm{AT}_{2} \mathrm{R}$ expression ratios in aged animals (Garcia-Garrote et al., 2019). This was attributed to ageassociated changes in the distribution of Ang II receptors, with nuclear $\mathrm{AT}_{1} \mathrm{Rs}$ becoming the most common (85\%) in older ages as opposed to nuclear $\mathrm{AT}_{2} \mathrm{Rs}$ being the most common (80\%) at young ages (Gwathmey et al., 2010). These distributional alterations were also shown in mitochondria of aged mice (Abadir et al., 2011). However, the same study showed that in vivo administration of $\mathrm{AT}_{1} \mathrm{R}$ blocker losartan for 20 weeks increased the number of mitochondrial $\mathrm{AT}_{2} \mathrm{Rs}$ and improved bioenergetics 
of the aging mitochondria without affecting the expression of mitochondrial $\mathrm{AT}_{1}$ Rs (Abadir et al., 2011).

The b-RAS distribution also shows age-related differences. In a recent study, a progressive decrease in the expression of $\mathrm{AT}_{2} \mathrm{Rs}$ with aging was shown in the SN (Rodriguez-Perez et al., 2019). Notably, in the same study, several changes in external appearance, spontaneous motor behavior, RAS components, and pro-oxidative and pro-inflammatory markers were found in young $\mathrm{AT}_{2} \mathrm{R} \mathrm{KO}$ mice as being similar to those observed in aged wild type mice. Regarding RAS changes, elevated Ang II and $\mathrm{AT}_{1} \mathrm{R}$ levels and decreased mRNA/protein expression of other protective RAS receptors were observed both in aged wild type and $\mathrm{AT}_{2} \mathrm{R}-\mathrm{KO}$ mice (Rodriguez-Perez et al., 2019). Another study using $\mathrm{AT}_{2} \mathrm{R}-\mathrm{KO}$ mice found increased $\mathrm{AT}_{1} \mathrm{R}$ expression in the brain ventricular-subventricular zone accompanied by a marked decrease in proliferation and generation of neuroblasts. This decrease was inhibited by treatment with the $\mathrm{AT}_{1} \mathrm{R}$ antagonist candesartan. Further, increased proliferation and generation of neuroblasts were shown in wild type mice with the administration of $\mathrm{AT}_{2} \mathrm{R}$ agonist C21 (Garcia-Garrote et al., 2019). Similarly, it was shown that $\mathrm{AT}_{1} \mathrm{R}$ blockade can enhance hippocampal neurogenesis in hypertensive state (Bhat et al., 2018; Drews et al., 2019). Interestingly, neurogenesis was enhanced in hippocampal dentate gyrus of adult rodents exposed to short-term heat as a result of activation of $\mathrm{AT}_{1} \mathrm{R}$ due to increase in Ang II (Koyama et al., 2018). This finding was in contrast to the aforementioned literature and might be because of the transient increase of Ang II with short-term application of the heat. However, further research is needed for a more definitive explanation. In another study about the importance of RAS on neurogenesis showed that permanent depletion of ACE2 impaired the effect of running on neurogenesis in the adult hippocampus (Klempin et al., 2018). Finally, similar observations were made for MasRs (Gwathmey et al., 2010) such that the protective Ang1-7/Mas axis expression decreased in aged rats similar to $\mathrm{AT}_{2} \mathrm{R}$ (Villar-Cheda et al., 2010; Costa-Besada et al., 2018).

Mitochondrial dysfunction has a pivotal role in cell aging. The distributional changes in RAS receptor levels in mitochondria with aging in favor of $\mathrm{AT}_{1}$ Rs elevates mitochondrial ROS levels. This can diminish mitochondrial integrity and function, leading to decreased ATP generation and further production of ROS and peroxynitrite, a cytotoxic anion that inhibits mitochondrial electron transport (Sastre et al., 2000; Abadir et al., 2012). ROS have been proposed as the leading molecular factor in the aging process (Harman, 1956). One cellular aging mechanism is one in which increased mitochondrial ROS levels lead to oxidation of mitochondrial protein/lipid and DNA mutations whose accumulations are linked to senescence and apoptosis (Abadir et al., 2012; Vajapey et al., 2014). Aggregation of modified proteins due to enhanced RAS activity could be the mechanism of accelerated premature aging in $\mathrm{AD}$ (Cooper et al., 2018).

Consistent with the detrimental effects of $\mathrm{AT}_{1} \mathrm{Rs}$ on mitochondria, it was shown that deletion of $\mathrm{AT}_{1} \mathrm{Rs}$ resulted in a marked prolongation of life span in mice by upregulating multiple mitochondrial and prosurvival genes, nicotinamide phosphoribosyltransferase (Nampt) and sirtuin 3 (SIRT3) in the kidney (Benigni et al., 2009). Similarly, it was shown within the brain that overactivation of the Ang II/AT $\mathrm{AT}_{1} \mathrm{R} / \mathrm{NOX}$ axis leads to increased cell vulnerability to oxidative stress by decreasing levels of SIRT3, which would typically suppress pro-oxidative RAS axis with a feed-forward mechanism (Diaz-Ruiz et al., 2020). The same study also showed that these effects could be counteracted by treatment with AT1 antagonists in aged rats (Diaz-Ruiz et al., 2020). On the other hand, SIRT1 and Ang II/AT $\mathrm{A}_{1} \mathrm{R}$ axis, both of which have roles in neuroinflammation, oxidative stress, and aging-related cell degeneration, also regulate each other, and this regulation is impaired in aged animals (Diaz-Ruiz et al., 2015). Further, lower SIRT1 in brain is associated with more brain tau pathology (Julien et al., 2009). In addition, glial-derived Ang II appears to participate in age-related impairments of autonomic function such that glial angiotensinogen deficiency prevents these impairments (Diz, 2008). The intracellular Ang II/AT $\mathrm{AT}_{1} \mathrm{R} / \mathrm{NOX}$ axis generates superoxide anions that promote the uncoupling of endothelial NOS, which in turn reduces NO availability and mitochondrial NOS activity with aging (Valdez et al., 2004). Finally, the Ang II/ $/ \mathrm{AT}_{1} \mathrm{R}$ axis accelerates cellular senescence by inducing telomere shortening and cell cycle arrest, which can be reversed by losartan (Feng et al., 2011; Conti et al., 2012). Similar to Ang II, agonistic angiotensin II type 1 receptor autoantibodies can activate the $\mathrm{AT}_{1} \mathrm{R}$ (Herse and LaMarca, 2013), which is consistent with the finding that higher levels of autoantibodies are associated with higher levels of inflammatory cytokines, weaker grip strength, slower walking speed, and increased risk for frailty (Abadir et al., 2017).

The compensatory mechanism of the b-RAS, which decreases oxidative stress and neuroinflammation, becomes less effective with age due to reduced $\mathrm{AT}_{2} \mathrm{R}$ with age (Villar-Cheda et al., 2010, 2012; Lu et al., 2015). In aged animals, this decrease in $\mathrm{AT}_{2} \mathrm{R}$ expression was shown to lead to a further increase in the pro-oxidative, pro-inflammatory effects and neuron vulnerability induced by activation of upregulated $\mathrm{AT}_{1}$ Rs (Labandeira-Garcia et al., 2017). As an example of neuronal vulnerability, neurotoxins lead to more dopaminergic neuron loss in aged compared to younger animals (McCormack et al., 2004).

The imbalance developing with age between proinflammatory and protective arms of RAS leads to inflammaging, which refers to aging-related pro-inflammatory changes observed in several tissues (Abadir, 2011; Labandeira-Garcia et al., 2017). This is associated with the pathogenesis of common and disabling diseases of older age, functional decline, frailty, and increased mortality (Abadir, 2011). Consistent with this, increased NOX activity due to RAS was seen in age-related diseases such as diabetes and atherosclerosis (Griendling et al., 2000; Mehta and Griendling, 2007). Aging and neuroinflammation in brain tissue together lead to exacerbated responses to lesions and neurodegeneration, hence being major risk factors for neurodegenerative diseases such as $\mathrm{AD}$ and Parkinson's disease (PD) (Collier et al., 2007; Labandeira-Garcia et al., 2017).

Lifelong accumulation of neuropathologies occurs in neurodegenerative diseases prior to clinical diagnosis (Braak and Braak, 1991; Bennett et al., 2012). Although neuropathologies are responsible, in large part, for the onset of dementia, they only account for a fraction of cognitive decline (Boyle et al., 2013, 2018, 2019). In this regard, frailty may be a critical determinant 
of the cognitive impairment in both $\mathrm{AD}$ and stroke (Bennett et al., 2012; Taylor-Rowan et al., 2019). A strong interaction between frailty and pathologies was shown in $\mathrm{AD}$ such that high frailty renders subjects more vulnerable to pathologies with both more frequent development of the disease and worse cognitive decline. By contrast, people with low frailty are more resilient to neuropathologies (Wallace et al., 2019).

Frailty has also been shown to be an independent factor determining both the prevalence of stroke and post-stroke mortality rates (Palmer et al., 2019; Evans et al., 2020). The last decade has witnessed a considerable increase in research on frailty. Frailty is strongly influenced by multiple factors, including inflammation, oxidant state, vascular regulations, and mitochondria dysfunctions, and apoptosis. RAS plays a broad and essential role in the regulation of these factors, and it is closely associated with both physical and cognitive frailty phenotypes. Given the availability of RAS-acting drugs and the canonical role of RAS in both frailty and pathological mechanisms of age-related neurodegenerative diseases, which is discussed in the subsequent sections, RAS deserves further research as a potential therapeutic agent in age-related diseases.

\section{Alzheimer's Disease}

Alzheimer's disease is a complicated neurodegenerative disease characterized by progressive neuronal losses and cognitive impairment. Based on the brain autopsies of 83 patients with and without dementia, Braak and Braak (1991) described the pathologic characteristics of the disease as degeneration of specific nerve cells, presence of neuritic plaques, and neurofibrillary tangles (NFT). The most prominent pathological changes were found to be the extracellular amyloid plaques and intraneuronal NFT accumulations, which had started to take place years before the appearance of clinical symptoms (Braak and Braak, 1991; Mcgeer and Mcgeer, 1995). Although it is possible that these accumulations are not causal in $\mathrm{AD}$ pathogenesis, they characterize $\mathrm{AD}$ as a unique neurodegenerative disease among different diseases that can lead to dementia. However, classical diagnostic approach focused solely on clinical syndromes of $\mathrm{AD}$ regardless of these unique $\mathrm{AD}$ neuropathologies. This has resulted in misdiagnosis and limited our understanding of $\mathrm{AD}$ on a biological basis. Thus, recently, a purely biological definition of $\mathrm{AD}$ was introduced based on in vivo identification and postmortem examination of distinctive AD neuropathologies (Jack et al., 2018). This new research framework recommends referring to the clinical symptoms of $\mathrm{AD}$ without neuropathologic verification as Alzheimer's clinical syndrome instead of what has been called 'probable or possible AD' according to the traditional approach (Jack et al., 2018). Various RAS-related mechanisms have been suggested as contributors to its pathogeneses. The b-RAS is involved with processes of learning and memory, neuronal differentiation, and nerve regeneration via several mechanisms, including oxidative stress, neuroinflammation, and vasculopathy, as discussed in the previous sections. The relation of $\mathrm{AD}$ and other pathologies to cognitive decline follow complex patterns (Boyle et al., 2017; Wilson et al., 2019). A few years before death the rate of cognitive decline increases markedly due to terminal decline (Wilson et al., 2012). Several predisposing factors, such as genetics, age, and possibly environmental toxins, contribute to the development of initial lesions like senile plaques and NFTs. These products lead to an inflammatory response, microglial activation, and cytokine release, which then accelerates neuronal dysfunction and cognitive decline (Mcgeer and Mcgeer, 1995). In this regard, inflammation was thought to contribute to the progressive neuropathology of $\mathrm{AD}$ (McGeer and McGeer, 2013). As discussed in Section "Receptor Functions According to Cell Type," the Ang II/AT ${ }_{1} \mathrm{R}$ axis of the b-RAS is an important contributor to neuroinflammation by enhancing microglial activation and polarization. Therefore, prolonged and unresolved inflammation harm neurons and synapses, which results in chronic dysregulation of glial cells followed by chronic deterioration in the brain structure and function (Denver and McClean, 2018). Furthermore, a recent study showed that higher Ang II levels are associated with smaller total gray matter, hippocampal, rostral middle frontal, and supramarginal parietal volumes which are related to cognitive domains that may decline in preclinical AD (Yasar et al., 2020).

A complementary explanation suggests the relation among increased oxidative stress, mitochondrial impairment, and alterations in the antioxidant system as a contributor to $\mathrm{AD}$ (Padurariu et al., 2013). As described in Section "Prelude to the Renin-Angiotensin System Signaling and Functions," over activity of the Ang II/AT $\mathrm{R}$ axis causes increased ROS and oxidative stress. First, oxidative stress causes damage by lipid peroxidation of the mitochondrial membrane as well as oxidation of structural and enzymatic proteins and nucleic acids. Increased oxidation of mitochondrial DNA impairs mitochondrial integrity and decreases ATP production, thus potentially resulting in mitochondrial dysfunction (Mecocci et al., 2018). As mitochondrial function declines, it leads to cellular alterations observed in $A D$, such as amyloid- $\beta(A \beta)$ production, tau phosphorylation, synaptic degeneration, and oxidative stress (Swerdlow, 2011, 2012). Secondly, oxidative stress-associated modifications of the proteins can result in aggregation of $A \beta$ and phosphorylation of tau protein, which could induce a vicious cycle of pathogenesis in $\mathrm{AD}$ (Kim et al., 2015). The amount of antioxidants is also an essential factor determining the extent of oxidative damage in the pathogenesis of $\mathrm{AD}$ (Mecocci et al., 2018). Their importance is supported by data showing neuroprotective effects of some anti-oxidants such as $\gamma$-tocopherol and lycopene (Yin et al., 2014; Morris et al., 2015).

Amyloid- $\beta$ accumulation is another important aspect of $\mathrm{AD}$ pathogenesis. Ang II enhances the $\gamma$-secretase activity and $A \beta$ production (Zhu et al., 2011). $A \beta$ production leads to $\mathrm{AT}_{2} \mathrm{R}$ oligomerization, which is associated with enhanced neurodegeneration (AbdAlla et al., 2009). In addition to the Ang $\mathrm{II} / \mathrm{AT}_{1} \mathrm{R}$ axis, $\mathrm{ACE}$ has also been investigated for its possible role in $A \beta$ degradation (Miners et al., 2011). Although ACE was shown to degrade $A \beta$ peptide (Hemming and Selkoe, 2005), it can also degrade neprilysin, an $A \beta$-degrading enzyme that may contribute to $A \beta$ aggregation (Carson and Turner, 2002). Moreover, it has been shown in brain tissue autopsy of $\mathrm{AD}$ patients that ACE levels are elevated in the hippocampus, frontal cortex, and caudate nucleus regardless of hypertension and that 
these levels have been reported to correlate with $\mathrm{AD}$ pathology (Miners et al., 2008, 2009). Similarly, it was shown in a recent study that cerebrospinal fluid (CSF) ACE activity was elevated in AD (Kehoe et al., 2019). Furthermore, the same study showed that RAS overactivity is correlated with CSF markers of capillary damage in $\mathrm{AD}$, including elevated CSF soluble platelet-derived growth factor receptor $\beta$ indicating pericyte damage and elevated CSF albumin indicating BBB breakdown.

Vascular disease may also contribute to the pathogenesis of AD. This is supported by the fact that many risk factors for vascular disease such as hypertension and diabetes are associated with Alzheimer's dementia (de La Torre, 2004). These relationships are complex and the association is likely due in part to mixed pathologies (Abner et al., 2016; Pruzin et al., 2017; Arvanitakis et al., 2018). The progressive degeneration of brain capillaries, such as thickened basement membrane, cerebral atrophy, reduced vessel elasticity, or genetic predisposition, disturbs the blood flow to the brain (de la Torre and Mussivand, 1993). The hypothesis proposes the impaired blood flow in conjunction with neuroinflammation as the central reason for $A \beta$ aggregates and neuronal damage in the $\mathrm{AD}$ (de la Torre, 2002). RAS can modulate both of these underlying factors. In this regard, Ang II/ $\mathrm{AT}_{1} \mathrm{R}$ axis causes vasoconstriction of the cerebral vessels, vascular remodeling, impaired cerebrovascular autoregulation, and endothelial dysfunction (Iadecola and Davisson, 2008; Pires et al., 2013). As mentioned so far, Ang II/ $\mathrm{AT}_{1} \mathrm{R}$ axis has pro-inflammatory and pro-oxidant effects that can damage the $\mathrm{BBB}$, increase its permeability, and reduce $\mathrm{CBF}$, thus contributing to the pathogenesis of the AD (Miners et al., 2011). Consistent with this, blockade of $\mathrm{AT}_{1} \mathrm{R}$ and activation of $\mathrm{AT}_{2} \mathrm{R}$ reverse the hypertension-induced cerebrovascular dysfunction and improve the barrier function of endothelial cells and diabetesassociated cerebral endothelial dysfunction (Alhusban et al., 2013; Gallego-Delgado et al., 2016; Fouda et al., 2019).

Interestingly, there is a relationship between $\mathrm{AD}$ and diabetes mellitus type 2, which are both age-associated diseases (Denver and McClean, 2018). IR increases the risk of developing cognitive decline, and IR has been shown in postmortem brain tissue of AD patients without diabetes (Talbot et al., 2012; Arvanitakis et al., 2020). Also, impaired neuronal insulin signaling was demonstrated in the AD brain (Denver and McClean, 2018). In the brain, normally functioning insulin signaling is very important for proliferation, differentiation, and neurite growth. Insulin plays an essential role in learning and memory (Blázquez et al., 2014). In this regard, it was shown in rats in a watermaze task that long-term fructose-drinking causes IR, impaired insulin signaling, oxidative stress, neuroinflammation, the downregulated activity of the cholinergic system, cognitive decline, impairments of spatial memory and learning (Yin et al., 2014). IR also causes endothelial dysfunction, which is important for AD development (Aronis and Mantzoros, 2012). Therefore, another impact of RAS in the aspect of $\mathrm{AD}$ might be impaired insulin signaling and its contribution to IR (Folli et al., 1999) through mechanisms mentioned in Sections "Neurons" and "Oxidative Stress." Interestingly, a significant increase in intracellular ACE was shown in high glucose conditions despite no change in extracellular ACE under the same circumstances (Cristovam et al., 2008).

Finally, b-RAS has important learning and memory-related effects (Ho and Nation, 2018). Among these effects, the overactivation of the Ang II/AT ${ }_{1} \mathrm{R}$ axis is known to decrease acetylcholine release (Barnes et al., 1992; Tota et al., 2013). This might complement the role of cholinergic dysfunction in $\mathrm{AD}$, proposing the loss of acetylcholine in the central nervous system as an important determinant of the cognitive decline in $\mathrm{AD}$ (Bartus et al., 1982; Kehoe, 2018). It was also shown that Ang II injection inhibits LTP in the hippocampus. On the other hand, the protective arm of the RAS has memory-enhancing effects. $\mathrm{AT}_{2} \mathrm{R}$ activation through Ang II/III initiate cellular proliferation and differentiation accompanied by regenerative processes. Ang (1-7)/MasR axis enhances the release of NO and facilitates LTP, thus resulting in improved memory (Wright and Harding, 2019). Ang IV enhances dopamine release in the striatum and acetylcholine release in the hippocampus, thus facilitating LTP and neuroprotection (Lee et al., 2001; Lew et al., 2003; Stragier et al., 2004; Davis et al., 2006). Ang IV increases concentrations of cognition-enhancing peptides such as vasopressin and oxytocin by inhibiting aminopeptidase activity of ATR4 (Tomizawa et al., 2003; Bielsky et al., 2005). Ang IV can stimulate angiogenesis and enhance NMDA currents and synaptic plasticity in the hippocampus by binding the c-Met receptor (Akimoto et al., 2004). Ang IV could increase CBF without significant changes in systemic blood pressure (Wright and Harding, 2019).

Renin-angiotensin system lies at the intersection of pathologies of $\mathrm{AD}$ through many mechanisms mentioned so far, thus being a potentially critical component of $\mathrm{AD}$ pathogenesis. In the light of this, angiotensin hypothesis was suggested for further research (Kehoe, 2018). Finally, the ready availability of RAS-modifying drugs makes RAS more attractive as those drugs can be repurposed for the prevention and treatment of $\mathrm{AD}$.

\section{Parkinson's Disease}

Parkinson's disease is a common neurodegenerative disease affecting more than 6 million individuals globally according to a recent study (Dorsey et al., 2018). It is characterized by dysregulation of the dopaminergic pathways and neuronal death as with other neurodegenerative diseases. Aging and neuroinflammation are two critical factors that have roles in the development and progression of PD. Brain RAS modulates both of these factors in SN (Valenzuela et al., 2010; Garrido-Gil et al., 2013b). The relationship between RAS and PD was first defined by Allen et al. (1992). It has been shown in several studies that b-RAS has a significant role in the progression of dopaminergic neuron degeneration in PD models (Grammatopoulos et al., 2007; Zawada et al., 2011; Sonsalla et al., 2013; Labandeira-Garcia et al., 2017). Moreover, increased CSF ACE activity in PD patients and an association between genetic polymorphism of the ACE gene and PD were also shown (Almeida-Santos et al., 2017).

The Ang II/ $/ \mathrm{AT}_{1} \mathrm{R}$ axis acting presynaptically in the $\mathrm{SN}$ and striatum enhances dopamine release (Mendelsohn et al., 1993; Brown et al., 1996). However, overactivation of this axis surprisingly shows a reverse effect, contributing to the loss of 
dopaminergic neurons and progression of neurodegeneration in PD models through oxidative stress induced by NOX complex activation and enhanced neuroinflammation mostly via microglia activation (Costa-Besada et al., 2018). Interestingly, Ang II $/ \mathrm{AT}_{1} \mathrm{R}$ axis did not lead to dopaminergic neuronal death in the absence of microglia (Joglar et al., 2009). These findings show the importance of microglia in PD. Finally, in $\mathrm{PD}$, low dopamine levels further increase neuroinflammation and neurodegeneration via the upregulation of the $\mathrm{AT}_{1} \mathrm{R} / \mathrm{NADPH}$ oxidase axis (Rodriguez-Perez et al., 2019).

Renin-angiotensin system also has protective roles against the progression of $\mathrm{PD}$. The Ang II/ $\mathrm{AT}_{2} \mathrm{R}$ axis can lead to actions opposing those of the Ang II/AT $\mathrm{A}_{1} \mathrm{R}$ axis in SN (Costa-Besada et al., 2018). Besides, Ang IV stimulates c-Met, and activation of the HGF/c-Met pathway inhibits the dopaminergic neuron loss in the $\mathrm{SN}$ in rats. Furthermore, maintenance of $\mathrm{AT}_{1} \mathrm{R}$ and $\mathrm{AT}_{2} \mathrm{R}$ balance via external modulations with $\mathrm{AT}_{1} \mathrm{R}$ blockage or hormonal replacement therapy-based $\mathrm{AT}_{2} \mathrm{R}$ upregulation was shown to be beneficial in PD (Farag et al., 2017). In addition, it has been shown that RAS blockade can reduce motor and nonmotor symptoms of PD and neuronal damage (Almeida-Santos et al., 2017). For example, the $\mathrm{AT}_{1} \mathrm{R}$ antagonist candesartan decreased the expression of nigral proinflammatory cytokines and dopaminergic cell vulnerability to neurotoxins in aged rats (Villar-Cheda et al., 2012). Finally, a similar modulation was obtained with estrogen replacement therapy, which led to a reduced nigral RAS and oxidative stress in young surgically menopausal rats than in aged menopausal rats. However, a remarkable reduction in dopaminergic neuron loss in both groups of menopausal rats was seen with the $\mathrm{AT}_{1} \mathrm{R}$ antagonist candesartan (Rodriguez-Perez et al., 2012).

\section{Vascular Cognitive Impairment}

Cerebrovascular disease is common and often followed by brain dysfunction, further leading to cognitive loss, which is called vascular cognitive impairment (Gorelick et al., 2011; Arvanitakis et al., 2016). Cognitive impairment is seen in nearly $30-40 \%$ of stroke survivors and progresses slowly even after a singlestroke lesion (Wiesmann et al., 2013; Levine et al., 2015). Two major risk factors of both stroke and the subsequent cognitive impairment are aging and hypertension, both of which affect CBF through vascular dysfunctionalities discussed in Section "Vascular Dysfunction" (Ivan et al., 2004; Ahmed et al., 2019). Diminished CBF leads to hypoperfusion and hypoxia by creating a pro-oxidative and pro-inflammatory environment in the brain, which eventually results in neuronal death, thus contributing to the development of cognitive impairments (Ahmed et al., 2019).

Because of its pro-oxidative and pro-inflammatory properties, $\mathrm{AT}_{1} \mathrm{R}$ overactivity plays an essential role in vascular cognitive impairment (Arroja et al., 2016). In this regard, $\mathrm{AT}_{1} \mathrm{R}$ overactivity promotes vasoconstriction, reduces $\mathrm{CBF}$, and increases oxidative stress, inflammation, and vulnerability to ischemia (LabandeiraGarcia et al., 2014). It was also shown that $\mathrm{AT}_{1} \mathrm{R}$-induced astrocyte senescence exacerbates cerebral ischemic injury (Liu et al., 2011). By contrast, the protective arm of RAS counteracts these effects. Six hours after ischemic injury in rodents, the MasR was found to be upregulated in the peri-infarct cortex (Arroja et al., 2016). Another study, reporting a similar overexpression of ACE2 and MasR in ischemic tissues, suggested that the Ang (1-7)/MasR axis potentially plays a pivotal role in the regulation of acute neuron injury in ischemic cerebrovascular diseases ( $\mathrm{Lu}$ et al., 2013). MasR activation and ACE2 overexpression reduced both inducible NOS and the production of pro-inflammatory cytokines in the peri-infarct cortex (Bedecs et al., 1997; Xia and Lazartigues, 2008; Gwathmey et al., 2009; Arroja et al., 2016). Because of its anti-oxidative, anti-inflammatory, and neuroprotective properties, the protective arm of RAS has been studied as a therapeutic option for vascular cognitive impairment. In this regard, the Ang (1-7)/MasR axis was shown to have proangiogenic properties; administration of Ang (1-7) for 4 weeks promoted brain angiogenesis (Jiang et al., 2014). MasR expression was found in large amounts in hippocampus, perirhinal cortex, and vascular endothelial cells, and it has been shown that Ang (1-7)/MasR axis facilitate LTP (Hay et al., 2017). Glycosylated Ang (1-7)/MasR agonist improved object recognition and spatial memory impairment and reduced ROS and inflammation in mouse models of VCI and dementia (Hay et al., 2019). Interestingly, in a study comparing wild-type mice, MasR KO mice, $\mathrm{AT}_{2} \mathrm{R} \mathrm{KO}$ mice, and $\mathrm{AT}_{2} \mathrm{R} /$ MasR double $\mathrm{KO}$ mice, it was found that cognitive status was unchanged in MasR KO mice despite decreased cerebral blood flow after bilateral carotid artery stenosis (Higaki et al., 2018).

Internal carotid artery administration of increasing doses of Ang IV significantly decreased cerebral infarct size in rats $24 \mathrm{~h}$ following embolic stroke, possibly due to Ang IV-facilitated the redistribution of blood flow to ischemic areas within a few minutes as indicated by cerebral arteriography (Faure et al., 2006). Furthermore, it was shown that C21, an $\mathrm{AT}_{2} \mathrm{R}$ agonist, prevented the development of cognitive impairment after stroke in aged animals and animal models of vascular dementia (Iwanami et al., 2015; Ahmed et al., 2019). The use of ARBs showed both vascular and neuroprotective effects after ischemic stroke and preserved cognitive function in aged animals with chronic cerebral hypoperfusion (Alhusban et al., 2015; Ahmed et al., 2018). Lastly, the TROPHY (TRial Of Preventing Hypertension) study also showed protective effects of valsartan against ischemic brain injury after middle cerebral artery occlusion in mice given non-hypotensive doses (Li et al., 2008).

\section{RENIN-ANGIOTENSIN SYSTEM-ACTING DRUGS}

As of today, an effective risk reduction, prevention, or treatment strategy is not available for $\mathrm{AD}$. Over 20 years, two categories of drugs have been used for the treatment of $\mathrm{AD}$. One of them is cholinesterase inhibitors that extend the half-life of acetylcholine, whereas the other is memantine, an NMDA receptor antagonist, that limits glutamate excitotoxicity and neuronal damage (Wright and Harding, 2019). With the discovery of b-RAS and its multidimensional effects on the nervous system beyond its well-known hypertensive effect, RASacting drugs have been considered as a potential preventive and therapeutic intervention for neurodegenerative diseases. There 
are three types of RAS-acting drugs: ARBs, ACEIs, and direct renin inhibitors (DRI), each of which act at different steps of the RAS process. While ARBs (e.g., losartan, valsartan, telmisartan, and candesartan) block binding of Ang II to the $\mathrm{AT}_{1} \mathrm{R}$, ACEIs (e.g., captopril, enalapril, lisinopril, and perindopril) block the hydrolysis of Ang I to Ang II. The blockade of $\mathrm{AT}_{1} \mathrm{R}$ results in increased Ang II levels and consequently increases stimulation of $\mathrm{AT}_{2} \mathrm{R}$. In contrast, ACEI causes lower Ang II levels and consequently reduces stimulation of both $\mathrm{AT}_{1} \mathrm{R}$ and $\mathrm{AT}_{2} \mathrm{R}$ (Düsing, 2016). It was hypothesized that ARBs have potential advantages over ACEIs in the prevention of cognitive impairment because of more specific concomitant blocking of harmful effects while possibly enhancing beneficial effects such as vasodilatation and endothelial modulation (Fournier et al., 2004; Anderson et al., 2011). DRIs directly inhibit generation of Ang I from angiotensinogen, acting upstream of both ARBs and ACEIs (Riccioni, 2013). RAS inhibitors can reduce $A \beta$ deposition and its consequences, and also suppress inflammation, oxidative stress, vascular damage/ischemia, and increase acetylcholine release and glutamate uptake (Gebre et al., 2018; Lebouvier et al., 2020). Especially, ARBs can prevent impairment of the BBB and reduce infiltration of inflammatory mediators observed in many neurodegenerative disease such as AD (Gebre et al., 2018). A summary of studies examining RAS-acting drugs in cognition and dementia is given in Table 1 .

\section{Angiotensin Receptor Blockers Studies Showing Positive Effects on Cognition and Neural Protection}

Early studies investigated cognitive effects of ARBs in animals. It was shown that pretreatment with losartan reduced chronic ethanol-induced cognitive deficits (Tracy et al., 1997) and improved both spatial and short-term working memory in animals (Raghavendra et al., 1998; Royea et al., 2020). It was shown that telmisartan has a long term anti-inflammatory effect by modulating microglia in vitro and in vivo (Torika et al., 2016). Chronic intranasal administration of losartan decreased plaque number in an $\mathrm{AD}$ mouse model (Danielyan et al., 2010) and also attenuated Ang II-induced cognitive impairment and tau phosphorylation (Tian et al., 2012). Candesartan was found to be more effective than perindopril in blunting the neuroinflammation in both astroglial and microglial cells of the rat brain (Bhat et al., 2016). An in vitro study screening 55 commonly prescribed antihypertensive drugs with respect to their anti- $\mathrm{A} \beta$ properties found that only valsartan and losartan are capable of both lowering $A \beta$ and decreasing oligomerization of $A \beta$ peptides in primary neuronal cultures, while candesartan was effective on oligomerization only (Wang et al., 2007; Zhao et al., 2009). Preventive treatment with valsartan significantly reduced brain $A \beta$ deposits and $A \beta$-mediated cognitive deterioration, independently of bloodpressure lowering in AD mice model (Wang et al., 2007). Interestingly, it was shown that olmesartan and losartan protect cognitive function and cerebrovascular activity independently from blood pressure changes through decreasing oxidative stress in brain microvessels without decreasing $A \beta$ levels
(Takeda et al., 2009; Ongali et al., 2014). Some ARBs especially telmisartan were found to be partial agonists of peroxisome proliferator-activated receptor- $\gamma$ (PPAR- $\gamma$ ) which is a target in $\mathrm{AD}$ with its anti-inflammatory, anti-amyloidogenic and insulinsensitizing effects. In this regard, it was hypothesized that beneficial effects of telmisartan are attributed not only to its $\mathrm{AT}_{1} \mathrm{R}$ antagonist properties but also to the activation of PPAR- $\gamma$ (Heneka et al., 2007; Torika et al., 2016; Lebouvier et al., 2020). In line with this, it was shown that diabetes-induced increases in BBB permeability was attenuated by telmisartan through PPAR- $\gamma$ activation to improve diabetes-induced cognitive decline (Min et al., 2012).

One of the earliest human studies was a double-blind randomized control trial which compares losartan and hydrochlorothiazide in 69 elderly patients. It was shown that losartan has a positive effect not only on blood pressure but also on impaired cognitive function, reversing even minimal cognitive deficits induced by hypertension (Tedesco et al., 1999). Similarly, losartan was found to improve memory in a comparative study between losartan and atenolol (Fogari et al., 2003). The Study on COgnition and Prognosis in the Elderly (SCOPE) is a double-blind and placebo-controlled study of candesartan conducted in 4937 mild-to-moderate hypertensive patients, aged between 70 and 89 years with a mean follow-up of 3.7 years. It was found that in patients with low cognitive function, decline of the mini-mental state exam score over time was less in the candesartan group (Skoog et al., 2005). Furthermore, candesartan was shown to be associated with less decline in attention and episodic memory during a follow up period of 44 months in a substudy of the SCOPE (Saxby et al., 2008). Consistent with the results of SCOPE trial, another study showed that trajectories of cognitive decline evaluated with periodic mini-mental state exam were less steep with antihypertensive administration, and interestingly, patients taking ARBs even had improved cognitive scores (Hajjar et al., 2005). On the other hand, ARBs were found to reduce the incidence and progression of $\mathrm{AD}$ and dementia when compared to ACEIs and other cardiovascular drugs in 819,491 predominantly male participants (98\%) aged 65 or older with cardiovascular disease (Li et al., 2010). A double-blind randomized controlled clinical trial called antihypertensives and vascular, endothelial, and cognitive function (AVEC) trial compared 1-year treatment of lisinopril, candesartan, or hydrochlorothiazide with regard to their effects on memory, executive function, $\mathrm{CBF}$, and central endothelial function. This study found that ARBs are associated with improvement in executive function in hypertensive older adults with early executive cognitive impairment (Hajjar et al., 2009, 2012). A secondary longitudinal data analysis of the Ginkgo Evaluation of Memory Study showed that diuretic, ARB, and ACEI uses were, in addition to and/or independently of mean systolic blood pressure, associated with reduced risk of $\mathrm{AD}$ in older adults with normal cognition $(n=1,928)$ while only diuretic use was associated with reduced risk in participants with MCI $(n=320)$ (Yasar et al., 2013). Furthermore, a meta-analysis of studies on $\mathrm{AD}$ and aging showed that $\mathrm{ARBs}$ have a protective role in the risk of cognitive impairment of aging and $\mathrm{AD}$, while both ACEIs and ARBs have benefits on prevention of 
TABLE 1 | Summary of research studies evaluating the effects of RAS-acting agents on cognition and dementia.

\begin{tabular}{|c|c|c|c|c|c|c|c|}
\hline Author/year & $\begin{array}{l}\text { Study } \\
\text { design }\end{array}$ & $\begin{array}{l}\text { Number of } \\
\text { patients }\end{array}$ & $\begin{array}{l}\text { Mean age } \\
\text { (years) }\end{array}$ & $\begin{array}{l}\text { Follow-up } \\
\text { (years) }\end{array}$ & Treatment & Disease & Results \\
\hline $\begin{array}{l}\text { Tzourio et al., } \\
2003\end{array}$ & $\begin{array}{l}\text { Double-blind } \\
\text { RCT }\end{array}$ & 6,105 & 64 & 3.9 & ACEI & Dementia & $\begin{array}{l}\text { Active treatment (perindopril with or without indapamide) was } \\
\text { associated with reduced risk of dementia (relative risk reduction, } 12 \% \\
\text { [95\% } \mathrm{Cl},-8 \% \text { to } 28 \% \text { ]; } P=0.2 \text { ). Cognitive decline was seen in } 9.1 \% \text { of } \\
\text { the actively treated group and } 11.0 \% \text { of the placebo group (risk } \\
\text { reduction, } 19 \% \text { [ } 95 \% \mathrm{Cl}, 4 \% \text { to } 32 \%] ; p=0.01 \text { ). }\end{array}$ \\
\hline $\begin{array}{l}\text { Ohrui et al., } \\
2004 a\end{array}$ & Cohort study & 4,124 & 69 & 8 & ACEI & $A D$ & $\begin{array}{l}\text { Central-acting captopril and perindopril were associated with a } \\
\text { significantly lower incidence of AD than the use of those that cannot } \\
\text { inhibit brain ACE (imidapril or enalapril) (odds ratio }=0.25,95 \% \\
\mathrm{Cl}=0.08-0.75 ; p=0.014 \text { ). }\end{array}$ \\
\hline $\begin{array}{l}\text { Ohrui et al., } \\
2004 b\end{array}$ & $\mathrm{RCT}$ & 162 & 76 & 1 & ACEI & $A D$ & $\begin{array}{l}\text { The mean 1-year decline in MMSE scores in the participants of } \\
\text { brain-penetrating ACEls (perindopril or captopril) was lower than those } \\
\text { in the participants of non-brain-penetrating ACEls (imidapril or enalapril) } \\
\text { and CCBs }(p<0.001) \text {. }\end{array}$ \\
\hline $\begin{array}{l}\text { Khachaturian } \\
\text { et al., } 2006\end{array}$ & Cohort study & 3,217 & 74.9 & 3 & ACEI & $A D$ & $\begin{array}{l}\text { In the analyses of } A D \text { risk among different types of antihypertensive } \\
\text { medications, ACEls (HR, 1.13; 95\% } \mathrm{Cl}, 0.60-1.98) \text { and } C C B s(H R \text {, } \\
0.86 ; 95 \% \mathrm{Cl}, 0.45-1.53) \text { showed no impact on AD risk. }\end{array}$ \\
\hline Li et al., 2010 & $\begin{array}{l}\text { Prospective } \\
\text { cohort } \\
\text { analysis }\end{array}$ & 819,491 & 74 & 4 & ARB/ACEl & $A D$ & $\begin{array}{l}\text { A significant reduction in the occurrence of AD was identified with ARBs } \\
\text { compared to lisinopril (HR 0.81, 95\% Cl 0.68-0.96, } P=0.016) \text {. }\end{array}$ \\
\hline $\begin{array}{l}\text { Yasar et al., } \\
2013\end{array}$ & $\begin{array}{l}\text { Post hoc } \\
\text { analysis of } \\
\text { RCT }\end{array}$ & 1,928 & 78.6 & 6.1 & ARB/ACEI & $A D$ & $\begin{array}{l}\text { HR for AD occurrence among participants with normal cognition was } \\
\text { found } 0.51 \text { in diuretic ( } 95 \% \mathrm{Cl} 0.31-0.82), 0.31 \text { in } \mathrm{ARB}(95 \% \mathrm{Cl} \\
0.14-0.68), 0.50 \text { in } \mathrm{ACEl}(95 \% \mathrm{Cl} 0.29-0.83), 0.62 \text { in } \mathrm{CCB}(95 \% \mathrm{Cl} \\
0.35-1.09) \text {, and } 0.58 \text { in } \mathrm{BB}(95 \% \mathrm{Cl} 0.36-0.93) \text { users. }\end{array}$ \\
\hline $\begin{array}{l}\text { Barthold } \\
\text { et al., } 2020\end{array}$ & $\begin{array}{l}\text { Retrospective } \\
\text { cohort study }\end{array}$ & 694,672 & 77.3 & 7 & ARB/ACEl & $A D$ & $\begin{array}{l}\text { The annual AD and related dementias incidence rate was found } 2.07 \% \\
\text { among persons using a RAS-acting antihypertensive and any statin, } \\
\text { and } 2.64 \% \text { among persons using a non-RAS-acting antihypertensive } \\
\text { and any statin. ACEI + pravastatin OR }=0.942(\mathrm{Cl}: 0.899-0.986 \\
p=0.011), A C E I+\text { rosuvastatin } O R=0.841(\mathrm{Cl}: 0.794-0.892 \\
p<0.001), A R B+\text { pravastatin } \mathrm{OR}=0.794(\mathrm{Cl}: 0.748-0.843 \\
p<0.001), A R B+\text { rosuvastatin } \mathrm{OR}=0.818(\mathrm{Cl}: 0.765-0.874 \\
p<0.001)\end{array}$ \\
\hline
\end{tabular}

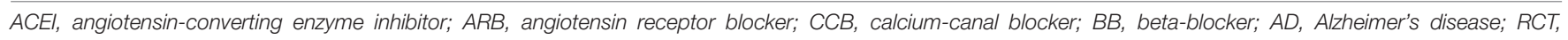
randomized controlled trial; HR, hazard ratio; Cl, confidence interval; OR, odds ratio.

$\mathrm{AD}$ (Zhuang et al., 2016). A more recent retrospective cohort study found that ARBs combined with statins reduced AD more than statins combined with non-RAS-acting antihypertensives (Barthold et al., 2020). Consistent with previous studies, ARBs were found to be more effective than ACEIs in reducing dementia risk. Similarly, a meta-analysis of 2 case-control studies and 7 cohort studies showed that ARB use was associated with a reduced risk of incident AD (Oscanoa et al., 2020). There are also ongoing studies which aim to further elucidate the role of ARBs on AD (Kehoe et al., 2018; Hajjar, 2020).

\section{Studies Showing Neutral or Negative Effects on Cognition and Neural Protection}

In contrast to many promising results of ARBs, there are also conflicting animal and human studies that did not demonstrate any beneficial effects of RAS-acting drugs. For example, some animal studies showed that losartan alone did not cause any changes in learning and memory (Kułakowska et al., 1996) whereas valsartan abolished the intracerebroventricular Ang II-induced improvement of memory retrieval and consolidation in animals (Braszko, 2005). Similar dissociation results were obtained in human studies as well. The SCOPE trial mentioned in the previous section did not show any difference between candesartan and placebo groups with regard to incidence of dementia (Lithell et al., 2003). The Ongoing Telmisartan Alone and in Combination with Ramipril Global Endpoint Trial (ONTARGET), a double-blind randomized controlled trial conducted on 25,620 participants, and the parallel Telmisartan Randomized Assessment Study in ACE Intolerant Subjects with Cardiovascular Disease (TRANSCEND) trial in 5,926 participants did not show any significant effect of ARBs on cognitive outcomes (Anderson et al., 2011). A quantitative meta-analysis of longitudinal studies was conducted to compare subjects with $(n=32,658)$ and without $(n=36,905)$ antihypertensive medication use (Chang-Quan et al., 2011). The study found that the risk of AD is unchanged even though risk of vascular dementia decreased with antihypertensive medication use.

\section{Angiotensin Converting Enzyme Inhibitors Studies Showing Positive Effects on Cognition and Neural Protection}

The ACEIs can improve basal learning performance, and antagonize scopolamine-induced learning deficits in animals (Barnes et al., 1992). Different cognitive effects of ACEIs in animal models were studied over the years. In the setting 
of diabetic rats with learning impairment, enalapril treatment improved water maze performance and hippocampal LTP (Manschot et al., 2003). Cilazapril improved memory in aged rats when administered at low doses without antihypertensive effects (Hirawa et al., 1999). Bhat et al. (2016) showed the antiinflammatory effects of perindopril in rodent glial cells. Captopril slowed the accumulation of $A \beta$ plaques and hippocampal ROS in a mouse model of AD (AbdAlla et al., 2013). Intranasal captopril treatment regulated microglial activation and decreased $\mathrm{A} \beta$ burden in an AD mouse model (Asraf et al., 2018). Although ACEIs have effects on varied brain functions, their activities within the brain were found to be different: enalapril and ramipril produced no significant inhibition of ACE at any time while captopril and zofenopril had modest, short-lasting effects, and lisinopril had long-lasting inhibitory effects (Cushman et al., 1989). In this regard, ACEIs are classified as central-acting and non-central-acting. Central-acting ACEIs are perindopril, captopril, fosinopril, lisinopril, trandolapril, and zofenopril, while benazepril, enalapril, moexepril, quinapril, and ramipril are noncentral-acting (Sink et al., 2009).

There are also many human studies showing positive effects of ACEI use. A review by Amenta et al. (2002) suggested that calcium channel blockers and ACEIs had positive effects on cognitive domains of hypertension compared to diuretics and beta-blockers. The Perindopril Protection Against Recurrent Stroke Study (PROGRESS), a randomized, doubleblind, placebo-controlled trial, showed reduced risk of dementia and cognitive decline with perindopril and indapamide in patients with history of prior stroke or transient ischemic attack (Tzourio et al., 2003). Furthermore, among patients with vascular disease or diabetes plus an additional risk factor in the Heart Outcomes Prevention Evaluation (HOPE) study, ramipril reduced the incidence of stroke and was associated with lower prevalence of cognitive impairment (Bosch et al., 2002). In a study evaluating effects of different antihypertensives drug classes in elderly patients with a blood pressure of less than $150 / 90 \mathrm{mmHg}$, it was shown that central-acting ACEIs were associated with a significantly lower incidence of AD compared to non-centralacting ACEIs, calcium channel blockers, beta-blockers, and diuretics (Ohrui et al., 2004a). Ohrui et al. (2004b) designed a randomized study to investigate the use of ACEIs as a possible treatment for mild-to-moderate $\mathrm{AD}$, in addition to cholinesterase inhibitor. In this study, mini-mental state examination score decline was significantly reduced in $\mathrm{AD}$ patients treated with central-acting ACEI compared to other drug classes (Ohrui et al., 2004b). Consistent with these results, the prescription of ACEIs was found to be independently associated with the stability of cognitive function after 1-year follow-up of mild cognitive impairment patients (Rozzini et al., 2006).

These findings were further expanded by a substudy of the Cardiovascular Health Study showing that centralacting ACEIs are associated with lower risk of cognitive decline while non-central acting ACEIs were associated with a greater risk of incident dementia (Sink et al., 2009). As an explanation, it was hypothesized that central-acting ACEIs act via mechanisms other than blood pressure control (Sink et al., 2009). Additionally, centrally active ACEIs were associated with a reduced rate of cognitive decline in dementia patients and improved cognitive scores in the first 6 months after treatment (Gao et al., 2013). Interestingly, a recent pharmacogenetic study suggested that ACEIs can slow cognitive decline independently of blood pressure variations in patients with AD, particularly for APOE4-carriers of specific ACE genotypes (de Oliveira et al., 2018).

\section{Studies Showing Neutral or Negative Effects on Cognition and Neural Protection}

As with ARBs, there are studies reporting conflicting results with respect to effects of ACEIs on cognition. In one of the earliest studies, no cognitive and CBF changes were seen in patients treated with ceranapril for 4 weeks (Weiner et al., 1992). The Hypertension Old People in Edinburgh (HOPE) study evaluated cognitive function after treatment with ACEI (captopril) or diuretic (bendrofluazide) and found no difference in cognitive function after 24 weeks (Starr et al., 1996). Similar results were seen after 18 weeks of perindopril treatment (Louis et al., 1999). Although the double-blind placebo-controlled Systolic Hypertension in Europe (Syst-Eur) trial showed that antihypertensive treatment was associated with a lower incidence of dementia in elderly people (Forette et al., 1998), its followup study showed that calcium channel blocker therapy was effective protection against dementia in older patients regardless of enalapril use (Forette et al., 2002). Consistent with previous studies, the Cache County Study showed that ACEIs have no specific effects on $\mathrm{AD}$ risk apart from the general positive effects of antihypertensive medications on incidence of $\mathrm{AD}$ (Khachaturian et al., 2006). In the Rotterdam study, subjects $(n=2015)$ taking antihypertensive medication at baseline had a reduced incidence of dementia that was significant for vascular dementia and not significant for AD (in't Veld et al., 2001). However, follow-up study of it showed that antihypertensive use reduced risks of all dementia including $\mathrm{AD}$, with duration of hypertensive use being an important determinant (Haag et al., 2009). The same study did not find any apparent differences among different types of antihypertensive drugs (Haag et al., 2009). Finally, an observational study showed that ACEIs increase the risk of mortality in $\mathrm{AD}$ patients (Kehoe et al., 2013). However, this finding was not replicated in other cohorts (Lebouvier et al., 2020).

\section{Renin Inhibitors}

Another potential modulator of the RAS-system is the class of drugs that directly inhibit renin. Aliskiren, a renin inhibitor, blocks the catalytic effects of renin, which is the first and ratelimiting step of the RAS. Besides its anti-hypertensive effects, it also promotes neuroprotection, improving functional outcomes in a model of ischemic stroke (Panahpour et al., 2019). Aliskiren pretreatment attenuated oxidative stress, glial activation, white matter lesion, and spatial working memory deficits by inhibiting brain renin (Dong et al., 2011). Additionally, aliskiren was shown to counteract pathophysiological mechanisms of $\mathrm{AD}$ in animal models. In particular, suppressed $A \beta$ neurotoxicity and attenuated $\mathrm{A} \beta$-induced intra-neuronal renin expression in rat cortical neurons (Chen et al., 2012). Furthermore, aliskiren 
also improved scopolamine-induced amnesia and increased acetylcholine through a decrease in acetylcholinesterase activity (Anil Kumar et al., 2015). However, a double-blind placebocontrolled trial showed that the incidence rate of dementia did not change in people over 80 years old who were treated with aliskiren for high blood pressure (Peters et al., 2008). Aliskiren is a promising agent for prevention or treatment of dementia (O'Caoimh et al., 2014). However, more clinical trials with longer follow-up periods are needed to investigate effects of DRIs on cognition comprehensively.

\section{CONCLUSION}

Alzheimer's disease and frailty are interrelating age-related disorders with a high level of morbidity and mortality. Although epidemiological and observational studies have shown close associations of frailty with $\mathrm{AD}$, the biological mechanisms responsible for linking these two conditions remain elusive. Mitochondrial dysfunction, chronic inflammation, and oxidative stress constitute primary theories of aging and have been implicated as major contributors to the pathogenesis of both frailty and $\mathrm{AD}$. The renin-angiotensin system is a central hormonal system that contributes to both inflammation

\section{REFERENCES}

Abadir, P. M. (2011). The frail renin-angiotensin system. Clin. Geriatr. Med. 27, 53-65. doi: 10.1016/j.cger.2010.08.004

Abadir, P. M., Carey, R. M., and Siragy, H. M. (2003). Angiotensin AT2 receptors directly stimulate renal nitric oxide in bradykinin B2-receptor-null mice. Hypertension 42, 600-604. doi: 10.1161/01.HYP.0000090323.58122.5C

Abadir, P. M., Foster, D. B., Crow, M., Cooke, C. A., Rucker, J. J., Jain, A., et al. (2011). Identification and characterization of a functional mitochondrial angiotensin system. Proc. Natl. Acad. Sci. U.S.A. 108, 14849-14854. doi: 10. 1073/pnas. 1101507108

Abadir, P. M., Jain, A., Powell, L. J., Xue, Q.-L., Tian, J., Hamilton, R. G., et al. (2017). Discovery and validation of agonistic angiotensin receptor autoantibodies as biomarkers of adverse outcomes. Circulation 135, 449-459. doi: 10.1161/CIRCULATIONAHA.116.022385

Abadir, P. M., Walston, J. D., and Carey, R. M. (2012). Subcellular characteristics of functional intracellular renin-angiotensin systems. Peptides 38, 437-445. doi: 10.1016/j.peptides.2012.09.016

AbdAlla, S., Langer, A., Fu, X., and Quitterer, U. (2013). ACE inhibition with captopril retards the development of signs of neurodegeneration in an animal model of Alzheimer's disease. Int. J. Mol. Sci. 14, 16917-16942. doi: 10.3390/ ijms140816917

AbdAlla, S., Lother, H., Abdel-tawab, A. M., and Quitterer, U. (2001). The angiotensin II AT2 receptor is an AT1 receptor antagonist. J. Biol. Chem. 276, 39721-39726. doi: 10.1074/jbc.M105253200

AbdAlla, S., Lother, H., el Missiry, A., Langer, A., Sergeev, P., el Faramawy, Y., et al. (2009). Angiotensin II AT2 receptor oligomers mediate G-protein dysfunction in an animal model of Alzheimer disease. J. Biol. Chem. 284, 6554-6565. doi: 10.1074/jbc.M807746200

Abner, E. L., Nelson, P. T., Kryscio, R. J., Schmitt, F. A., Fardo, D. W., Woltjer, R. L., et al. (2016). Diabetes is associated with cerebrovascular but not Alzheimer's disease neuropathology. Alzheimers Dement. 12, 882-889. doi: 10.1016/j.jalz. 2015.12.006

Abrahão, M. V., dos Santos, N. F. T., Kuwabara, W. M. T., do Amaral, F. G., do Carmo Buonfiglio, D., Peres, R., et al. (2019). Identification of insulin-regulated aminopeptidase (IRAP) in the rat pineal gland and the modulation of melatonin synthesis by angiotensin IV. Brain Res. 1704, 40-46. doi: 10.1016/j.brainres. 2018.09.015 and mitochondrial dysfunction. Many important studies have emerged that suggest that angiotensin system blocking drugs, commonly used in clinical practice for hypertension and heart failure, can favorably impact many chronic disease states, tissues and organ systems that are negatively impacted by age and inflammation. The choice of RAS-blocking drug and deciding on the onset of treatment remain uncharted territory.

\section{AUTHOR CONTRIBUTIONS}

All authors listed have made a substantial, direct and intellectual contribution to the work, and approved it for publication.

\section{FUNDING}

This study was supported by the Johns Hopkins Older Americans Independence Center National Institute on Aging (grants P30 AG021334), and NIH Grants R01AG046441 and R01AG17917, and the Bright Focus Foundation Research Award (PMA) and the Nathan W. and Margaret T. Shock Aging Research Foundation. Nathan Shock Scholar in Aging.

Ahmed, H. A., Ishrat, T., Pillai, B., Bunting, K. M., Patel, A., Vazdarjanova, A., et al. (2018). Role of angiotensin system modulation on progression of cognitive impairment and brain MRI changes in aged hypertensive animalsa randomized double- blind pre-clinical study. Behav. Brain Res. 346, 29-40. doi: 10.1016/j.bbr.2017.12.007

Ahmed, H. A., Ishrat, T., Pillai, B., Bunting, K. M., Vazdarjanova, A., Waller, J. L., et al. (2019). Angiotensin receptor (AT2R) agonist C21 prevents cognitive decline after permanent stroke in aged animals-A randomized double- blind pre-clinical study. Behav. Brain Res. 359, 560-569. doi: 10.1016/j.bbr.2018.10.010

Akimoto, M., Baba, A., Ikeda-Matsuo, Y., Yamada, M. K., Itamura, R., Nishiyama, N., et al. (2004). Hepatocyte growth factor as an enhancer of nmda currents and synaptic plasticity in the hippocampus. Neuroscience 128, 155-162. doi: 10.1016/j.neuroscience.2004.06.031

Albiston, A. L., Diwakarla, S., Fernando, R. N., Mountford, S. J., Yeatman, H. R., Morgan, B., et al. (2011). Identification and development of specific inhibitors for insulin-regulated aminopeptidase as a new class of cognitive enhancers. $\mathrm{Br}$. J. Pharmacol. 164, 37-47. doi: 10.1111/j.1476-5381.2011.01402.x

Albiston, A. L., McDowall, S. G., Matsacos, D., Sim, P., Clune, E., Mustafa, T., et al. (2001). Evidence that the angiotensin IV (AT(4)) receptor is the enzyme insulinregulated aminopeptidase. J. Biol. Chem. 276, 48623-48626. doi: 10.1074/jbc. C100512200

Albiston, A. L., Mustafa, T., McDowall, S. G., Mendelsohn, F. A. O., Lee, J., and Chai, S. Y. (2003). AT4 receptor is insulin-regulated membrane aminopeptidase: potential mechanisms of memory enhancement. Trends Endocrinol. Metab. 14, 72-77. doi: 10.1016/s1043-2760(02)0 0037-1

Alhusban, A., Fouda, A. Y., Pillai, B., Ishrat, T., Soliman, S., and Fagan, S. C. (2015). Compound 21 is pro-angiogenic in the brain and results in sustained recovery after ischemic stroke. J. Hypertens. 33, 170-180. doi: 10.1097/HJH. 0000000000000364

Alhusban, A., Kozak, A., Ergul, A., and Fagan, S. C. (2013). AT1 receptor antagonism is proangiogenic in the brain: BDNF a novel mediator. J. Pharmacol. Exp. Ther. 344, 348-359. doi: 10.1124/jpet.112.197483

Allen, A. M., MacGregor, D. P., Chai, S. Y., Donnan, G. A., Kaczmarczyk, S., Richardson, K., et al. (1992). Angiotensin II receptor binding associated with nigrostriatal dopaminergic neurons in human basal ganglia. Ann. Neurol. 32, 339-344. doi: 10.1002/ana.410320306 
Almad, A., and Maragakis, N. J. (2018). A stocked toolbox for understanding the role of astrocytes in disease. Nat. Rev. Neurol. 14, 351-362. doi: 10.1038/s41582018-0010-2

Almeida-Santos, A. F., Kangussu, L. M., and Campagnole-Santos, M. J. (2017). The renin-angiotensin system and the neurodegenerative diseases: a brief review. Protein Peptide Lett. 24, 841-853.

Amenta, F., Mignini, F., Rabbia, F., Tomassoni, D., and Veglio, F. (2002). Protective effect of anti-hypertensive treatment on cognitive function in essential hypertension: analysis of published clinical data. J. Neurol. Sci. 20, 147-151. doi: 10.1016/s0022-510x(02)00281-2

Anderson, C., Teo, K., Gao, P., Arima, H., Dans, A., Unger, T., et al. (2011). Renin-angiotensin system blockade and cognitive function in patients at high risk of cardiovascular disease: analysis of data from the ONTARGET and TRANSCEND studies. Lancet Neurol. 10, 43-53. doi: 10.1016/S1474-4422(10) 70250-7

Anil Kumar, K. V., Nagwar, S., Thyloor, R., and Satyanarayana, S. (2015). Antistress and nootropic activity of drugs affecting the renin-angiotensin system in rats based on indirect biochemical evidence. J. Renin Angiotensin Aldosterone Syst. 16, 801-812. doi: 10.1177/1470320313516173

Aronis, K. N., and Mantzoros, C. S. (2012). A brief history of insulin resistance: from the first insulin radioimmunoassay to selectively targeting protein kinase C pathways. Metab. Clin. Exp. 61, 445-449. doi: 10.1016/j.metabol.2012. 01.001

Arroja, M. M. C., Reid, E., and McCabe, C. (2016). Therapeutic potential of the renin angiotensin system in ischaemic stroke. Exp. Transl. Stroke Med. 8:8. doi: 10.1186/s13231-016-0022-1

Arvanitakis, Z., Capuano, A. W., Lamar, M., Shah, R. C., Barnes, L. L., Bennett, D. A., et al. (2018). Late-life blood pressure association with cerebrovascular and Alzheimer disease pathology. Neurology 91, e517-e525. doi: 10.1212/WNL. 0000000000005951

Arvanitakis, Z., Capuano, A. W., Leurgans, S. E., Bennett, D. A., and Schneider, J. A. (2016). Relation of cerebral vessel disease to Alzheimer's disease dementia and cognitive function in elderly people: a cross-sectional study. Lancet Neurol. 15, 934-943. doi: 10.1016/S1474-4422(16)30029-1

Arvanitakis, Z., Wang, H.-Y., Capuano, A. W., Khan, A., Taïb, B., Anokye-Danso, F., et al. (2020). Brain insulin signaling, Alzheimer's disease pathology, and cognitive function. Ann. Neurol. 88, 513-525. doi: 10.1002/ana.25826

Asraf, K., Torika, N., Apte, R. N., and Fleisher-Berkovich, S. (2018). Microglial activation is modulated by captopril: in vitro and in vivo studies. Front. Cell Neurosci. 12:116. doi: 10.3389/fncel.2018.00116

Babior, B. M. (2004). NADPH oxidase. Curr. Opin. Immunol. 16, 42-47. doi: 10.1016/j.coi.2003.12.001

Barnes, J., Barnes, N., Costall, B., Coughlan, J., Kelly, M., Naylor, R., et al. (1992). Angiotensin-converting enzyme inhibition, angiotensin, and cognition. J. Cardiovasc. Pharmacol. 19(Suppl. 6), S63-S71.

Barnham, K. J., Masters, C. L., and Bush, A. I. (2004). Neurodegenerative diseases and oxidative stress. Nat. Rev. Drug Discov. 3, 205-214. doi: 10.1038/nrd1330

Barthold, D., Joyce, G., Brinton, R. D., Wharton, W., Kehoe, P. G., and Zissimopoulos, J. (2020). Association of combination statin and antihypertensive therapy with reduced Alzheimer's disease and related dementia risk. PLoS One 15:e0229541. doi: 10.1371/journal.pone.0229541

Bartus, R. T., Dean, R. L., Beer, B., and Lippa, A. S. (1982). The cholinergic hypothesis of geriatric memory dysfunction. Science 217, 408-414. doi: 10.1126/ science.7046051

Bear, M. F., Connors, B. W., and Paradiso, M. A. (2016). Neuroscience: Exploring the Brain, 4th Edn. Philadelphia, PA: Wolters Kluwer.

Bechara, R. I., Pelaez, A., Palacio, A., Joshi, P. C., Hart, C. M., Brown, L. A. S., et al. (2005). Angiotensin II mediates glutathione depletion, transforming growth factor-betal expression, and epithelial barrier dysfunction in the alcoholic rat lung. Am. J. Physiol. Lung Cell Mol. Physiol. 289, L363-L370. doi: 10.1152/ ajplung.00141.2005

Bedecs, K., Elbaz, N., Sutren, M., Masson, M., Susini, C., Strosberg, A. D., et al. (1997). Angiotensin II type 2 receptors mediate inhibition of mitogen-activated protein kinase cascade and functional activation of SHP-1 tyrosine phosphatase. Biochem. J. 325, 449-454. doi: 10.1042/bj3250449

Benicky, J., Sánchez-Lemus, E., Pavel, J., and Saavedra, J. M. (2009). Antiinflammatory effects of angiotensin receptor blockers in the brain and the periphery. Cell Mol. Neurobiol. 29, 781-792. doi: 10.1007/s10571-009-9368-4
Benigni, A., Corna, D., Zoja, C., Sonzogni, A., Latini, R., Salio, M., et al. (2009). Disruption of the Ang II type 1 receptor promotes longevity in mice. J. Clin. Invest. 119, 524-530. doi: 10.1172/JCI36703

Benigni, A., Orisio, S., Noris, M., Iatropoulos, P., Castaldi, D., Kamide, K., et al. (2013). Variations of the angiotensin II type 1 receptor gene are associated with extreme human longevity. AGE 35, 993-1005. doi: 10.1007/s11357-0129408-8

Bennett, D. A., Schneider, J. A., Buchman, A. S., Barnes, L. L., Boyle, P. A., and Wilson, R. S. (2012). Overview and findings from the rush memory and aging project. Curr. Alzheimer Res. 9, 646-663. doi: 10.2174/156720512801322663

Bernstein, K. E., Koronyo, Y., Salumbides, B. C., Sheyn, J., Pelissier, L., Lopes, D. H. J., et al. (2014). Angiotensin-converting enzyme overexpression in myelomonocytes prevents Alzheimer's-like cognitive decline. J. Clin. Invest. 124, 1000-1012. doi: 10.1172/JCI66541

Bhat, S. A., Goel, R., Shukla, R., and Hanif, K. (2016). Angiotensin receptor blockade modulates NFKB and STAT3 signaling and inhibits glial activation and neuroinflammation better than angiotensin-converting enzyme inhibition. Mol. Neurobiol. 53, 6950-6967. doi: 10.1007/s12035-015-9584-5

Bhat, S. A., Goel, R., Shukla, S., Shukla, R., and Hanif, K. (2018). Angiotensin receptor blockade by inhibiting glial activation promotes hippocampal neurogenesis via activation of $\mathrm{Wnt} / \beta$-Catenin signaling in hypertension. Mol. Neurobiol. 55, 5282-5298. doi: 10.1007/s12035-017-0754-5

Biancardi, V. C., and Stern, J. E. (2016). Compromised blood-brain barrier permeability: novel mechanism by which circulating angiotensin II signals to sympathoexcitatory centres during hypertension. J. Physiol. 594, 1591-1600. doi: 10.1113/JP271584

Biancardi, V. C., Stranahan, A. M., Krause, E. G., de Kloet, A. D., and Stern, J. E. (2015). Cross talk between AT1 receptors and Toll-like receptor 4 in microglia contributes to angiotensin II-derived ROS production in the hypothalamic paraventricular nucleus. Am. J. Physiol. Heart Circ. Physiol. 310, H404-H415. doi: 10.1152/ajpheart.00247.2015

Bielsky, I. F., Hu, S.-B., Ren, X., Terwilliger, E. F., and Young, L. J. (2005). The V1a vasopressin receptor is necessary and sufficient for normal social recognition: a gene replacement study. Neuron 47, 503-513. doi: 10.1016/j.neuron.2005. 06.031

Blázquez, E., Velázquez, E., Hurtado-Carneiro, V., and Ruiz-Albusac, J. M. (2014). Insulin in the brain: its pathophysiological implications for states related with central insulin resistance, type 2 diabetes and Alzheimer's disease. Front. Endocrinol. 5:161. doi: 10.3389/fendo.2014.00161

Bodiga, V. L., and Bodiga, S. (2013). Renin angiotensin system in cognitive function and dementia. Asian J. Neurosci. 2013:102602. doi: 10.1155/2013/1 02602

Borrajo, A., Rodriguez-Perez, A. I., Diaz-Ruiz, C., Guerra, M. J., and LabandeiraGarcia, J. L. (2014). Microglial TNF- $\alpha$ mediates enhancement of dopaminergic degeneration by brain angiotensin. Glia 62, 145-157. doi: 10.1002/glia.22595

Bosch, J., Yusuf, S., Pogue, J., Sleight, P., Lonn, E., Rangoonwala, B., et al. (2002). Use of ramipril in preventing stroke: double blind randomised trial. $B M J$ 324:699. doi: 10.1136/bmj.324.7339.699

Boyle, P. A., Buchman, A. S., Wilson, R. S., Leurgans, S. E., and Bennett, D. A. (2010). Physical frailty is associated with incident mild cognitive impairment in community-based older persons. J. Am. Geriatr. Soc. 58, 248-255. doi: 10.1111/ j.1532-5415.2009.02671.x

Boyle, P. A., Wilson, R. S., Yu, L., Barr, A. M., Honer, W. G., Schneider, J. A., et al. (2013). Much of late life cognitive decline is not due to common neurodegenerative pathologies. Ann. Neurol. 74, 478-489. doi: 10.1002/ana. 23964

Boyle, P. A., Yang, J., Yu, L., Leurgans, S. E., Capuano, A. W., Schneider, J. A., et al. (2017). Varied effects of age-related neuropathologies on the trajectory of late life cognitive decline. Brain 140, 804-812. doi: 10.1093/brain/aww341

Boyle, P. A., Yu, L., Leurgans, S. E., Wilson, R. S., Brookmeyer, R., Schneider, J. A., et al. (2019). Attributable risk of Alzheimer's dementia attributed to age-related neuropathologies. Ann. Neurol. 85, 114-124. doi: 10.1002/ana. 25380

Boyle, P. A., Yu, L., Wilson, R. S., Leurgans, S. E., Schneider, J. A., and Bennett, D. A. (2018). Person-specific contribution of neuropathologies to cognitive loss in old age. Ann. Neurol. 83, 74-83. doi: 10.1002/ana.25123

Braak, H., and Braak, E. (1991). Neuropathological stageing of Alzheimer-related changes. Acta Neuropathol. 82, 239-259. doi: 10.1007/bf00308809 
Braszko, J. J. (2005). Valsartan abolishes most of the memory-improving effects of intracerebroventricular angiotensin II in rats. Clin. Exp. Hypertens. 27, 635-649. doi: $10.1080 / 10641960500298723$

Braszko, J. J. (2006). D2 dopamine receptor blockade prevents cognitive effects of Ang IV and des-Phe6 Ang IV. Physiol. Behav. 88, 152-159. doi: 10.1016/j. physbeh.2006.03.025

Braszko, J. J. (2009). Dopamine D4 receptor antagonist L745,870 abolishes cognitive effects of intracerebroventricular angiotensin IV and des-Phe(6)-Ang IV in rats. Eur. Neuropsychopharmacol. 19, 85-91. doi: 10.1016/j.euroneuro. 2008.08.011

Braun-Menendez, E., Fasciolo, J. C., Leloir, L. F., and Muñoz, J. M. (1940). The substance causing renal hypertension. J. Physiol. (Lond.) 98, 283-298. doi: 10. 1113/jphysiol.1940.sp003850

Brown, D. C., Steward, L. J., Ge, J., and Barnes, N. M. (1996). Ability of angiotensin II to modulate striatal dopamine release via the AT1 receptor in vitro and in vivo. Br. J. Pharmacol. 118, 414-420. doi: 10.1111/j.1476-5381.1996.tb 15418.x

Buchman, A. S., Yu, L., Wilson, R. S., Boyle, P. A., Schneider, J. A., and Bennett, D. A. (2014). Brain pathology contributes to simultaneous change in physical frailty and cognition in old age. J. Gerontol. A Biol. Sci. Med. Sci. 69, 1536-1544. doi: 10.1093/gerona/glu117

Cai, H. (2005). NAD(P)H Oxidase-dependent self-propagation of hydrogen peroxide and vascular disease. Circ. Res. 96, 818-822. doi: 10.1161/01.RES. 0000163631.07205.fb

Capone, C., Faraco, G., Park, L., Cao, X., Davisson, R. L., and Iadecola, C. (2011). The cerebrovascular dysfunction induced by slow pressor doses of angiotensin II precedes the development of hypertension. Am. J. Physiol. Heart Circ. Physiol. 300, H397-H407. doi: 10.1152/ajpheart.00679. 2010

Carey, R. M., Howell Nancy, L., Jin, X.-H., and Siragy Helmy, M. (2001). Angiotensin Type 2 receptor-mediated hypotension in angiotensin Type1 receptor-blocked rats. Hypertension 38, 1272-1277. doi: 10.1161/hy1201. 096576

Carey, R. M., and Siragy, H. M. (2003). Newly recognized components of the renin-angiotensin system: potential roles in cardiovascular and renal regulation. Endocr. Rev. 24, 261-271. doi: 10.1210/er.2003-0001

Carson, J. A., and Turner, A. J. (2002). Beta-amyloid catabolism: roles for neprilysin (NEP) and other metallopeptidases? J. Neurochem. 81, 1-8. doi: 10.1046/j.14714159.2002.00855.x

Celsi, F., Ferri, A., Casciati, A., D'Ambrosi, N., Rotilio, G., Costa, A., et al. (2004). Overexpression of superoxide dismutase 1 protects against beta-amyloid peptide toxicity: effect of estrogen and copper chelators. Neurochem. Int. 44, 25-33. doi: 10.1016/s0197-0186(03)0 0101-3

Chai, S. Y., Bastias, M. A., Clune, E. F., Matsacos, D. J., Mustafa, T., Lee, J. H., et al. (2000). Distribution of angiotensin IV binding sites (AT4 receptor) in the human forebrain, midbrain and pons as visualised by in vitro receptor autoradiography. J. Chem. Neuroanat. 20, 339-348. doi: 10.1016/ s0891-0618(00)00112-5

Chai, S. Y., Fernando, R., Peck, G., Ye, S.-Y., Mendelsohn, F. A. O., Jenkins, T. A., et al. (2004). What?s new in the renin-angiotensin system? The angiotensin IV/AT4 receptor. CMLS Cell. Mol. Life Sci. 61, 2728-2737. doi: 10.1007/s00018004-4246-1

Chan, S. H. H., Hsu, K.-S., Huang, C.-C., Wang, L.-L., Ou, C.-C., and Chan Julie, Y. H. (2005). NADPH oxidase-derived superoxide anion mediates angiotensin II-induced pressor effect via activation of p38 mitogen-activated protein kinase in the rostral ventrolateral medulla. Circ. Res. 97, 772-780. doi: 10.1161/01.RES. 0000185804.79157.C0

Chan, S.-L., and Baumbach, G. L. (2013). Deficiency of Nox2 prevents angiotensin II-induced inward remodeling in cerebral arterioles. Front. Physiol 4:133. doi: $10.3389 /$ fphys.2013.00133

Chandel, N. S. (2014). Mitochondria as signaling organelles. BMC Biol. 12:34. doi: 10.1186/1741-7007-12-34

Chandel, N. S., McClintock, D. S., Feliciano, C. E., Wood, T. M., Melendez, J. A., Rodriguez, A. M., et al. (2000). Reactive oxygen species generated at mitochondrial complex III stabilize hypoxia-inducible factor-1alpha during hypoxia: a mechanism of $\mathrm{O} 2$ sensing. J. Biol. Chem. 275, 25130-25138. doi: 10.1074/jbc.M001914200
Chang-Quan, H., Hui, W., Chao-min, W., Zheng-Rong, W., Jun-Wen, G., YongHong, L., et al. (2011). The association of antihypertensive medication use with risk of cognitive decline and dementia: a meta-analysis of longitudinal studies. Int. J. Clin. Pract. 65, 1295-1305. doi: 10.1111/j.1742-1241.2011.0 2810.x

Chen, H., Yoshioka, H., Kim, G. S., Jung, J. E., Okami, N., Sakata, H., et al. (2011). Oxidative stress in ischemic brain damage: mechanisms of cell death and potential molecular targets for neuroprotection. Antioxid. Redox Signal. 14, 1505-1517. doi: 10.1089/ars.2010.3576

Chen, P., Guo, A. M., Edwards, P. A., Trick, G., and Scicli, A. G. (2007). Role of NADPH oxidase and ANG II in diabetes-induced retinal leukostasis. Am. J. Physiol. Regul. Integr. Comp. Physiol. 293, R1619-R1629. doi: 10.1152/ajpregu. 00290.2007

Chen, S.-D., Wu, C.-L., Lin, T.-K., Chuang, Y.-C., and Yang, D.-I. (2012). Renin inhibitor aliskiren exerts neuroprotection against amyloid beta-peptide toxicity in rat cortical neurons. Neurochem. Int. 61, 369-377. doi: 10.1016/j.neuint.2012. 05.012

Choi, S.-H., Aid, S., Kim, H.-W., Jackson, S. H., and Bosetti, F. (2012). Inhibition of NADPH oxidase promotes alternative and anti-inflammatory microglial activation during neuroinflammation. J. Neurochem. 120, 292-301. doi: 10 1111/j.1471-4159.2011.07572.x

Chrissobolis, S., Banfi, B., Sobey, C. G., and Faraci, F. M. (2012). Role of Nox isoforms in angiotensin II-induced oxidative stress and endothelial dysfunction in brain. J. Appl. Physiol. (1985) 113, 184-191. doi: 10.1152/japplphysiol.00455. 2012

Collier, T. J., Lipton, J., Daley, B. F., Palfi, S., Chu, Y., Sortwell, C., et al. (2007). Aging-related changes in the nigrostriatal dopamine system and the response to MPTP in nonhuman primates: diminished compensatory mechanisms as a prelude to parkinsonism. Neurobiol. Dis. 26, 56-65. doi: 10.1016/j.nbd.2006.11. 013

Conti, S., Cassis, P., and Benigni, A. (2012). Aging and the renin-angiotensin system. Hypertension 60, 878-883. doi: 10.1161/HYPERTENSIONAHA.110. 155895

Cooper, H. A., Scalia, R., Rizzo, V., and Eguchi, S. (2018). Angiotensin II- and Alzheimer-type cardiovascular aging. Circ. Res. 123, 651-653. doi: 10.1161/ CIRCRESAHA.118.313477

Costa-Besada, M. A., Valenzuela, R., Garrido-Gil, P., Villar-Cheda, B., Parga, J. A., Lanciego, J. L., et al. (2018). Paracrine and intracrine Angiotensin 1-7/Mas receptor axis in the substantia nigra of rodents, monkeys, and humans. Mol. Neurobiol. 55, 5847-5867. doi: 10.1007/s12035-017-0805-y

Costantino, L., and Barlocco, D. (2008). STAT 3 as a target for cancer drug discovery. Curr. Med. Chem. 15, 834-843. doi: 10.2174/0929867087839 55464

Cristovam, P. C., Arnoni, C. P., de Andrade, M. C. C., Casarini, D. E., Pereira, L. G., Schor, N., et al. (2008). ACE-dependent and chymase-dependent angiotensin II generation in normal and glucose-stimulated human mesangial cells. Exp. Biol. Med. (Maywood) 233, 1035-1043. doi: 10.3181/0708-RM-229

Cushman, D. W., Wang, F. L., Fung, W. C., Harvey, C. M., and DeForrest, J. M. (1989). Differentiation of angiotensin-converting enzyme (ACE) inhibitors by their selective inhibition of ACE in physiologically important target organs. Am. J. Hypertens. 2, 294-306. doi: 10.1093/ajh/2.4.294

Danielyan, L., Klein, R., Hanson, L. R., Buadze, M., Schwab, M., Gleiter, C. H., et al. (2010). Protective effects of intranasal losartan in the APP/PS1 transgenic mouse model of Alzheimer disease. Rejuvenation Res. 13, 195-201. doi: 10.1089/ rej.2009.0944

Dasuri, K., Zhang, L., and Keller, J. N. (2013). Oxidative stress, neurodegeneration, and the balance of protein degradation and protein synthesis. Free Radical Biol. Med. 62, 170-185. doi: 10.1016/j.freeradbiomed.2012. 09.016

Davis, C. J., Kramár, E. A., De, A., Meighan, P. C., Simasko, S. M., Wright, J. W., et al. (2006). AT4 receptor activation increases intracellular calcium influx and induces a non-N-methyl-d-aspartate dependent form of long-term potentiation. Neuroscience 137, 1369-1379. doi: 10.1016/j.neuroscience.2005. 10.051

De Bundel, D., Smolders, I., Yang, R., Albiston, A. L., Michotte, Y., and Chai, S. Y. (2009). Angiotensin IV and LVV-haemorphin 7 enhance spatial working memory in rats: effects on hippocampal glucose levels and blood flow. Neurobiol. Learn Mem. 92, 19-26. doi: 10.1016/j.nlm.2009.02.004 
de Gasparo, M., Catt, K. J., Inagami, T., Wright, J. W., and Unger, T. (2000). International union of pharmacology. XXIII. The angiotensin II receptors. Pharmacol. Rev. 52, 415-472.

de Kloet, A. D., Pitra, S., Wang, L., Hiller, H., Pioquinto, D. J., Smith, J. A., et al. (2016). Angiotensin Type-2 receptors influence the activity of vasopressin neurons in the paraventricular nucleus of the hypothalamus in male mice. Endocrinology 157, 3167-3180. doi: 10.1210/en.2016-1131

de la Torre, J. C. (2002). Alzheimer disease as a vascular disorder. Stroke 33, 1152-1162. doi: 10.1161/01.STR.0000014421.15948.67

de La Torre, J. C. (2004). Alzheimer's disease is a vasocognopathy: a new term to describe its nature. Neurol. Res. 26, 517-524. doi: 10.1179/ 016164104225016254

de la Torre, J. C., and Mussivand, T. (1993). Can disturbed brain microcirculation cause Alzheimer's disease? Neurol. Res. 15, 146-153. doi: 10.1080/01616412. 1993.11740127

de Oliveira, F. F., Chen, E. S., Smith, M. C., and Bertolucci, P. H. F. (2018). Pharmacogenetics of angiotensin-converting enzyme inhibitors in patients with Alzheimer's disease dementia. Curr. Alzheimer Res. 15, 386-398. doi: 10.2174/ 1567205014666171016101816

De Silva, T. M., Broughton, B. R. S., Drummond, G. R., Sobey, C. G., and Miller, A. A. (2009). Gender influences cerebral vascular responses to angiotensin II through Nox2-derived reactive oxygen species. Stroke 40, 1091-1097. doi: 10.1161/STROKEAHA.108.531707

De Silva, T. M., and Faraci, F. M. (2013). Effects of angiotensin II on the cerebral circulation: role of oxidative stress. Front. Physiol. 3:484. doi: 10.3389/fphys. 2012.00484

Denver, P., and McClean, P. (2018). Distinguishing normal brain aging from the development of Alzheimer's disease: inflammation, insulin signaling and cognition. Neural Regen. Res. 13:1719. doi: 10.4103/1673-5374.238608

Diaz-Ruiz, C., Rodriguez-Perez, A. I., Beiroa, D., Rodriguez-Pallares, J., and Labandeira-Garcia, J. L. (2015). Reciprocal regulation between sirtuin-1 and angiotensin-II in the substantia nigra: implications for aging and neurodegeneration. Oncotarget 6, 26675-26689. doi: 10.18632/oncotarget.5596

Diaz-Ruiz, C., Villar-Cheda, B., Dominguez-Meijide, A., Garrido-Gil, P., Guerra, M. J., and Labandeira-Garcia, J. L. (2020). Aging-related overactivity of the angiotensin/AT1 axis decreases sirtuin 3 levels in the substantia nigra, which induces vulnerability to oxidative stress and neurodegeneration. J. Gerontol. A Biol. Sci. Med. Sci. 75, 416-424. doi: 10.1093/gerona/gly259

Diz, D. I. (2008). Lewis K. Dahl memorial lecture: the renin-angiotensin system and aging. Hypertension 52, 37-43. doi: 10.1161/HYPERTENSIONAHA.107. 108985

Dong, Y.-F., Kataoka, K., Toyama, K., Sueta, D., Koibuchi, N., Yamamoto, E., et al. (2011). Attenuation of brain damage and cognitive impairment by direct renin inhibition in mice with chronic cerebral hypoperfusion. Hypertension 58 , 635-642. doi: 10.1161/HYPERTENSIONAHA.111.173534

Dorsey, E. R., Elbaz, A., Nichols, E., Abd-Allah, F., Abdelalim, A., Adsuar, J. C., et al. (2018). Global, regional, and national burden of Parkinson's disease, 1990-2016: a systematic analysis for the global burden of disease study 2016. Lancet Neurol. 17, 939-953. doi: 10.1016/S1474-4422(18)30295-3

Drews, H. J., Yenkoyan, K., Lourhmati, A., Buadze, M., Kabisch, D., Verleysdonk, S., et al. (2019). Intranasal losartan decreases perivascular beta amyloid, inflammation, and the decline of neurogenesis in hypertensive rats. Neurotherapeutics 16, 725-740. doi: 10.1007/s13311-019-00723-6

Dröge, W. (2002). Free radicals in the physiological control of cell function. Physiol. Rev. 82, 47-95. doi: 10.1152/physrev.00018.2001

Düsing, R. (2016). Pharmacological interventions into the renin-angiotensin system with ACE inhibitors and angiotensin II receptor antagonists: effects beyond blood pressure lowering. Ther. Adv. Cardiovasc. Dis. 10, 151-161. doi: $10.1177 / 1753944716644130$

Dzau, V. J. (1988). Tissue renin-angiotensin system: physiologic and pharmacologic implications. Introduction. Circulation 77(6 Pt 2), I1-I3.

Elased, K. M., Cunha, T. S., Marcondes, F. K., and Morris, M. (2008). Brain angiotensin-converting enzymes: role of angiotensin-converting enzyme 2 in processing angiotensin II in mice. Exp. Physiol. 93, 665-675. doi: 10.1113/ expphysiol.2007.040311

Esposito, L., Raber, J., Kekonius, L., Yan, F., Yu, G.-Q., Bien-Ly, N., et al. (2006). Reduction in mitochondrial superoxide dismutase modulates Alzheimer's disease-like pathology and accelerates the onset of behavioral changes in human amyloid precursor protein transgenic mice. J. Neurosci. 26, 5167-5179. doi: 10.1523/JNEUROSCI.0482-06.2006

Evans, N. R., Wall, J., To, B., Wallis, S. J., Romero-Ortuno, R., and Warburton, E. A. (2020). Clinical frailty independently predicts early mortality after ischaemic stroke. Age Ageing 49, 588-591. doi: 10.1093/ageing/afaa004

Faraci, F. M., and Heistad, D. D. (1990). Regulation of large cerebral arteries and cerebral microvascular pressure. Circ. Res. 66, 8-17. doi: 10.1161/01.res.66.1.8

Faraci, F. M., Lamping, K. G., Modrick, M. L., Ryan, M. J., Sigmund, C. D., and Didion, S. P. (2006). Cerebral vascular effects of angiotensin II: new insights from genetic models. J. Cereb. Blood Flow Metab. 26, 449-455. doi: 10.1038/sj. jcbfm.9600204

Farag, E., Sessler, D. I., Ebrahim, Z., Kurz, A., Morgan, J., Ahuja, S., et al. (2017). The renin angiotensin system and the brain: new developments. J. Clin. Neurosci. 46, 1-8. doi: 10.1016/j.jocn.2017.08.055

Faure, S., Chapot, R., Tallet, D., Javellaud, J., Achard, J. M., and Oudart, N. (2006). Cerebroprotective effect of angiotensin IV in experimental ischemic stroke in the rat mediated by AT(4) receptors. J. Physiol. Pharmacol. 57, 329-342.

Feng, X., Wang, L., and Li, Y. (2011). Change of telomere length in angiotensin IIinduced human glomerular mesangial cell senescence and the protective role of losartan. Mol. Med. Rep. 4, 255-260. doi: 10.3892/mmr.2011.436

Fernando, R. N., Albiston, A. L., and Chai, S. Y. (2008). The insulin-regulated aminopeptidase IRAP is colocalised with GLUT4 in the mouse hippocampus potential role in modulation of glucose uptake in neurones? Eur. J. Neurosci. 28 , 588-598. doi: 10.1111/j.1460-9568.2008.06347.x

Fogari, R., Mugellini, A., Zoppi, A., Derosa, G., Pasotti, C., Fogari, E., et al. (2003). Influence of losartan and atenolol on memory function in very elderly hypertensive patients. J. Hum. Hypertens. 17, 781-785. doi: 10.1038/sj.jhh. 1001613

Fogarty, D. J., and Matute, C. (2001). Angiotensin receptor-like immunoreactivity in adult brain white matter astrocytes and oligodendrocytes. Glia 35, 131-146. doi: 10.1002/glia.1078

Folli, F., Saad, M. J., Velloso, L., Hansen, H., Carandente, O., Feener, E. P., et al. (1999). Crosstalk between insulin and angiotensin II signalling systems. Exp. Clin. Endocrinol. Diabetes 107, 133-139. doi: 10.1055/s-0029-12 12088

Forette, F., Seux, M.-L., Staessen, J. A., Thijs, L., Babarskiene, M.-R., Babeanu, S., et al. (2002). The prevention of dementia with antihypertensive treatment: new evidence from the Systolic Hypertension in Europe (Syst-Eur) study. Arch. Intern. Med. 162, 2046-2052. doi: 10.1001/archinte.162.18.2046

Forette, F., Seux, M. L., Staessen, J. A., Thijs, L., Birkenhäger, W. H., Babarskiene, M. R., et al. (1998). Prevention of dementia in randomised double-blind placebo-controlled Systolic Hypertension in Europe (Syst-Eur) trial. Lancet 352, 1347-1351. doi: 10.1016/s0140-6736(98)03086-4

Forrester, S. J., Booz, G. W., Sigmund, C. D., Coffman, T. M., Kawai, T., Rizzo, V., et al. (2018). Angiotensin II signal transduction: an update on mechanisms of physiology and pathophysiology. Physiol Rev 98, 1627-1738. doi: 10.1152/ physrev.00038.2017

Fouda, A. Y., Fagan, S. C., and Ergul, A. (2019). The brain vasculature and cognition: renin-angiotensin system, endothelin and beyond. Arterioscler Thromb Vasc. Biol. 39, 593-602. doi: 10.1161/ATVBAHA.118.3 11906

Fouda, A. Y., Pillai, B., Dhandapani, K. M., Ergul, A., and Fagan, S. C. (2017). Role of interleukin-10 in the neuroprotective effect of the Angiotensin type 2 receptor agonist, compound 21, after ischemia/reperfusion injury. Eur. J. Pharmacol. 799, 128-134. doi: 10.1016/j.ejphar.2017.02.016

Fournier, A., Messerli, F. H., Achard, J. M., and Fernandez, L. (2004). Cerebroprotection mediated by angiotensin II: a hypothesis supported by recent randomized clinical trials. J. Am. Coll. Cardiol. 43, 1343-1347. doi: 10.1016/j.jacc.2003.10.060

Freund, M., Walther, T., and von Bohlen und Halbach, O. (2012). Immunohistochemical localization of the angiotensin-(1-7) receptor Mas in the murine forebrain. Cell Tissue Res. 348, 29-35. doi: 10.1007/s00441-0121354-3

Fried, L. P., Tangen, C. M., Walston, J., Newman, A. B., Hirsch, C., Gottdiener, J., et al. (2001). Frailty in Older AdultsEvidence for a phenotype. J. Gerontol. A Biol. Sci. Med. Sci. 56, M146-M157. doi: 10.1093/gerona/56.3.M146

Füchtbauer, L., Toft-Hansen, H., Khorooshi, R., and Owens, T. (2010). Expression of astrocytic type 2 angiotensin receptor in central nervous system 
inflammation correlates with blood-brain barrier breakdown. J. Mol. Neurosci. 42, 89-98. doi: 10.1007/s12031-010-9371-8

Fujita, T., Hirooka, K., Nakamura, T., Itano, T., Nishiyama, A., Nagai, Y., et al. (2012). Neuroprotective effects of angiotensin II type 1 receptor (AT1-R) blocker via modulating AT1-R signaling and decreased extracellular glutamate levels. Invest. Ophthalmol. Vis. Sci. 53, 4099-4110. doi: 10.1167/iovs.11-9167

Fukumoto, M., Takai, S., Ishizaki, E., Sugiyama, T., Oku, H., Jin, D., et al. (2008). Involvement of angiotensin II-dependent vascular endothelial growth factor gene expression via NADPH oxidase in the retina in a type 2 diabetic rat model. Curr. Eye Res. 33, 885-891. doi: 10.1080/027136808023 89851

Fuxe, K., Ganten, D., Hökfelt, T., Locatelli, V., Poulsen, K., Stock, G., et al. (1980). Renin-like immunocytochemical activity in the rat and mouse brain. Neurosci. Lett. 18, 245-250. doi: 10.1016/0304-3940(80)90292-X

Gallego-Delgado, J., Basu-Roy, U., Ty, M., Alique, M., Fernandez-Arias, C., Movila, A., et al. (2016). Angiotensin receptors and $\beta$-catenin regulate brain endothelial integrity in malaria. J. Clin. Invest. 126, 4016-4029. doi: 10.1172/JCI 87306

Ganten, D., Marquez-Julio, A., Granger, P., Hayduk, K., Karsunky, K. P., Boucher, R., et al. (1971). Renin in dog brain. Am. J. Physiol. 221, 1733-1737. doi: 10.1152/ajplegacy.1971.221.6.1733

Gao, H.-M., Zhou, H., and Hong, J.-S. (2012). NADPH oxidases: novel therapeutic targets for neurodegenerative diseases. Trends Pharmacol. Sci. 33, 295-303. doi: $10.1016 /$ j.tips.2012.03.008

Gao, H.-M., Zhou, H., and Hong, J.-S. (2014). "Oxidative stress, neuroinflammation, and neurodegeneration," in Neuroinflammation and Neurodegeneration, eds P. K. Peterson and M. Toborek (New York, NY: Springer New York), 81-104. doi: 10.1007/978-1-4939-1071-7_5

Gao, L., and Zucker, I. H. (2011). AT2 receptor signaling and sympathetic regulation. Curr. Opin. Pharmacol. 11, 124-130. doi: 10.1016/j.coph.2010. 11.004

Gao, Y., O'Caoimh, R., Healy, L., Kerins, D. M., Eustace, J., Guyatt, G., et al. (2013). Effects of centrally acting ACE inhibitors on the rate of cognitive decline in dementia. BMJ Open 3:e002881. doi: 10.1136/bmjopen-2013-002881

Garcia-Garrote, M., Perez-Villalba, A., Garrido-Gil, P., Belenguer, G., Parga, J. A., Perez-Sanchez, F., et al. (2019). Interaction between angiotensin type 1, type 2 , and Mas receptors to regulate adult neurogenesis in the brain ventricularsubventricular zone. Cells 8:1551. doi: 10.3390/cells8121551

Gard, P. R. (2008). Cognitive-enhancing effects of angiotensin IV. BMC Neurosci. 9(Suppl. 2):S15. doi: 10.1186/1471-2202-9-S2-S15

Garrido-Gil, P., Rodriguez-Pallares, J., Dominguez-Meijide, A., Guerra, M. J., and Labandeira-Garcia, J. L. (2013a). Brain angiotensin regulates iron homeostasis in dopaminergic neurons and microglial cells. Exp. Neurol. 250, 384-396. doi: 10.1016/j.expneurol.2013.10.013

Garrido-Gil, P., Rodriguez-Perez, A. I., Fernandez-Rodriguez, P., Lanciego, J. L., and Labandeira-Garcia, J. L. (2017). Expression of angiotensinogen and receptors for angiotensin and prorenin in the rat and monkey striatal neurons and glial cells. Brain Struct. Funct. 222, 2559-2571. doi: 10.1007/s00429-016$1357-\mathrm{z}$

Garrido-Gil, P., Valenzuela, R., Villar-Cheda, B., Lanciego, J. L., and LabandeiraGarcia, J. L. (2013b). Expression of angiotensinogen and receptors for angiotensin and prorenin in the monkey and human substantia nigra: an intracellular renin-angiotensin system in the nigra. Brain Struct. Funct. 218, 373-388. doi: 10.1007/s00429-012-0402-9

Gebre, A. K., Altaye, B. M., Atey, T. M., Tuem, K. B., and Berhe, D. F. (2018). Targeting renin-angiotensin system against Alzheimer's disease. Front. Pharmacol. 9:440. doi: 10.3389/fphar.2018.00440

Ghafourifar, P., and Richter, C. (1997). Nitric oxide synthase activity in mitochondria. FEBS Lett. 418, 291-296. doi: 10.1016/s0014-5793(97)0 $1397-5$

Ghanouni, P., Steenhuis, J. J., Farrens, D. L., and Kobilka, B. K. (2001). Agonistinduced conformational changes in the G-protein-coupling domain of the beta 2 adrenergic receptor. Proc. Natl. Acad. Sci. U.S.A. 98, 5997-6002. doi: 10.1073/ pnas. 101126198

Girouard, H., Park, L., Anrather, J., Zhou, P., and Iadecola, C. (2006). Angiotensin II attenuates endothelium-dependent responses in the cerebral microcirculation through nox-2-derived radicals. Arterioscler. Thromb. Vasc. Biol. 26, 826-832. doi: 10.1161/01.ATV.0000205849.22807.6e
Gorelick, P. B., Scuteri, A., Black, S. E., Decarli, C., Greenberg, S. M., Iadecola, C., et al. (2011). Vascular contributions to cognitive impairment and dementia: a statement for healthcare professionals from the american heart association/american stroke association. Stroke 42, 2672-2713. doi: 10.1161/ STR.0b013e3182299496

Gowrisankar, Y. V., and Clark, M. A. (2016). Angiotensin II induces interleukin-6 expression in astrocytes: role of reactive oxygen species and NF-кB. Mol. Cell. Endocrinol. 437, 130-141. doi: 10.1016/j.mce.2016.08.013

Grammatopoulos, T. N., Jones, S. M., Ahmadi, F. A., Hoover, B. R., Snell, L. D., Skoch, J., et al. (2007). Angiotensin type 1 receptor antagonist losartan, reduces MPTP-induced degeneration of dopaminergic neurons in substantia nigra. Mol. Neurodegener. 2:1. doi: 10.1186/1750-1326-2-1

Greenland, K., Wyse, B., and Sernia, C. (1996). Identification and characterization of angiotensinIV binding sites in rat neurone and astrocyte cell cultures. J. Neuroendocrinol. 8, 687-693. doi: 10.1046/j.1365-2826.1996.05074.x

Griendling, K. K., Murphy, T. J., and Alexander, R. W. (1993). Molecular biology of the renin-angiotensin system. Circulation 87, 1816-1828.

Griendling, K. K., Sorescu, D., and Ushio-Fukai, M. (2000). NAD(P)H Oxidase: role in cardiovascular biology and disease. Circ. Res. 86, 494-501. doi: 10.1161/ 01.RES.86.5.494

Grobe, J. L., Xu, D., and Sigmund, C. D. (2008). An intracellular renin-angiotensin system in neurons: fact, hypothesis, or fantasy. Physiology (Bethesda) 23, 187193. doi: 10.1152/physiol.00002.2008

Grune, T., Jung, T., Merker, K., and Davies, K. J. A. (2004). Decreased proteolysis caused by protein aggregates, inclusion bodies, plaques, lipofuscin, ceroid, and "aggresomes" during oxidative stress, aging, and disease. Int. J. Biochem. Cell Biol. 36, 2519-2530. doi: 10.1016/j.biocel.2004.04.020

Guimaraes, P. S., Oliveira, M. F., Braga, J. F., Nadu, A. P., Schreihofer, A., Santos, R. A. S., et al. (2014). Increasing angiotensin-(1-7) levels in the brain attenuates metabolic syndrome-related risks in fructose-fed rats. Hypertension 63, 1078-1085. doi: 10.1161/HYPERTENSIONAHA.113.01847

Guo, S., Som, A. T., Arai, K., and Lo, E. H. (2019). Effects of angiotensin-II on brain endothelial cell permeability via PPARalpha regulation of para- and trans-cellular pathways. Brain Res. 1722:146353. doi: 10.1016/j.brainres.2019. 146353

Gwathmey, T. M., Alzayadneh, E. M., Pendergrass, K. D., and Chappell, M. C. (2012). Novel roles of nuclear angiotensin receptors and signaling mechanisms. Am. J. Physiol. Regul. Integr. Comp. Physiol. 302, R518-R530. doi: 10.1152/ ajpregu.00525.2011

Gwathmey, T. M., Shaltout, H. A., Pendergrass, K. D., Pirro, N. T., Figueroa, J. P., Rose, J. C., et al. (2009). Nuclear angiotensin II type 2 (AT2) receptors are functionally linked to nitric oxide production. Am. J. Physiol. Renal Physiol. 296, F1484-F1493. doi: 10.1152/ajprenal.90766.2008

Gwathmey, T. M., Pendergrass, K. D., Reid, S. D., Rose, J. C., Diz, D. I., and Chappell, M. C. (2010). Angiotensin-(1-7)-angiotensin-converting enzyme 2 attenuates reactive oxygen species formation to angiotensin II within the cell nucleus. Hypertension 55, 166-171. doi: 10.1161/HYPERTENSIONAHA.109. 141622

Haag, M. D. M., Hofman, A., Koudstaal, P. J., Breteler, M. M. B., and Stricker, B. H. C. (2009). Duration of antihypertensive drug use and risk of dementia: a prospective cohort study. Neurology 72, 1727-1734. doi: 10.1212/01.wnl. $0000345062.86148 .3 \mathrm{f}$

Hajjar, I. (2020). Candesartan's Effects on Alzheimer's Disease And Related Biomarkers. Clinicaltrials.gov. Available online at: https://clinicaltrials.gov/ct2/ show/NCT02646982 (accessed July 1, 2020).

Hajjar, I., Catoe, H., Sixta, S., Boland, R., Johnson, D., Hirth, V., et al. (2005). Crosssectional and longitudinal association between antihypertensive medications and cognitive impairment in an elderly population. J. Gerontol. A Biol. Sci. Med. Sci. 60, 67-73. doi: 10.1093/gerona/60.1.67

Hajjar, I., Hart, M., Chen, Y.-L., Mack, W., Milberg, W., Chui, H., et al. (2012). Effect of antihypertensive therapy on cognitive function in early executive cognitive impairment: a double-blind randomized clinical trial. Arch. Intern. Med. 172, 442-444. doi: 10.1001/archinternmed.2011.1391

Hajjar, I., Hart, M., Milberg, W., Novak, V., and Lipsitz, L. (2009). The rationale and design of the antihypertensives and vascular, endothelial, and cognitive function (AVEC) trial in elderly hypertensives with early cognitive impairment: role of the renin angiotensin system inhibition. BMC Geriatr. 9:48. doi: 10.1186/14712318-9-48 
Harding, J. W., Sullivan, M. J., Hanesworth, J. M., Cushing, L. L., and Wright, J. W. (1988). Inability of [125I]Sar1, Ile8-Angiotensin II to move between the blood and cerebrospinal fluid compartments. J. Neurochem. 50, 554-557. doi: 10.1111/j.1471-4159.1988.tb02946.x

Harman, D. (1956). Aging: a theory based on free radical and radiation chemistry. J. Gerontol. 11, 298-300. doi: 10.1093/geronj/11.3.298

Hay, M., Polt, R., Heien, M. L., Vanderah, T. W., Largent-Milnes, T. M., Rodgers, K., et al. (2019). A novel angiotensin-(1-7) glycosylated Mas receptor agonist for treating vascular cognitive impairment and inflammation-related memory dysfunction. J. Pharmacol. Exp. Ther. 369, 9-25. doi: 10.1124/jpet.118.2 54854

Hay, M., Vanderah, T. W., Samareh-Jahani, F., Constantopoulos, E., Uprety, A. R., Barnes, C. A., et al. (2017). Cognitive impairment in heart failure: a protective role for angiotensin-(1-7). Behav. Neurosci. 131, 99-114. doi: 10. 1037/bne0000182

Hellner, K., Walther, T., Schubert, M., and Albrecht, D. (2005). Angiotensin-(17) enhances LTP in the hippocampus through the G-protein-coupled receptor Mas. Mol. Cell. Neurosci. 29, 427-435. doi: 10.1016/j.mcn.2005.03.012

Hemming, M. L., and Selkoe, D. J. (2005). Amyloid beta-protein is degraded by cellular angiotensin-converting enzyme (ACE) and elevated by an ACE inhibitor. J. Biol. Chem. 280, 37644-37650. doi: 10.1074/jbc.M508460200

Heneka, M. T., Carson, M. J., Khoury, J. E., Landreth, G. E., Brosseron, F., Feinstein, D. L., et al. (2015). Neuroinflammation in Alzheimer's disease. Lancet Neurol. 14, 388-405. doi: 10.1016/S1474-4422(15)70016-5

Heneka, M. T., Landreth, G. E., and Hüll, M. (2007). Drug insight: effects mediated by peroxisome proliferator-activated receptor-gamma in CNS disorders. Nat. Clin. Pract. Neurol. 3, 496-504. doi: 10.1038/ncpneuro0586

Hermann, K., Raizada, M. K., Summers, C., and Phillips, M. I. (1987). Presence of renin in primary neuronal and glial cells from rat brain. Brain Res. 437, 205-213. doi: 10.1016/0006-8993(87)91637-4

Herse, F., and LaMarca, B. (2013). Angiotensin II Type 1 receptor autoantibody (AT1-AA)-mediated pregnancy hypertension. Am. J. Reprod. Immunol. 69, 413-418. doi: 10.1111/aji.12072

Higaki, A., Mogi, M., Iwanami, J., Min, L.-J., Bai, H.-Y., Shan, B.-S., et al. (2018). Beneficial effect of Mas receptor deficiency on vascular cognitive impairment in the presence of angiotensin II Type 2 receptor. J. Am. Heart Assoc. 7:e008121. doi: 10.1161/JAHA.117.008121

Hilgers, R. H. P., and Webb, R. C. (2005). Molecular aspects of arterial smooth muscle contraction: focus on Rho. Exp. Biol. Med. (Maywood) 230, 829-835. doi: 10.1177/153537020523001107

Hirawa, N., Uehara, Y., Kawabata, Y., Numabe, A., Gomi, T., Ikeda, T., et al. (1999). Long-term inhibition of renin-angiotensin system sustains memory function in aged Dahl rats. Hypertension 34, 496-502. doi: 10.1161/01.hyp.34. 3.496

Hirose, S., Naruse, M., Ohtsuki, K., and Inagami, T. (1981). Totally inactive renin zymogen and different forms of active renin in hog brain tissues. J. Biol. Chem. 256, 5572-5576.

Ho, J. K., and Nation, D. A. (2018). Cognitive benefits of angiotensin IV and angiotensin-(1-7): a systematic review of experimental studies. Neurosci. Biobehav. Rev. 92, 209-225. doi: 10.1016/j.neubiorev.2018.05.005

Holownia, A., and Braszko, J. J. (2007). The effect of angiotensin II and IV on ERK1/2 and CREB signalling in cultured rat astroglial cells. Naunyn Schmiedebergs Arch. Pharmacol. 376, 157-163. doi: 10.1007/s00210-007-0 192-4

Hongpaisan, J., Winters, C. A., and Andrews, S. B. (2004). Strong calcium entry activates mitochondrial superoxide generation, upregulating kinase signaling in hippocampal neurons. J. Neurosci. 24, 10878-10887. doi: 10.1523/JNEUROSCI. 3278-04.2004

Hornig, B., Landmesser, U., Kohler, C., Ahlersmann, D., Spiekermann, S., Christoph, A., et al. (2001). Comparative effect of ace inhibition and angiotensin II type 1 receptor antagonism on bioavailability of nitric oxide in patients with coronary artery disease: role of superoxide dismutase. Circulation 103, 799-805. doi: 10.1161/01.cir.103.6.799

Iadecola, C., and Davisson, R. L. (2008). Hypertension and cerebrovascular dysfunction. Cell Metab. 7, 476-484. doi: 10.1016/j.cmet.2008.03.010

Inoue, Y., Nakamura, N., and Inagami, T. (1997). A review of mutagenesis studies of angiotensin II type 1 receptor, the three-dimensional receptor model in search of the agonist and antagonist binding site and the hypothesis of a receptor activation mechanism. J. Hypertens. 15, 703-714. doi: 10.1097/ 00004872-199715070-00001

in't Veld, B. A., Ruitenberg, A., Hofman, A., Stricker, B. H., and Breteler, M. M. (2001). Antihypertensive drugs and incidence of dementia: the Rotterdam Study. Neurobiol. Aging 22, 407-412. doi: 10.1016/s0197-4580(00)0 0241-4

Intengan, H. D., and Schiffrin, E. L. (2001). Vascular remodeling in hypertension: roles of apoptosis, inflammation, and fibrosis. Hypertension 38, 581-587. doi: 10.1161/hy09t1.096249

Ivan, C. S., Seshadri, S., Beiser, A., Au, R., Kase, C. S., Kelly-Hayes, M., et al. (2004). Dementia after stroke. Stroke 35, 1264-1268. doi: 10.1161/01.STR.0000127810. 92616.78

Iwanami, J., Mogi, M., Tsukuda, K., Wang, X.-L., Nakaoka, H., Kan-no, H., et al. (2015). Direct angiotensin II type 2 receptor stimulation by compound 21 prevents vascular dementia. J. Am. Soc. Hypertension 9, 250-256. doi: 10.1016/ j.jash.2015.01.010

Jack, C. R., Bennett, D. A., Blennow, K., Carrillo, M. C., Dunn, B., Haeberlein, S. B., et al. (2018). NIA-AA research framework: toward a biological definition of Alzheimer's disease. Alzheimers Dement. 14, 535-562. doi: 10.1016/j.jalz.2018. 02.018

Jackson, L., Eldahshan, W., Fagan, S. C., and Ergul, A. (2018). Within the brain: the renin angiotensin system. Int. J. Mol. Sci. 19:876. doi: 10.3390/ijms190 30876

Jiang, T., Gao, L., Lu, J., and Zhang, Y.-D. (2013). ACE2-Ang-(1-7)-Mas axis in brain: a potential target for prevention and treatment of ischemic stroke. Curr. Neuropharmacol. 11, 209-217. doi: 10.2174/1570159X11311020007

Jiang, T., Yu, J.-T., Zhu, X.-C., Zhang, Q.-Q., Tan, M.-S., Cao, L., et al. (2014). Angiotensin-(1-7) induces cerebral ischaemic tolerance by promoting brain angiogenesis in a Mas/eNOS-dependent pathway. Br. J. Pharmacol. 171, 42224232. doi: 10.1111/bph. 12770

Joglar, B., Rodriguez-Pallares, J., Rodriguez-Perez, A. I., Rey, P., Guerra, M. J., and Labandeira-Garcia, J. L. (2009). The inflammatory response in the MPTP model of Parkinson's disease is mediated by brain angiotensin: relevance to progression of the disease. J. Neurochem. 109, 656-669. doi: 10.1111/j.14714159.2009.05999.x

Jöhren, O., Inagami, T., and Saavedra, J. M. (1995). AT1A, AT1B, and AT2angiotensin II receptor subtype gene expression in rat brain. NeuroReport 6, 2549-2552. doi: 10.1097/00001756-199512150-00024

Julien, C., Tremblay, C., Emond, V., Lebbadi, M., Salem, N., Bennett, D. A., et al. (2009). Sirtuin 1 reduction parallels the accumulation of tau in Alzheimer disease. J. Neuropathol. Exp. Neurol. 68, 48-58. doi: 10.1097/NEN. 0b013e3181922348

Kandalam, U., Sarmiento, N., Haspula, D., and Clark, M. A. (2015). Angiotensin III induces signal transducer and activator of transcription 3 and interleukin-6 mRNA levels in cultured rat astrocytes. J. Renin Angiotensin Aldosterone Syst. 16, 758-767. doi: 10.1177/1470320314534509

Kazama, K., Wang, G., Frys, K., Anrather, J., and Iadecola, C. (2003). Angiotensin II attenuates functional hyperemia in the mouse somatosensory cortex. Am. J. Physiol. Heart Circ. Physiol. 285, H1890-H1899. doi: 10.1152/ajpheart.00464. 2003

Kehoe, P. G. (2018). The coming of age of the angiotensin hypothesis in Alzheimer's disease: progress toward disease prevention and treatment? J. Alzheimers Dis. 62, 1443-1466. doi: 10.3233/JAD-171119

Kehoe, P. G., Al Mulhim, N., Zetterberg, H., Blennow, K., and Miners, J. S. (2019). Cerebrospinal fluid changes in the renin-angiotensin system in Alzheimer's disease. J. Alzheimer's Dis. 72, 525-535. doi: 10.3233/JAD- 190721

Kehoe, P. G., Blair, P. S., Howden, B., Thomas, D. L., Malone, I. B., Horwood, J., et al. (2018). The rationale and design of the reducing pathology in Alzheimer's disease through angiotensin TaRgeting (RADAR) trial. J. Alzheimers Dis. 61, 803-814. doi: 10.3233/JAD-170101

Kehoe, P. G., Davies, N. M., Martin, R. M., and Ben-Shlomo, Y. (2013). Associations of angiotensin targeting antihypertensive drugs with mortality and hospitalization in primary care patients with dementia. J. Alzheimers Dis. 33, 999-1008. doi: 10.3233/JAD-2012-121090

Keisuke, S., Nakagawa, P., Gomez, J., Morgan, D. A., Littlejohn, N. K., Folchert, M. D., et al. (2017). Selective deletion of Renin-b in the brain alters drinking and metabolism. Hypertension 70, 990-997. doi: 10.1161/HYPERTENSIONAHA. 117.09923 
Khachaturian, A. S., Zandi, P. P., Lyketsos, C. G., Hayden, K. M., Skoog, I., Norton, M. C., et al. (2006). Antihypertensive medication use and incident Alzheimer disease: the cache county study. Arch. Neurol. 63, 686-692. doi: 10.1001/archneur.63.5.noc60013

Kigerl, K. A., Gensel, J. C., Ankeny, D. P., Alexander, J. K., Donnelly, D. J., and Popovich, P. G. (2009). Identification of two distinct macrophage subsets with divergent effects causing either neurotoxicity or regeneration in the injured mouse spinal cord. J. Neurosci. 29, 13435-13444. doi: 10.1523/JNEUROSCI. 3257-09.2009

Kim, G. H., Kim, J. E., Rhie, S. J., and Yoon, S. (2015). The role of oxidative stress in neurodegenerative diseases. Exp. Neurobiol. 24, 325-340. doi: 10.5607/en.2015. 24.4.325

Kimura, S., Zhang, G.-X., Nishiyama, A., Shokoji, T., Yao, L., Fan, Y.-Y., et al. (2005). Role of NAD(P)H oxidase- and mitochondria-derived reactive oxygen species in cardioprotection of ischemic reperfusion injury by angiotensin II. Hypertension 45, 860-866. doi: 10.1161/01.HYP.0000163462.98381.7f

Klempin, F., Mosienko, V., Matthes, S., Villela, D. C., Todiras, M., Penninger, J. M., et al. (2018). Depletion of angiotensin-converting enzyme 2 reduces brain serotonin and impairs the running-induced neurogenic response. Cell Mol. Life Sci. 75, 3625-3634. doi: 10.1007/s00018-018-2815-y

Knowles, W. D., and Phillips, M. I. (1980). Angiotensin II responsive cells in the organum vasculosum lamina terminalis (OVLT) recorded in hypothalamic brain slices. Brain Res. 197, 256-259. doi: 10.1016/0006-8993(80) 90455-2

Kobori, H., Nangaku, M., Navar, L. G., and Nishiyama, A. (2007). The intrarenal renin-angiotensin system: from physiology to the pathobiology of hypertension and kidney disease. Pharmacol. Rev. 59, 251-287. doi: 10.1124/pr.59.3.3

Koyama, Y., Mukuda, T., Hamasaki, S., Nakane, H., and Kaidoh, T. (2018). Short-term heat exposure promotes hippocampal neurogenesis via activation of angiotensin II Type 1 receptor in adult rats. Neuroscience 385, 121-132. doi: 10.1016/j.neuroscience.2018.05.045

Kułakowska, A., Karwowska, W., Wiśniewski, K., and Braszko, J. J. (1996). Losartan influences behavioural effects of angiotensin II in rats. Pharmacol. Res. 34, 109-115. doi: 10.1006/phrs.1996.0073

Kumar, H., Lim, H.-W., More, S. V., Kim, B.-W., Koppula, S., Kim, I. S., et al. (2012). The role of free radicals in the aging brain and Parkinson's disease: convergence and parallelism. Int. J. Mol. Sci. 13, 10478-10504. doi: 10.3390/ ijms 130810478

Kumar, R., Thomas, C. M., Yong, Q. C., Chen, W., and Baker, K. M. (2012). The intracrine renin-angiotensin system. Clin. Sci. (Lond) 123, 273-284. doi: $10.1042 /$ CS20120089

Kunieda, T., Minamino, T., Nishi, J.-I., Tateno, K., Oyama, T., Katsuno, T., et al. (2006). Angiotensin II induces premature senescence of vascular smooth muscle cells and accelerates the development of atherosclerosis via a p21-dependent pathway. Circulation 114, 953-960. doi: 10.1161/ CIRCULATIONAHA.106.626606

Labandeira-Garcia, J. L., Garrido-Gil, P., Rodriguez-Pallares, J., Valenzuela, R.,

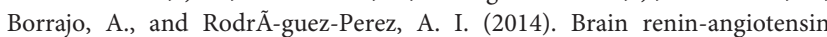
system and dopaminergic cell vulnerability. Front. Neuroanat. 8:67. doi: 10. 3389/fnana.2014.00067

Labandeira-Garcia, J. L., Rodríguez-Perez, A. I., Garrido-Gil, P., RodriguezPallares, J., Lanciego, J. L., and Guerra, M. J. (2017). Brain reninangiotensin system and microglial polarization: implications for aging and neurodegeneration. Front. Aging Neurosci. 9:129. doi: 10.3389/fnagi.2017. 00129

Labandeira-Garcia, J. L., Rodríguez-Perez, A. I., Villar-Cheda, B., Borrajo, A., Dominguez-Meijide, A., and Guerra, M. J. (2015). Rho kinase and dopaminergic degeneration: a promising therapeutic target for Parkinson's disease. Neuroscientist 21, 616-629. doi: 10.1177/1073858414554954

Lanz, T. V., Ding, Z., Ho, P. P., Luo, J., Agrawal, A. N., Srinagesh, H., et al. (2010). Angiotensin II sustains brain inflammation in mice via TGF-beta. J. Clin. Invest. 120, 2782-2794. doi: 10.1172/JCI41709

Lautner, R. Q., Villela, D. C., Fraga-Silva, R. A., Silva, N., Verano-Braga, T., CostaFraga, F., et al. (2013). Discovery and characterization of alamandine: a novel component of the renin-angiotensin system. Circ. Res. 112, 1104-1111. doi: 10.1161/CIRCRESAHA.113.301077

Lavoie, J. L., Cassell Martin, D., Gross Kenneth, W., and Sigmund Curt, D. (2004a). Adjacent expression of renin and angiotensinogen in the rostral ventrolateral medulla using a dual-reporter transgenic model. Hypertension 43, 1116-1119. doi: 10.1161/01.HYP.0000125143.73301.94

Lavoie, J. L., Cassell, M. D., Gross, K. W., and Sigmund, C. D. (2004b). Localization of renin expressing cells in the brain, by use of a REN-eGFP transgenic model. Physiol. Genom. 16, 240-246. doi: 10.1152/physiolgenomics.00131.2003

Lazaroni, T. L. N., Raslan, A. C. S., Fontes, W. R. P., de Oliveira, M. L., Bader, M., Alenina, N., et al. (2012). Angiotensin-(1-7)/Mas axis integrity is required for the expression of object recognition memory. Neurobiol. Learn. Memory 97 , 113-123. doi: 10.1016/j.nlm.2011.10.003

Lebouvier, T., Chen, Y., Duriez, P., Pasquier, F., and Bordet, R. (2020). Antihypertensive agents in Alzheimer's disease: beyond vascular protection. Expert Rev. Neurother. 20, 175-187. doi: 10.1080/14737175.2020.1708195

Lee, J., Chai, S.-Y., Mendelsohn, F. A. O., Morris, M. J., and Allen, A. M. (2001). Potentiation of cholinergic transmission in the rat hippocampus by angiotensin IV and LVV-hemorphin-7. Neuropharmacology 40, 618-623. doi: 10.1016/ S0028-3908(00)00188-X

Lee, J., Mustafa, T., McDowall, S. G., Mendelsohn, F. A. O., Brennan, M., Lew, R. A., et al. (2003). Structure-activity study of LVV-hemorphin-7: angiotensin AT4 receptor ligand and inhibitor of insulin-regulated aminopeptidase. J. Pharmacol. Exp. Ther. 305, 205-211. doi: 10.1124/jpet.102.045492

Lee-Kirsch, M. A., Gaudet, F., Cardoso, M. C., and Lindpaintner, K. (1999). Distinct renin isoforms generated by tissue-specific transcription initiation and alternative splicing. Circ. Res. 84, 240-246. doi: 10.1161/01.res.84.2.240

Lenkei, Z., Palkovits, M., Corvol, P., and Llorens-Cortes, C. (1996). Distribution of angiotensin II type-2 receptor (AT2) mRNA expression in the adult rat brain. J. Comp. Neurol. 373, 322-339. doi: 10.1002/(SICI)1096-9861(19960923)373: $3<322:: A I D-C N E 2>3.0 . C O ; 2-4$

Lenkei, Z., Palkovits, M., Corvol, P., and Llorens-Cortès, C. (1997). Expression of angiotensin type-1 (AT1) and type-2 (AT2) receptor mRNAs in the adult rat brain: a functional neuroanatomical review. Front. Neuroendocrinol. 18, 383-439. doi: 10.1006/frne.1997.0155

Leonhardt, J., Villela, D. C., Teichmann, A., Münter, L.-M., Mayer, M. C., Mardahl, M., et al. (2017). Evidence for heterodimerization and functional interaction of the angiotensin type 2 receptor and the receptor MAS. Hypertension 69, 1128-1135. doi: 10.1161/HYPERTENSIONAHA.116.08814

Levine, D. A., Galecki, A. T., Langa, K. M., Unverzagt, F. W., Kabeto, M. U., Giordani, B., et al. (2015). Trajectory of cognitive decline after incident stroke. JAMA 314, 41-51. doi: 10.1001/jama.2015.6968

Lew, R. A., Mustafa, T., Ye, S., McDowall, S. G., Chai, S. Y., and Albiston, A. L. (2003). Angiotensin AT4 ligands are potent, competitive inhibitors of insulin regulated aminopeptidase (IRAP). J. Neurochem. 86, 344-350. doi: 10.1046/j. 1471-4159.2003.01852.x

Li, H., Horke, S., and Förstermann, U. (2013). Oxidative stress in vascular disease and its pharmacological prevention. Trends Pharmacol. Sci. 34, 313-319. doi: 10.1016/j.tips.2013.03.007

Li, J.-M., Mogi, M., Iwanami, J., Min, L.-J., Tsukuda, K., Sakata, A., et al. (2008). Temporary pretreatment with the angiotensin II type 1 receptor blocker, valsartan, prevents ischemic brain damage through an increase in capillary density. Stroke 39, 2029-2036. doi: 10.1161/STROKEAHA.107. 503458

Li, N.-C., Lee, A., Whitmer, R. A., Kivipelto, M., Lawler, E., Kazis, L. E., et al. (2010). Use of angiotensin receptor blockers and risk of dementia in a predominantly male population: prospective cohort analysis. BMJ 340:b5465. doi: 10.1136/bmj. b5465

Li, W., Peng, H., Cao, T., Sato, R., McDaniels, S. J., Kobori, H., et al. (2012a). Brain-targeted (pro)renin receptor knockdown attenuates angiotensin II-dependent hypertension. Hypertension 59, 1188-1194. doi: 10.1161/ HYPERTENSIONAHA.111.190108

Li, W., Peng, H., Seth, D. M., and Feng, Y. (2012b). The Prorenin and (Pro)renin receptor: new players in the brain renin-angiotensin system? Int. J. Hypertens. 2012:290635. doi: 10.1155/2012/290635

Lithell, H., Hansson, L., Skoog, I., Elmfeldt, D., Hofman, A., Olofsson, B., et al. (2003). The study on cognition and prognosis in the elderly (SCOPE): principal results of a randomized double-blind intervention trial. J. Hypertens. 21, 875886. doi: 10.1097/00004872-200305000-00011

Liu, G., Hosomi, N., Hitomi, H., Pelisch, N., Fu, H., Masugata, H., et al. (2011). Angiotensin II induces human astrocyte senescence through reactive oxygen species production. Hypertension Res. 34, 479-483. doi: 10.1038/hr.2010.269 
Liu, M., Shi, P., and Sumners, C. (2016). Direct anti-inflammatory effects of angiotensin-(1-7) on microglia. J. Neurochem. 136, 163-171. doi: 10.1111/jnc. 13386

Loloi, J., Miller, A. J., Bingaman, S. S., Silberman, Y., and Arnold, A. C. (2018). Angiotensin-(1-7) contributes to insulin-sensitizing effects of angiotensinconverting enzyme inhibition in obese mice. Am. J. Physiol. Endocrinol. Metab. 315, E1204-E1211. doi: 10.1152/ajpendo.00281.2018

Louis, W. J., Mander, A. G., Dawson, M., O’Callaghan, C., and Conway, E. L. (1999). Use of computerized neuropsychological tests (CANTAB) to assess cognitive effects of antihypertensive drugs in the elderly. Cambridge Neuropsychological Test Automated Battery. J. Hypertens. 17, 1813-1819. doi: 10.1097/00004872-199917121-00005

Lu, J., Jiang, T., Wu, L., Gao, L., Wang, Y., Zhou, F., et al. (2013). The expression of angiotensin-converting enzyme 2-angiotensin-(1-7)-Mas receptor axis are upregulated after acute cerebral ischemic stroke in rats. Neuropeptides 47, 289-295. doi: 10.1016/j.npep.2013.09.002

Lu, J., Wu, L., Jiang, T., Wang, Y., Zhao, H., Gao, Q., et al. (2015). Angiotensin AT2 receptor stimulation inhibits activation of NADPH oxidase and ameliorates oxidative stress in rotenone model of Parkinson's disease in CATH.a cells. Neurotoxicol. Teratol. 47, 16-24. doi: 10.1016/j.ntt.2014.11.004

Ma, L., and Chan, P. (2020). Understanding the physiological links between physical frailty and cognitive decline. Aging Dis. 11, 405-418. doi: 10.14336/ AD.2019.0521

Ma, L., Zhang, L., Sun, F., Li, Y., and Tang, Z. (2019). Cognitive function in Prefrail and frail community-dwelling older adults in China. BMC Geriatr. 19:53. doi: 10.1186/s12877-019-1056-8

Ma, P. C., Maulik, G., Christensen, J., and Salgia, R. (2003). c-Met: structure, functions and potential for therapeutic inhibition. Cancer Metastasis Rev. 22, 309-325. doi: 10.1023/A:1023768811842

MacGregor, D. P., Murone, C., Song, K., Allen, A. M., Paxinos, G., and Mendelsohn, F. A. (1995). Angiotensin II receptor subtypes in the human central nervous system. Brain Res. 675, 231-240. doi: 10.1016/0006-8993(95) 00076-3

Manschot, S. M., Biessels, G. J., Cameron, N. E., Cotter, M. A., Kamal, A., Kappelle, L. J., et al. (2003). Angiotensin converting enzyme inhibition partially prevents deficits in water maze performance, hippocampal synaptic plasticity and cerebral blood flow in streptozotocin-diabetic rats. Brain Res. 966, 274-282. doi: 10.1016/s0006-8993(02)04211-7

Massaad, C. A., and Klann, E. (2011). Reactive oxygen species in the regulation of synaptic plasticity and memory. Antioxid Redox Signal. 14, 2013-2054. doi: 10.1089/ars.2010.3208

Mateos, L., Perez-Alvarez, M. J., and Wandosell, F. (2016). Angiotensin II type-2 receptor stimulation induces neuronal VEGF synthesis after cerebral ischemia. Biochim. Biophys. Acta 1862, 1297-1308. doi: 10.1016/j.bbadis.2016. 03.013

Maul, B., von Bohlen und Halbach, O., Becker, A., Sterner-Kock, A., Voigt, J.-P., Siems, W.-E., et al. (2008). Impaired spatial memory and altered dendritic spine morphology in angiotensin II type 2 receptor-deficient mice. J. Mol. Med. 86, 563-571. doi: 10.1007/s00109-008-0316-4

McCormack, A. L., Monte, D. A. D., Delfani, K., Irwin, I., DeLanney, L. E., Langston, W. J., et al. (2004). Aging of the nigrostriatal system in the squirrel monkey. J. Comp. Neurol. 471, 387-395. doi: 10.1002/cne.20036

Mcgeer, P., and Mcgeer, E. (1995). The inflammatory response system of brain: implications for therapy of Alzheimer and other neurodegenerative diseases. Brain Res. Rev. 21, 195-218. doi: 10.1016/0165-0173(95)00011-9

McGeer, P. L., and McGeer, E. G. (2013). The amyloid cascade-inflammatory hypothesis of Alzheimer disease: implications for therapy. Acta Neuropathol. 126, 479-497. doi: 10.1007/s00401-013-1177-7

Mecocci, P., Boccardi, V., Cecchetti, R., Bastiani, P., Scamosci, M., Ruggiero, C., et al. (2018). A long journey into aging, brain aging, and Alzheimer's disease following the oxidative stress Tracks1. J. Alzheimer's Dis. 62, 1319-1335. doi: 10.3233/JAD- 170732

Medelsohn, F. A. O., Jenkins, T. A., and Berkovic, S. F. (1993). Effects of angiotensin II on dopamine and serotonin turnover in the striatum of conscious rats. Brain Res. 613, 221-229. doi: 10.1016/0006-8993(93)90902-Y

Mehta, P. K., and Griendling, K. K. (2007). Angiotensin II cell signaling: physiological and pathological effects in the cardiovascular system. Am. J. Physiol. Cell Physiol. 292, C82-C97. doi: 10.1152/ajpcell.00287.2006
Mendelsohn, F. A., Jenkins, T. A., and Berkovic, S. F. (1993). Effects of angiotensin II on dopamine and serotonin turnover in the striatum of conscious rats. Brain Res. 613, 221-229. doi: 10.1016/0006-8993(93)90902-y

Millan, M. A., Jacobowitz, D. M., Aguilera, G., and Catt, K. J. (1991). Differential distribution of AT1 and AT2 angiotensin II receptor subtypes in the rat brain during development. Proc. Natl. Acad. Sci. U.S.A. 88, 11440-11444. doi: 10. 1073/pnas.88.24.11440

Miller, F. J., Filali, M., Huss, G. J., Stanic, B., Chamseddine, A., Barna, T. J., et al. (2007). Cytokine activation of nuclear factor kappa B in vascular smooth muscle cells requires signaling endosomes containing Nox1 and ClC-3. Circ. Res. 101, 663-671. doi: 10.1161/CIRCRESAHA.107.151076

Milsted, A., Barna, B. P., Ransohoff, R. M., Brosnihan, K. B., and Ferrario, C. M. (1990). Astrocyte cultures derived from human brain tissue express angiotensinogen mRNA. Proc. Natl. Acad. Sci. U.S.A. 87, 5720-5723. doi: 10. 1073/pnas.87.15.5720

Min, L.-J., Mogi, M., Shudou, M., Jing, F., Tsukuda, K., Ohshima, K., et al. (2012). Peroxisome proliferator-activated receptor- $\gamma$ activation with angiotensin II type 1 receptor blockade is pivotal for the prevention of blood-brain barrier impairment and cognitive decline in type 2 diabetic mice. Hypertension 59, 1079-1088. doi: 10.1161/HYPERTENSIONAHA.112.192401

Miners, J. S., Ashby, E., Van Helmond, Z., Chalmers, K. A., Palmer, L. E., Love, S., et al. (2008). Angiotensin-converting enzyme (ACE) levels and activity in Alzheimer's disease, and relationship of perivascular ACE-1 to cerebral amyloid angiopathy. Neuropathol. Appl. Neurobiol. 34, 181-193. doi: 10.1111/j.13652990.2007.00885.x

Miners, J. S., van Helmond, Z., Raiker, M., Love, S., and Kehoe, P. G. (2011). ACE variants and association with brain $\mathrm{A} \beta$ levels in Alzheimer's disease. Am. J. Transl. Res. 3, 73-80.

Miners, S., Ashby, E., Baig, S., Harrison, R., Tayler, H., Speedy, E., et al. (2009). Angiotensin-converting enzyme levels and activity in Alzheimer's disease: differences in brain and CSF ACE and association with ACE1 genotypes. Am. J. Transl. Res. 1, 163-177.

Miura, S., Imaizumi, S., and Saku, K. (2013). Recent progress in molecular mechanisms of angiotensin II type 1 and 2 receptors. Curr. Pharm. Design 19, 2981-2987. doi: 10.2174/1381612811319170002

Mogi, M., and Horiuchi, M. (2013). Effect of angiotensin II type 2 receptor on stroke, cognitive impairment and neurodegenerative diseases. Geriatr. Gerontol. Int. 13, 13-18. doi: 10.1111/j.1447-0594.2012.00900.x

Mogi, M., Iwanami, J., and Horiuchi, M. (2012). Roles of brain Angiotensin II in cognitive function and dementia. Int. J. Hypertens. 2012, 1-7. doi: 10.1155/ 2012/169649

Morris, M. C., Schneider, J. A., Li, H., Tangney, C. C., Nag, S., Bennett, D. A., et al. (2015). Brain tocopherols related to Alzheimer's disease neuropathology in humans. Alzheimer's Dement. 11, 32-39. doi: 10.1016/j.jalz.2013.12.015

Mountford, S. J., Albiston, A. L., Charman, W. N., Ng, L., Holien, J. K., Parker, M. W., et al. (2014). Synthesis, structure-activity relationships and brain uptake of a novel series of benzopyran inhibitors of insulin-regulated aminopeptidase. J. Med. Chem. 57, 1368-1377. doi: 10.1021/jm401540f

Murakami, K., Murata, N., Noda, Y., Tahara, S., Kaneko, T., Kinoshita, N., et al. (2011). SOD1 (copper/zinc superoxide dismutase) deficiency drives amyloid $\beta$ protein oligomerization and memory loss in mouse model of Alzheimer disease. J. Biol. Chem. 286, 44557-44568. doi: 10.1074/jbc.M111.2 79208

Nakagawa, P., Gomez, J., Grobe, J. L., and Sigmund, C. D. (2020). The Reninangiotensin system in the central nervous system and its role in blood pressure regulation. Curr. Hypertens. Rep. 22:7. doi: 10.1007/s11906-019-1011-2

Nguyen, G., and Contrepas, A. (2008). The (pro)renin receptors. J. Mol. Med. 86, 643-646. doi: 10.1007/s00109-008-0319-1

Nguyen, G., Delarue, F., Burcklé, C., Bouzhir, L., Giller, T., and Sraer, J.-D. (2002). Pivotal role of the renin/prorenin receptor in angiotensin II production and cellular responses to renin. J. Clin. Invest. 109, 1417-1427. doi: 10.1172/ JCI14276

O'Caoimh, R., Kehoe, P. G., and Molloy, D. W. (2014). Renin angiotensin aldosterone system inhibition in controlling dementia-related cognitive decline. J. Alzheimer's Dis. 42, S575-S586. doi: 10.3233/JAD-141284

O'Connor, A. T., and Clark, M. A. (2018). Astrocytes and the renin angiotensin system: relevance in disease pathogenesis. Neurochem. Res. 43, 1297-1307. doi: 10.1007/s11064-018-2557-0 
Ohrui, T., Matsui, T., Yamaya, M., Arai, H., Ebihara, S., Maruyama, M., et al. (2004a). Angiotensin-converting enzyme inhibitors and incidence of Alzheimer's disease in Japan. J. Am. Geriatr. Soc. 52, 649-650. doi: 10.1111/j. 1532-5415.2004.52178_7.x

Ohrui, T., Tomita, N., Sato-Nakagawa, T., Matsui, T., Maruyama, M., Niwa, K., et al. (2004b). Effects of brain-penetrating ACE inhibitors on Alzheimer disease progression. Neurology 63, 1324-1325. doi: 10.1212/01.wnl.0000140705.23869. e9

Ongali, B., Nicolakakis, N., Tong, X.-K., Aboulkassim, T., Papadopoulos, P., RosaNeto, P., et al. (2014). Angiotensin II type 1 receptor blocker losartan prevents and rescues cerebrovascular, neuropathological and cognitive deficits in an Alzheimer's disease model. Neurobiol. Dis. 68, 126-136. doi: 10.1016/j.nbd. 2014.04.018

Oscanoa, T. J., Amado, J., Vidal, X., and Romero-Ortuno, R. (2020). Angiotensinreceptor blockers and the risk of Alzheimer's disease: a meta-analysis. Curr. Clin. Pharmacol. 15:1. doi: 10.2174/1574884715666200131120224

Ou, Z., Jiang, T., Gao, Q., Tian, Y.-Y., Zhou, J.-S., Wu, L., et al. (2016). Mitochondrial-dependent mechanisms are involved in angiotensin II-induced apoptosis in dopaminergic neurons. J. Renin Angiotensin Aldosterone Syst. 17:1470320316672349. doi: 10.1177/1470320316672349

Padurariu, M., Ciobica, A., Lefter, R., Serban, I. L., Stefanescu, C., and Chirita, R. (2013). The oxidative stress hypothesis in Alzheimer's disease. Psychiatr. Danub. 25, 401-409.

Page, I. H., and Helmer, O. M. (1940). A crystalline pressor substance (angiotonin) resulting from the reaction between renin and renin-activator. J. Exp. Med. 71, 29-42. doi: 10.1084/jem.71.1.29

Palmer, K., Vetrano, D. L., Padua, L., Romano, V., Rivoiro, C., Scelfo, B., et al. (2019). Frailty syndromes in persons with cerebrovascular disease: a systematic review and meta-analysis. Front. Neurol. 10:1255. doi: 10.3389/fneur.2019. 01255

Panahpour, H., Terpolilli, N. A., Schaffert, D., Culmsee, C., and Plesnila, N. (2019). Central application of Aliskiren, a renin inhibitor, improves outcome after experimental stroke independent of its blood pressure lowering effect. Front. Neurol. 10:942. doi: 10.3389/fneur.2019.00942

Paul, M., Poyan Mehr, A., and Kreutz, R. (2006). Physiology of local reninangiotensin systems. Physiol. Rev. 86, 747-803. doi: 10.1152/physrev.00036. 2005

Pederson, E. S., Harding, J. W., and Wright, J. W. (1998). Attenuation of scopolamine-induced spatial learning impairments by an angiotensin IV analog. Regul. Pept. 74, 97-103. doi: 10.1016/s0167-0115(98)00028-7

Peters, J. (2008). Secretory and cytosolic (pro)renin in kidney, heart, and adrenal gland. J. Mol. Med. 86, 711-714. doi: 10.1007/s00109-008-0328-0

Peters, R., Beckett, N., Forette, F., Tuomilehto, J., Clarke, R., Ritchie, C., et al. (2008). Incident dementia and blood pressure lowering in the Hypertension in the Very Elderly Trial cognitive function assessment (HYVET-COG): a doubleblind, placebo controlled trial. Lancet Neurol. 7, 683-689. doi: 10.1016/S14744422(08)70143-1

Pires, P. W., Dams Ramos, C. M., Matin, N., and Dorrance, A. M. (2013). The effects of hypertension on the cerebral circulation. Am. J. Physiol. Heart Circ. Physiol. 304, H1598-H1614. doi: 10.1152/ajpheart.00490.2012

Pruzin, J. J., Schneider, J. A., Capuano, A. W., Leurgans, S. E., Barnes, L. L., Ahima, R. S., et al. (2017). Diabetes, hemoglobin A1C, and regional Alzheimer disease and infarct pathology. Alzheimer Dis. Assoc. Disord. 31, 41-47. doi: 10.1097/ WAD.0000000000000172

Qin, L., Liu, Y., Wang, T., Wei, S.-J., Block, M. L., Wilson, B., et al. (2004). NADPH oxidase mediates lipopolysaccharide-induced neurotoxicity and proinflammatory gene expression in activated microglia. J. Biol. Chem. 279, 1415-1421. doi: 10.1074/jbc.M307657200

Quitterer, U., Pohl, A., Langer, A., Koller, S., and Abdalla, S. (2011). A cleavable signal peptide enhances cell surface delivery and heterodimerization of Cerulean-tagged angiotensin II AT1 and bradykinin B2 receptor. Biochem. Biophys. Res. Commun. 409, 544-549. doi: 10.1016/j.bbrc.2011. 05.041

Raghavendra, V., Chopra, K., and Kulkarni, S. K. (1998). Involvement of cholinergic system in losartan-induced facilitation of spatial and short-term working memory. Neuropeptides 32, 417-421. doi: 10.1016/s0143-4179(98) 90065-8
Regenhardt, R. W., Desland, F., Mecca, A. P., Pioquinto, D. J., Afzal, A., Mocco, J., et al. (2013). Anti-inflammatory effects of angiotensin-(1-7) in ischemic stroke. Neuropharmacology 71, 154-163. doi: 10.1016/j.neuropharm.2013.03.025

Riccioni, G. (2013). The role of direct renin inhibitors in the treatment of the hypertensive diabetic patient. Ther. Adv. Endocrinol. Metab. 4, 139-145. doi: $10.1177 / 2042018813490779$

Rietdijk, C. D., van Wezel, R. J. A., Garssen, J., and Kraneveld, A. D. (2016). Neuronaltoll-like receptors and neuro-immunity in parkinson's disease, Alzheimer's disease and stroke. Neuroimmunol. Neuroinflamm. 3, 27-37. doi: 10.20517/2347-8659.2015.28

Robertson, D. A., Savva, G. M., and Kenny, R. A. (2013). Frailty and cognitive impairment-A review of the evidence and causal mechanisms. Ageing Res. Rev. 12, 840-851. doi: 10.1016/j.arr.2013.06.004

Rodrigues, S. F., and Granger, D. N. (2012). Cerebral microvascular inflammation in DOCA salt-induced hypertension: role of Angiotensin II and mitochondrial superoxide. J. Cereb. Blood Flow Metab. 32, 368-375. doi: 10.1038/jcbfm.20 11.139

Rodriguez-Iturbe, B., Sepassi, L., Quiroz, Y., Ni, Z., Wallace, D. C., and Vaziri, N. D. (2007). Association of mitochondrial SOD deficiency with salt-sensitive hypertension and accelerated renal senescence. J. Appl. Physiol. 102, 255-260. doi: 10.1152/japplphysiol.00513.2006

Rodriguez-Pallares, J., Rey, P., Parga, J. A., Muñoz, A., Guerra, M. J., and Labandeira-Garcia, J. L. (2008). Brain angiotensin enhances dopaminergic cell death via microglial activation and NADPH-derived ROS. Neurobiol. Dis. 31, 58-73. doi: 10.1016/j.nbd.2008.03.003

Rodriguez-Perez, A. I., Borrajo, A., Rodriguez-Pallares, J., Guerra, M. J., and Labandeira-Garcia, J. L. (2015). Interaction between NADPH-oxidase and Rhokinase in angiotensin II-induced microglial activation. Glia 63, 466-482. doi: 10.1002/glia.22765

Rodriguez-Perez, A. I., Garrido-Gil, P., Pedrosa, M. A., Garcia-Garrote, M., Valenzuela, R., Navarro, G., et al. (2019). Angiotensin type 2 receptors: role in aging and neuroinflammation in the substantia nigra. Brain Behav. Immun. 87, 256-271. doi: 10.1016/j.bbi.2019.12.011

Rodriguez-Perez, A. I., Valenzuela, R., Villar-Cheda, B., Guerra, M. J., and Labandeira-Garcia, J. L. (2012). Dopaminergic neuroprotection of hormonal replacement therapy in young and aged menopausal rats: role of the brain angiotensin system. Brain 135, 124-138. doi: 10.1093/brain/ awr320

Royea, J., Lacalle-Aurioles, M., Trigiani, L. J., Fermigier, A., and Hamel, E. (2020). AT2R's (Angiotensin II Type 2 Receptor's) role in cognitive and cerebrovascular deficits in a mouse model of Alzheimer disease. Hypertension 75, 1464-1474. doi: 10.1161/HYPERTENSIONAHA.119.14431

Royea, J., Zhang, L., Tong, X.-K., and Hamel, E. (2017). Angiotensin IV receptors mediate the cognitive and cerebrovascular benefits of losartan in a mouse model of Alzheimer's disease. J. Neurosci. 37, 5562-5573. doi: 10.1523/JNEUROSCI. 0329- 17.2017

Rozzini, L., Chilovi, B. V., Bertoletti, E., Conti, M., Del Rio, I., Trabucchi, M., et al. (2006). Angiotensin converting enzyme (ACE) inhibitors modulate the rate of progression of amnestic mild cognitive impairment. Int. J. Geriatr. Psychiatry 21, 550-555. doi: 10.1002/gps.1523

Saavedra, J. M. (2005). Brain angiotensin II: new developments, unanswered questions and therapeutic opportunities. Cell Mol. Neurobiol. 25, 485-512. doi: 10.1007/s10571-005-4011-5

Saavedra, J. M. (2017). Beneficial effects of Angiotensin II receptor blockers in brain disorders. Pharmacol. Res. 125, 91-103. doi: 10.1016/j.phrs.2017.06.017

Sadoshima, J., Xu, Y., Slayter, H. S., and Izumo, S. (1993). Autocrine release of angiotensin II mediates stretch-induced hypertrophy of cardiac myocytes in vitro. Cell 75, 977-984. doi: 10.1016/0092-8674(93)90541-w

Sastre, J., Pallardó, F. V., and Viña, J. (2000). Mitochondrial oxidative stress plays a key role in aging and Apoptosis. IUBMB Life 49, 427-435. doi: 10.1080/ 152165400410281

Saxby, B. K., Harrington, F., Wesnes, K. A., McKeith, I. G., and Ford, G. A. (2008). Candesartan and cognitive decline in older patients with hypertension: a substudy of the SCOPE trial. Neurology 70, 1858-1866. doi: 10.1212/01.wnl. 0000311447.85948 .78

Shacter, E. (2000). Quantification and significance of protein oxidation in biological samples. Drug Metab. Rev. 32, 307-326. doi: 10.1081/dmr-100102336 
Shan, Z., Cuadra, A. E., Sumners, C., and Raizada, M. K. (2008). Characterization of a functional (pro)renin receptor in rat brain neurons. Exp. Physiol. 93, 701-708. doi: 10.1113/expphysiol.2008.041988

Shen, X. Z., Lukacher, A. E., Billet, S., Williams, I. R., and Bernstein, K. E. (2008). Expression of angiotensin-converting enzyme changes major histocompatibility complex class I peptide presentation by modifying C termini of peptide precursors. J. Biol. Chem. 283, 9957-9965. doi: 10.1074/jbc. M709574200

Sherrod, M., Liu, X., Zhang, X., and Sigmund, C. D. (2005). Nuclear localization of angiotensinogen in astrocytes. Am. J. Physiol. Regul. Integr. Comp. Physiol. 288, R539-R546. doi: 10.1152/ajpregu.00594.2004

Shimamura, M., Sato, N., Waguri, S., Uchiyama, Y., Hayashi, T., Iida, H., et al. (2006). Gene transfer of hepatocyte growth factor gene improves learning and memory in the chronic stage of cerebral infarction. Hypertension 47, 742-751. doi: 10.1161/01.HYP.0000208598.57687.3e

Shulaev, V., and Oliver, D. J. (2006). Metabolic and proteomic markers for oxidative stress. new tools for reactive oxygen species research. Plant Physiol. 141, 367-372. doi: 10.1104/pp.106.077925

Sian, J., Dexter, D. T., Lees, A. J., Daniel, S., Agid, Y., Javoy-Agid, F., et al. (1994). Alterations in glutathione levels in Parkinson's disease and other neurodegenerative disorders affecting basal ganglia. Ann. Neurol. 36, 348-355. doi: 10.1002/ana.410360305

Singh, K. D., and Karnik, S. S. (2016). Angiotensin receptors: structure, function, signaling and clinical applications. J. Cell Signal. 1:111. doi: 10.4172/jcs.10 00111

Sink, K. M., Leng, X., Williamson, J., Kritchevsky, S. B., Yaffe, K., Kuller, L., et al. (2009). Angiotensin-converting enzyme inhibitors and cognitive decline in older adults with hypertension: results from the Cardiovascular health study. Arch. Intern. Med. 169, 1195-1202. doi: 10.1001/archinternmed.2009.175

Sinn, P. L., and Sigmund, C. D. (2000). Identification of three human renin mRNA isoforms from alternative tissue-specific transcriptional initiation. Physiol. Genomics 3, 25-31. doi: 10.1152/physiolgenomics.2000.3.1.25

Siragy, H. M., de Gasparo, M., and Carey, R. M. (2000). Angiotensin type 2 receptor mediates valsartan-induced hypotension in conscious rats. Hypertension 35 , 1074-1077. doi: 10.1161/01.HYP.35.5.1074

Skoog, I., Lithell, H., Hansson, L., Elmfeldt, D., Hofman, A., Olofsson, B., et al. (2005). Effect of baseline cognitive function and antihypertensive treatment on cognitive and cardiovascular outcomes: study on COgnition and Prognosis in the Elderly (SCOPE). Am. J. Hypertens. 18, 1052-1059. doi: 10.1016/j.amjhyper. 2005.02.013

Sonsalla, P. K., Coleman, C., Wong, L.-Y., Harris, S. L., Richardson, J. R., Gadad, B. S., et al. (2013). The angiotensin converting enzyme inhibitor captopril protects nigrostriatal dopamine neurons in animal models of parkinsonism. Exp. Neurol. 250, 376-383. doi: 10.1016/j.expneurol.2013.10.014

Stadler, T., Veltmar, A., Qadri, F., and Unger, T. (1992). Angiotensin II evokes noradrenaline release from the paraventricular nucleus in conscious rats. Brain Res. 569, 117-122. doi: 10.1016/0006-8993(92)90377-L

Starr, J. M., Whalley, L. J., and Deary, I. J. (1996). The effects of antihypertensive treatment on cognitive function: results from the HOPE study. J. Am. Geriatr. Soc. 44, 411-415. doi: 10.1111/j.1532-5415.1996.tb06412.x

Steckelings, U. M., Widdop, R. E., Paulis, L., and Unger, T. (2010). The angiotensin AT2 receptor in left ventricular hypertrophy. J. Hypertens. 28, S50-S55.

Stornetta, R. L., Hawelu-Johnson, C. L., Guyenet, P. G., and Lynch, K. R. (1988). Astrocytes synthesize angiotensinogen in brain. Science 242, 1444-1446. doi: 10.1126/science. 3201232

Stragier, B., Sarre, S., Vanderheyden, P., Vauquelin, G., Fournié-Zaluski, M.-C., Ebinger, G., et al. (2004). Metabolism of angiotensin II is required for its in vivo effect on dopamine release in the striatum of the rat. J. Neurochem. 90, 1251-1257. doi: 10.1111/j.1471-4159.2004.02600.x

Subra, J., Gillette-Guyonnet, S., Cesari, M., Oustric, S., Vellas, B., and The Platform Team. (2012). The integration of frailty into clinical practice: preliminary results from the Gérontopôle. J. Nutr. Health Aging 16, 714-720. doi: 10.1007/s12603012-0391-7

Sumners, C., Alleyne, A., Rodríguez, V., Pioquinto, D. J., Ludin, J. A., Kar, S., et al. (2020). Brain angiotensin type- 1 and type- 2 receptors: cellular locations under normal and hypertensive conditions. Hypertension Res. 43, 281-295. doi: 10.1038/s41440-019-0374-8
Sumners, C., Fleegal, M. A., and Zhu, M. (2002). Angiotensin At1 receptor signalling pathways in neurons. Clin. Exp. Pharmacol. Physiol. 29, 483-490. doi: 10.1046/j.1440-1681.2002.03660.x

Sun, H., Wu, H., Yu, X., Zhang, G., Zhang, R., Zhan, S., et al. (2015). Angiotensin II and its receptor in activated microglia enhanced neuronal loss and cognitive impairment following pilocarpine-induced status epilepticus. Mol. Cell. Neurosci. 65, 58-67. doi: 10.1016/j.mcn.2015. 02.014

Suzuki, H., Motley, E. D., Frank, G. D., Utsunomiya, H., and Eguchi, S. (2005). Recent progress in signal transduction research of the angiotensin II type1 receptor: protein kinases, vascular dysfunction and structural requirement. Curr. Med. Chem. Cardiovasc. Hematol. Agents 3, 305-322. doi: 10.2174/ 156801605774322355

Swerdlow, R. H. (2011). Brain aging, Alzheimer's disease, and mitochondria. Biochim. Biophys. Acta 1812, 1630-1639. doi: 10.1016/j.bbadis.2011.08.012

Swerdlow, R. H. (2012). Alzheimer's disease pathologic cascades: who comes first, what drives what. Neurotox. Res. 22, 182-194. doi: 10.1007/s12640-011-9272-9

Takane, K., Hasegawa, Y., Lin, B., Koibuchi, N., Cao, C., Yokoo, T., et al. (2017). Detrimental effects of centrally administered Angiotensin II are enhanced in a mouse model of Alzheimer disease independently of blood pressure. J. Am. Heart Assoc. 6:e04897. doi: 10.1161/JAHA.116.004897

Takeda, S., Sato, N., Takeuchi, D., Kurinami, H., Shinohara, M., Niisato, K., et al. (2009). Angiotensin receptor blocker prevented beta-amyloid-induced cognitive impairment associated with recovery of neurovascular coupling. Hypertension 54, 1345-1352. doi: 10.1161/HYPERTENSIONAHA.109.1 38586

Talbot, K., Wang, H.-Y., Kazi, H., Han, L.-Y., Bakshi, K. P., Stucky, A., et al. (2012). Demonstrated brain insulin resistance in Alzheimer's disease patients is associated with IGF-1 resistance, IRS-1 dysregulation, and cognitive decline. J. Clin. Invest. 122, 1316-1338. doi: 10.1172/JCI59903

Tang, Y., and Le, W. (2016). Differential roles of M1 and M2 microglia in neurodegenerative diseases. Mol. Neurobiol. 53, 1181-1194. doi: 10.1007/ s12035-014-9070-5

Taylor-Rowan, M., Keir, R., Cuthbertson, G., Shaw, R., Drozdowska, B., Elliott, E., et al. (2019). Pre-stroke frailty is independently associated with post-stroke cognition: a cross-sectional study. J. Int. Neuropsychol. Soc. 25, 501-506. doi: $10.1017 /$ S1355617719000092

Tedesco, A., and Ally, A. (2009). Angiotensin II type-2 (AT2) receptor antagonism alters cardiovascular responses to static exercise and simultaneously changes glutamate/GABA levels within the ventrolateral medulla. Neurosci. Res. 64, 372-379. doi: 10.1016/j.neures.2009.04.008

Tedesco, M. A., Ratti, G., Mennella, S., Manzo, G., Grieco, M., Rainone, A. C., et al. (1999). Comparison of losartan and hydrochlorothiazide on cognitive function and quality of life in hypertensive patients. Am. J. Hypertens. 12, 1130-1134. doi: 10.1016/S0895-7061(99)00156-9

Tetzner, A., Gebolys, K., Meinert, C., Klein, S., Uhlich, A., Trebicka, J., et al. (2016). G-Protein-coupled receptor MrgD Is a receptor for Angiotensin-(1-7) involving Adenylyl Cyclase, cAMP, and Phosphokinase A. Hypertension 68, 185-194. doi: 10.1161/HYPERTENSIONAHA.116.07572

Tian, M., Zhu, D., Xie, W., and Shi, J. (2012). Central angiotensin II-induced Alzheimer-like tau phosphorylation in normal rat brains. FEBS Lett. 586, 3737-3745. doi: 10.1016/j.febslet.2012.09.004

Tigerstedt, R., and Bergman, P. Q. (1898). Niere und Kreislauf1. Skand. Arch. Für Physiol. 8, 223-271. doi: 10.1111/j.1748-1716.1898.tb00272.x

Tomizawa, K., Iga, N., Lu, Y.-F., Moriwaki, A., Matsushita, M., Li, S.-T., et al. (2003). Oxytocin improves long-lasting spatial memory during motherhood through MAP kinase cascade. Nature Neurosci. 6, 384-390. doi: 10.1038/ nn 1023

Torika, N., Asraf, K., Danon, A., Apte, R. N., and Fleisher-Berkovich, S. (2016). Telmisartan modulates glial activation: in vitro and in vivo studies. PLoS One 11:e0155823. doi: 10.1371/journal.pone.0155823

Tota, S., Goel, R., Pachauri, S. D., Rajasekar, N., Najmi, A. K., Hanif, K., et al. (2013). Effect of angiotensin II on spatial memory, cerebral blood flow, cholinergic neurotransmission, and brain derived neurotrophic factor in rats. Psychopharmacology (Berl.) 226, 357-369. doi: 10.1007/s00213-012-2913-8

Tota, S., Kamat, P. K., Saxena, G., Hanif, K., Najmi, A. K., and Nath, C. (2012). Central angiotensin converting enzyme facilitates memory impairment in 
intracerebroventricular streptozotocin treated rats. Behav. Brain Res. 226, 317330. doi: 10.1016/j.bbr.2011.07.047

Tracy, H. A., Wayner, M. J., and Armstrong, D. L. (1997). Losartan improves the performance of ethanol-intoxicated rats in an eight-arm radial maze. Alcohol 14, 511-517. doi: 10.1016/s0741-8329(97)00041-4

Trepiccione, F., Gerber, S. D., Grahammer, F., López-Cayuqueo, K. I., Baudrie, V., Pãunescu, T. G., et al. (2016). Renal Atp6ap2/(Pro)renin Receptor Is Required for Normal Vacuolar H+-ATPase Function but Not for the Renin-Angiotensin System. JASN 27, 3320-3330. doi: 10.1681/ASN.2015080915

Tsai, I.-C., Pan, Z., Cheng, H.-P., Liu, C.-H., Lin, B.-T., and Jiang, M. J. (2016). Reactive oxygen species derived from NADPH oxidase 1 and mitochondria mediate angiotensin II-induced smooth muscle cell senescence. J. Mol. Cell. Cardiol. 98, 18-27. doi: 10.1016/j.yjmcc.2016.07.001

Tsuda, K. (2012). Renin-angiotensin system and sympathetic neurotransmitter release in the central nervous system of hypertension. Int. J. Hypertens. 2012:474870. doi: 10.1155/2012/474870

Tsutsumi, K., and Saavedra, J. M. (1991). Characterization and development of angiotensin II receptor subtypes (AT1 and AT2) in rat brain. Am. J. Physiol. 261, R209-R216. doi: 10.1152/ajpregu.1991.261.1.R209

Turrens, J. F. (2003). Mitochondrial formation of reactive oxygen species. J. Physiol. (Lond.) 552, 335-344. doi: 10.1113/jphysiol.2003.049478

Tyndall, S. J., and Walikonis, R. S. (2007). Signaling by hepatocyte growth factor in neurons is induced by pharmacological stimulation of synaptic activity. Synapse 61, 199-204. doi: 10.1002/syn.20362

Tzourio, C., Anderson, C., Chapman, N., Woodward, M., Neal, B., MacMahon, S., et al. (2003). Effects of blood pressure lowering with perindopril and indapamide therapy on dementia and cognitive decline in patients with cerebrovascular disease. Arch. Intern. Med. 163, 1069-1075. doi: 10.1001/ archinte.163.9.1069

Unger, T., Chung, O., Csikos, T., Culman, J., Gallinat, S., Gohlke, P., et al. (1996). Angiotensin receptors. J. Hypertens. Suppl. 14, S95-S103.

Unger, T., and Li, J. (2004). The role of the renin-angiotensin-aldosterone system in heart failure. J. Renin Angiotensin Aldosterone Syst. 5(Suppl. 1), S7-S10. doi: $10.3317 /$ jraas.2004.024

Vajapey, R., Rini, D., Walston, J., and Abadir, P. (2014). The impact of age-related dysregulation of the angiotensin system on mitochondrial redox balance. Front. Physiol. 5:439. doi: 10.3389/fphys.2014.00439

Valdez, L. B., Zaobornyj, T., Alvarez, S., Bustamante, J., Costa, L. E., and Boveris, A. (2004). Heart mitochondrial nitric oxide synthase. Effects of hypoxia and aging. Mol. Aspects Med. 25, 49-59. doi: 10.1016/j.mam.2004.02.008

Valenzuela, R., Barroso-Chinea, P., Villar-Cheda, B., Joglar, B., Muñoz, A., Lanciego, J. L., et al. (2010). Location of Prorenin receptors in primate substantia nigra: effects on dopaminergic cell death. J. Neuropathol. Exp. Neurol. 69, 1130-1142. doi: 10.1097/NEN.0b013e3181fa0308

Valenzuela, R., Costa-Besada, M. A., Iglesias-Gonzalez, J., Perez-Costas, E., VillarCheda, B., Garrido-Gil, P., et al. (2016). Mitochondrial angiotensin receptors in dopaminergic neurons. Role in cell protection and aging-related vulnerability to neurodegeneration. Cell Death Dis. 7:e2427. doi: 10.1038/cddis.20 16.327

Valero-Esquitino, V., Lucht, K., Namsolleck, P., Monnet-Tschudi, F., Stubbe, T., Lucht, F., et al. (2015). Direct angiotensin type 2 receptor (AT2R) stimulation attenuates T-cell and microglia activation and prevents demyelination in experimental autoimmune encephalomyelitis in mice. Clin. Sci. 128, 95-109. doi: 10.1042/CS20130601

van Thiel, B. S., Góes Martini, A., Te Riet, L., Severs, D., Uijl, E., Garrelds, I. M., et al. (2017). Brain renin-angiotensin system: does it exist? Hypertension 69, 1136-1144. doi: 10.1161/HYPERTENSIONAHA.116. 08922

Vila-Porcile, E., and Corvol, P. (1998). Angiotensinogen, prorenin, and renin are Co-localized in the secretory granules of all glandular cells of the rat anterior pituitary: an immunoultrastructural study. J. Histochem. Cytochem. 46, 301-311. doi: 10.1177/002215549804600303

Villar-Cheda, B., Costa-Besada, M. A., Valenzuela, R., Perez-Costas, E., MelendezFerro, M., and Labandeira-Garcia, J. L. (2017). The intracellular angiotensin system buffers deleterious effects of the extracellular paracrine system. Cell Death Dis. 8:e3044. doi: 10.1038/cddis.2017.439

Villar-Cheda, B., Valenzuela, R., Rodriguez-Perez, A. I., Guerra, M. J., and Labandeira-Garcia, J. L. (2012). Aging-related changes in the nigral angiotensin system enhances proinflammatory and pro-oxidative markers and 6-OHDAinduced dopaminergic degeneration. Neurobiol. Aging 33, 204.e1-204.e11. doi: 10.1016/j.neurobiolaging.2010.08.006

Villar-Cheda, B., Rodríguez-Pallares, J., Valenzuela, R., Muñoz, A., Guerra, M. J., Baltatu, O. C., et al. (2010). Nigral and striatal regulation of angiotensin receptor expression by dopamine and angiotensin in rodents: implications for progression of Parkinson's disease. Eur. J. Neurosci. 32, 1695-1706. doi: 10.1111/ j.1460-9568.2010.07448.x

Villela, D., Leonhardt, J., Patel, N., Joseph, J., Kirsch, S., Hallberg, A., et al. (2015). Angiotensin type 2 receptor (AT2R) and receptor Mas: a complex liaison. Clin. Sci. (Lond) 128, 227-234. doi: 10.1042/CS20130515

Vowinckel, E., Reutens, D., Becher, B., Verge, G., Evans, A., Owens, T., et al. (1997). PK11195 binding to the peripheral benzodiazepine receptor as a marker of microglia activation in multiple sclerosis and experimental autoimmune encephalomyelitis. J. Neurosci. Res. 50, 345-353. doi: 10.1002/(SICI)10974547(19971015)50:2<345::AID-JNR22>3.0.CO;2-5

Wallace, L. M., Theou, O., Godin, J., Andrew, M. K., Bennett, D. A., and Rockwood, K. (2019). Investigation of frailty as a moderator of the relationship between neuropathology and dementia in Alzheimer's disease: a cross-sectional analysis of data from the rush memory and aging project. Lancet Neurol. 18, 177-184. doi: 10.1016/s1474-4422(18)30371-5

Wang, G. (2004). NADPH oxidase contributes to Angiotensin II signaling in the nucleus tractus solitarius. J. Neurosci. 24, 5516-5524. doi: 10.1523/JNEUROSCI. 1176-04.2004

Wang, J., Ho, L., Chen, L., Zhao, Z., Zhao, W., Qian, X., et al. (2007). Valsartan lowers brain $\beta$-amyloid protein levels and improves spatial learning in a mouse model of Alzheimer disease. J. Clin. Invest. 117, 3393-3402. doi: 10.1172/ JCI31547

Weiner, M. F., Bonte, F. J., Tintner, R., Ford, N., Svetlik, D., and Riall, T. (1992). ACE inhibitor lacks acute effect on cognition or brain blood flow in alzheimer's disease. Drug Dev. Res. 26, 467-471. doi: 10.1002/ddr.430260410

Wiesmann, M., Kiliaan, A. J., and Claassen, J. A. H. R. (2013). Vascular aspects of cognitive impairment and dementia. J. Cereb. Blood Flow Metab. 33, 1696-1706. doi: 10.1038/jcbfm.2013.159

Williams, I. M., Otero, Y. F., Bracy, D. P., Wasserman, D. H., Biaggioni, I., and Arnold, A. C. (2016). CHRONIC ANGIOTENSIN-(1-7) IMPROVES INSULIN SENSITIVITY IN HIGH-FAT FED MICE INDEPENDENT OF BLOOD PRESSURE. Hypertension 67, 983-991. doi: 10.1161/HYPERTENSIONAHA. 115.06935

Wilson, R. S., Segawa, E., Hizel, L. P., Boyle, P. A., and Bennett, D. A. (2012). Terminal dedifferentiation of cognitive abilities. Neurology 78, 1116-1122. doi: 10.1212/WNL.0b013e31824f7ff2

Wilson, R. S., Yang, J., Yu, L., Leurgans, S. E., Capuano, A. W., Schneider, J. A., et al. (2019). Postmortem neurodegenerative markers and trajectories of decline in cognitive systems. Neurology 92, e831-e840. doi: 10.1212/WNL. 0000000000006949

Wilson, W. L., Munn, C., Ross, R. C., Harding, J. W., and Wright, J. W. (2009). The role of the AT4 and cholinergic systems in the Nucleus Basalis Magnocellularis (NBM): effects on spatial memory. Brain Res. 1272, 25-31. doi: 10.1016/j. brainres.2009.03.025

Winklewski, P. J., Radkowski, M., Wszedybyl-Winklewska, M., and Demkow, U. (2015). Brain inflammation and hypertension: the chicken or the egg? $J$ Neuroinflammation 12:85. doi: 10.1186/s12974-015-0306-8

Wosik, K., Cayrol, R., Dodelet-Devillers, A., Berthelet, F., Bernard, M., Moumdjian, R., et al. (2007). Angiotensin II controls occludin function and is required for blood brain barrier maintenance: relevance to multiple sclerosis. J. Neurosci. 27, 9032-9042. doi: 10.1523/JNEUROSCI.2088-07.2007

Wright, J. W., and Harding, J. W. (2011). Brain renin-angiotensin-a new look at an old system. Prog. Neurobiol. 95, 49-67. doi: 10.1016/j.pneurobio.2011.07.001

Wright, J. W., and Harding, J. W. (2013). The brain renin-angiotensin system: a diversity of functions and implications for CNS diseases. Pflügers Arch. Eur. J. Physiol. 465, 133-151. doi: 10.1007/s00424-012-1102-2

Wright, J. W., and Harding, J. W. (2015). The brain hepatocyte growth Factor/cMet receptor system: a new target for the treatment of Alzheimer's disease. J. Alzheimer's Dis. 45, 985-1000. doi: 10.3233/JAD-142814

Wright, J. W., and Harding, J. W. (2019). Contributions by the brain renin-angiotensin system to memory, cognition, and Alzheimer's disease. J. Alzheimer's Dis. 67, 469-480. doi: 10.3233/JAD-181035 
Wright, J. W., Kawas, L. H., and Harding, J. W. (2013). A role for the brain RAS in Alzheimer's and Parkinson's diseases. Front. Endocrinol. (Lausanne) 4:158. doi: $10.3389 /$ fendo. 2013.00158

Wyse, B., Greenland, K., and Sernia, C. (1995). Specific binding sites for (38)angiotensin in C6 glioma cells. Brain Res. 681, 41-46. doi: 10.1016/00068993(95)00278- $\mathrm{x}$

Xia, H., and Lazartigues, E. (2008). Angiotensin-converting enzyme 2 in the brain: properties and future directions. J. Neurochem. 107, 1482-1494. doi: 10.1111/j. 1471-4159.2008.05723.x

Xiong, S., Salazar, G., San Martin, A., Ahmad, M., Patrushev, N., Hilenski, L., et al. (2010). PGC-1 alpha serine 570 phosphorylation and GCN5mediated acetylation by angiotensin II drive catalase down-regulation and vascular hypertrophy. J. Biol. Chem. 285, 2474-2487. doi: 10.1074/jbc.M109.0 65235

$\mathrm{Xu}$, Q., Jensen, D. D., Peng, H., and Feng, Y. (2016). The critical role of the central nervous system (pro)renin receptor in regulating systemic blood pressure. Pharmacol. Ther. 164, 126-134. doi: 10.1016/j.pharmthera.2016. 04.006

Yang, R.-F., Yin, J.-X., Li, Y.-L., Zimmerman, M. C., and Schultz, H. D. (2010). Angiotensin-(1-7) increases neuronal potassium current via a nitric oxidedependent mechanism. Am. J. Physiol. Cell Physiol. 300, C58-C64. doi: 10.1152/ ajpcell.00369.2010

Yasar, S., Moored, K. D., Adam, A., Zabel, F., Chuang, Y. F., Varma, V. R., et al. (2020). Angiotensin II blood levels are associated with smaller hippocampal and cortical volumes in cognitively normal older adults. J. Alzheimer's Dis. JAD 75, 521-529. doi: 10.3233/JAD-20 0118

Yasar, S., Xia, J., Yao, W., Furberg, C. D., Xue, Q.-L., Mercado, C. I., et al. (2013). Antihypertensive drugs decrease risk of Alzheimer disease: Ginkgo evaluation of memory study. Neurology 81, 896-903. doi: 10.1212/WNL. 0b013e3182a35228

Yin, Q., Ma, Y., Hong, Y., Hou, X., Chen, J., Shen, C., et al. (2014). Lycopene attenuates insulin signaling deficits, oxidative stress, neuroinflammation, and cognitive impairment in fructose-drinking insulin resistant rats. Neuropharmacology 86, 389-396. doi: 10.1016/j.neuropharm.2014. 07.020
Zawada, W. M., Banninger, G. P., Thornton, J., Marriott, B., Cantu, D., Rachubinski, A. L., et al. (2011). Generation of reactive oxygen species in 1methyl-4-phenylpyridinium (MPP+) treated dopaminergic neurons occurs as an NADPH oxidase-dependent two-wave cascade. J. Neuroinflammation 8:129. doi: 10.1186/1742-2094-8-129

Zawada, W. M., Mrak, R. E., Biedermann, J., Palmer, Q. D., Gentleman, S. M., Aboud, O., et al. (2015). Loss of angiotensin II receptor expression in dopamine neurons in Parkinson's disease correlates with pathological progression and is accompanied by increases in Nox4- and 8-OH guanosine-related nucleic acid oxidation and caspase-3 activation. Acta Neuropathol. Commun. 3:9. doi: 10.1186/s40478-015-0189-Z

Zhang, H., Han, G. W., Batyuk, A., Ishchenko, A., White, K. L., Patel, N., et al. (2017). Structural basis for selectivity and diversity in angiotensin II receptors. Nature 544, 327-332. doi: 10.1038/nature22035

Zhao, W., Wang, J., Ho, L., Ono, K., Teplow, D. B., and Pasinetti, G. M. (2009). Identification of antihypertensive drugs which inhibit amyloid-beta protein oligomerization. J. Alzheimers Dis. 16, 49-57. doi: 10.3233/JAD-2009-0925

Zhu, D., Shi, J., Zhang, Y., Wang, B., Liu, W., Chen, Z., et al. (2011). Central angiotensin II stimulation promotes $\beta$ amyloid production in Sprague Dawley rats. PLoS ONE 6:e16037. doi: 10.1371/journal.pone.0016037

Zhuang, S., Wang, H.-F., Wang, X., Li, J., and Xing, C.-M. (2016). The association of renin-angiotensin system blockade use with the risks of cognitive impairment of aging and Alzheimer's disease: a meta-analysis. J. Clin. Neurosci. 33, 32-38. doi: 10.1016/j.jocn.2016.02.036

Conflict of Interest: The authors declare that the research was conducted in the absence of any commercial or financial relationships that could be construed as a potential conflict of interest.

Copyright (c) 2020 Cosarderelioglu, Nidadavolu, George, Oh, Bennett, Walston and Abadir. This is an open-access article distributed under the terms of the Creative Commons Attribution License (CC BY). The use, distribution or reproduction in other forums is permitted, provided the original author(s) and the copyright owner(s) are credited and that the original publication in this journal is cited, in accordance with accepted academic practice. No use, distribution or reproduction is permitted which does not comply with these terms. 